\title{
Robert Walser und die Befreiung der Narration
}

Robert Walser macht den Eindruck eines, so unspezifisch das Wort ist, ,unordentlichen' Schriftstellers. Insbesondere in den späten Jahren werden die Erzähler sprunghaft, die Texte widersprüchlich und mehrfach codiert. Die Referenzen auf andere Werke wachsen ins Uferlose und verbergen zunehmend ihren Ursprung. Die Kommentierung des eigenen Erzählens vervielfacht sich. Erzählte Welt und das Erzählen der Welt werden mit Lust durcheinandergebracht. Schon Walter Benjamin hat bekanntlich in Walsers Schreiben eine „Verwahrlosung“ und „Sprachverwilderung“ festgestellt.197 Eine ,Verwilderung“ lässt sich auch an den Figuren, den Geschichten und Erzählverfahren ausmachen. Identitäten sind, wie schon bei Simon. Eine Liebesgeschichte gesehen, Masken in Rollenspielen, Normen des Anstands, der Sexualität und Geschlechterdifferenzen werden provoziert und verletzt.

Nicht zuletzt provoziert auch der Autor Walser gängige Ordnungsvorstellungen. Seine Rolle als Künstler, seine Mittellosigkeit und die zunehmende Erfolgslosigkeit führten dazu, dass er als Außenseiter wahrgenommen wurde, eine Rolle, die er und andere pflegten, wie sich etwa in Carl Seeligs Wanderungen mit Robert Walser (1957) zeigt. Paradoxerweise wurde dieses Bild zum Katalysator seiner Wiederentdeckung. ${ }^{198}$ Mit der Einlieferung in die Psychiatrische Heil- und Pflegeanstalt Waldau im Jahr 1929 wurde Walser auch in dieser Hinsicht als Exempel für das Abnorme statuiert. In der Waldau schrieb er noch regelmäßig, wobei sich insbesondere die Prager Presse unter dem Feuilletonleiter Otto Pick als wichtiger Abnehmer erwies. ${ }^{199}$ Mit der Versetzung im Jahr 1933 in die Ausserrhodische Heil- und Pflegeanstalt in Herisau schien Walser mit seinem literarischen Verstummen und der beobachteten Integration in den Klinikalltag zu einer absurden Affirmation der Ordnung zu

197 Walter Benjamin, „Robert Walser [1929]“, in Walter Benjamin. Gesammelte Schriften. Unter Mitwirkung von Theodor W. Adorno und Gershom Scholem, hg. von Rolf Tiedemann und Hermann Schweppenhäuser, Bd. II.1: Aufsätze, Essays, Vorträge, 7 Bde. (Frankfurt am Main: Suhrkamp, 1991), 325. Wiederabgedruckt in: Katharina Kerr, Hrsg., Über Robert Walser, 3 Bde. (Frankfurt am Main: Suhrkamp, 1978f.).

198 Vgl. Lucas Marco Gisi, „Leben und Werk““, in Robert Walser-Handbuch. Leben - WerkWirkung, hg. von Lucas Marco Gisi (Stuttgart: Metzler, 2015), 1-6; Jochen Greven, Robert Walser - ein Außenseiter wird zum Klassiker. Abenteuer einer Wiederentdeckung (Konstanz: Libelle, 2003).

199 Vgl. die Bände der Kritischen Ausgabe KWA III.4 und KWA V.2. 
gelangen. ${ }^{200}$ Zeugen die sachlichen Dankes- und Grußkarten aus Herisau von einer Aufgabe der Subversion, so gibt es doch auch Anzeichen, dass er sich in einer paradoxen Weise gerade dadurch gegen diese Ordnung der Institution gewehrt hat. ${ }^{201}$

Walsers Texte fordern nach wie vor und stets aufs Neue auf eigentümliche Art und Weise inhaltliche wie verfahrenstechnische Ordnungsmodelle heraus und etablieren eigene, prekäre Formen. ${ }^{202}$,Unordnung ist an einen Begriff von Ordnung gebunden. Im Fall Walsers referiert die narrative ,Unordnung‘ auf etablierte Erzählformen, deren Verfestigung sich im Realismus vollzog und sich nach wie vor als Standard in der Narratologie und der Definition von Erzählen hält. ${ }^{203}$ Walser setzt sich mit diesen Ordnungen auseinander und tut dies in spezifischer Weise über narrative Verfahren, die im Folgenden herausgearbeitet werden. Aus der Perspektive dieser Ordnung erscheinen Walsers Verfahren chaotisch, fehlerhaft und defizitär. Im Folgenden soll deren produktive Seite herausgestellt und gezeigt werden, wie Walser über scheinbar unordentliche Verfahren andere Formen von Ordnung herstellt.

Dass Robert Walser keine explizit poetologischen Schriften hinterlassen hat, gehört durchaus zum Programm. Die Ansichten zu Erzählen und Ordnen will er nicht begründet wissen, sondern im Spiel mit Masken und Erzählern stets aufs Neue erforschen, was es so schwierig macht, überhaupt eine Haltung zu destillieren, die über dieses Spiel hinausgeht. Gerade diese asystematische Haltung ist zentral für Walsers ,Unordnung‘. Einer resoluten Systematisierung

200 Es gibt auch einzelne Augenzeugen, die Walser schreiben gesehen haben wollen. Vgl. Barbara Auer, „Geschrieben, aber nicht gedruckt? Quellen zu Robert Walsers Schreibtätigkeit in der Heil- und Pflegeanstalt Herisau“, Appenzellische Jahrbücher 133 (2005): 38-41. Zum Klinikalltag Walsers vgl. Livia Knüsel, „Herr Walser hilft stets fleissig in der Hausindustrie. Falzt zusammen mit Herrn Solenthaler Papiersäcke.' Robert Walser in der Arbeitstherapie“, Appenzellische Jahrbücher 133 (2005): 24-37, https://doi.org/10.5169/ seals-283393.

201 Vgl. Margit Gigerl, „,Lassen Sie ihn weiter hindämmern ...' oder weshalb Robert Walser nicht geheilt wurde“, Appenzellische Jahrbücher 133 (2005): 10-23, https://doi.org/10.5169/ seals-283392; Lucas Marco Gisi, „Das Schweigen des Schriftstellers. Robert Walser und das Macht-Wissen der Psychiatrie", in Wissen und Nicht-Wissen in der Klinik. Dynamiken der Psychiatrie um 1900, hg. von Martina Wernli (Bielefeld: transcript, 2012), 231-259.

202 Der Bedeutung der Ambivalenz in Walsers Werk ist jüngst ein Sammelband gewidmet worden. Im Vorwort schreiben die Herausgeber: „Das Konzept der ,Ambivalenz‘ wäre so etwas wie ein theoretischer Schlüssel, der Walsers Texte neu aufschließt und konfiguriert.“ Kurt Lüscher u. a., „Vorwort“, in Robert Walsers Ambivalenzen, hg. von Kurt Lüscher u. a. (Paderborn: Wilhelm Fink, 2018), 7.

203 Gerade diesen Punkt hat die postklassische Narratologie vielfach kritisiert. Die Anbindung an die narratologische Theorie wird später vollzogen. Siehe Kap. 5 Narratologische Konzepte des grenzwertigen Erzählens, S. $247 \mathrm{ff}$. unten. 
muss genau dieser Aspekt von Walsers Schreiben entgehen. Die einzige Möglichkeit scheint darin zu liegen, die Texte in ihrem Vollzug, mithin in ihren Verfahren zu analysieren. Walsers Poetiken, aufgrund ihrer Asystematizität scheint der Plural angemessen, müssen über die Analyse der Verfahren seiner Prosastücke eruiert werden.

In diesem Kapitel zu Robert Walser, das den Hauptteil der vorliegenden Studie ausmacht, werden die zentralen Erzählstrategien sowie ihre Thematisierung und Ordnungsleistung herausgearbeitet. Ist auch Theodor Fontanes Der Stechlin, wie im vorhergehenden Kapitel gesehen, keineswegs vor Ambivalenz gefeit, sind seine Ordnung und die Verfahren, mit denen er diese herstellt, auch durchaus prekär, so hat sich bei Walser die Ambivalenz auf der Ebene des Erzählens deutlich durchgeschlagen und ist explizit geworden. Walsers Erzählern ist es weder möglich noch erscheint es ihnen erstrebenswert, ihre Geschichten in ordentliche Bahnen zu lenken.

In Robert Walsers Werk sind Ordnung und Erzählen von Beginn an zentrale Themen. ${ }^{204}$ Schon im frühsten gedruckten Prosatext Walsers, Der Greifensee, am 2.7.1899 im Sonntagsblatt des Bund erschienen und $1914 \mathrm{im}$ Band Geschichten wiederabgedruckt, entwickelt sich - in der Retrospektive durchaus programmatisch - ein Spaziergang nicht nur zu einer Metapher des Erzählvorgangs, sondern zu einer wechselseitigen Überblendung von Spazieren und Schreiben. ${ }^{205}$ In dieser Überblendung ersetzt nicht die eine Tätigkeit die andere, vielmehr stehen beide nebeneinander in einer dynamischen Relation. Der Akt des Erzählens wird nicht nur abgebildet, sondern in seinem Vollzug greifbar gemacht, wodurch auch - paradoxerweise - der Erzähler mehr zu einer Wirkung des Erzählens zu werden scheint, als er dessen Ursache darstellt. Solche Verfahren stehen in einem eklatanten Kontrast zu denjenigen des Stechlin, der nur ein Jahr vor Walsers Greifensee als Buch erschien.

Besonders in seinem Frühwerk beschäftigt sich Walser mit dem Verhältnis von Bild und Erzählung; in dieser Auseinandersetzung wird auch die traditionell bedeutsame Grenze von Erzählen und Zeigen thematisiert. ${ }^{206}$

204 Vgl. dazu Moritz Baßler: „Sein Werk weist von Der Greifensee bis zum Bleistiftgebiet eine hohe formale und inhaltliche Konstanz auf." „Robert Walser in den ,Weißen Blättern“, in Historiografie der Moderne. Carl Einstein, Paul Klee, Robert Walser und die wechselseitige Erhellung der Künste, hg. von Michael Baumgartner, Andreas Michel und Reto Sorg (Paderborn: Wilhelm Fink, 2016), 301.

205 Vgl. dazu auch: Hubert Thüring, „Schwelle und Glück. Zur Poetik zweier früher Texte Robert Walsers: ,Der Greifensee‘ (1899) und ,Glück' (1900)“, in Der Witz der Philologie. Rhetorik - Poetik - Edition. Festschrift für Wolfram Groddeck zum 65. Geburtstag, hg. von Felix Christen u. a. (Frankfurt am Main: Stroemfeld, 2014), 140-162.

206 Nachweise für Walsers dezidierte Auseinandersetzung mit poetologischen Schriften zum Verhältnis von Literatur und Malerei liefert Marc Caduff, der in einer Lektüre des frühen 
Das Erzählverfahren der Digression ist ebenfalls ein zentrales Mittel, mit dem Walser die Möglichkeiten und Grenzen narrativer Ordnung auslotet. Als dritte Erzählstrategie ist die Performanz zu erwähnen: Walser macht den Erzählvorgang selbst zur Erzählung. Mit diesem Verfahren problematisiert er nicht nur die Ordnung der Erzählung, sondern auf einer Metaebene immer auch die übergeordneten diskursiven Ordnungen der Zeit im Sinn der "Jetztzeit". 207

Diese Erzählverfahren lassen sich als Subversion konventioneller Erzählordnungen beschreiben. Die Konvention stellt hier die Erzählform des Realismus, die sich durch ein hohes Maß an Ordnung und einer positiven Bewertung dieser Ordnungsleistung auszeichnet, wie es besonders bei Fontane deutlich ist. Robert Walsers Erzählen findet in der Subversion von Erzählen gleichsam Antrieb.

Der Begriff der Subversion hat jedoch einen schalen Beigeschmack. Sie ist abhängig von demjenigen, das subvertiert wird und scheint so nicht mit eigenem Recht zu gelten. Im Folgenden soll gerade der Aspekt der Produktion gegen die nicht selten attestierte Devianz und Minderwertigkeit solch subversiver Erzählformen betont werden. ${ }^{208}$ Robert Walsers prekäres Erzählen erschöpft sich weder in der Abgrenzung zu anderen Erzählformen noch ist es eine solitäre Erscheinung in der literarischen Moderne. Dies darf mittlerweile als Konsens in der Robert Walser-Forschung gelten. ${ }^{209}$

Textes Ein Maler aus Fritz Kocher's Aufsätze den Bezug zu Lessings Laokoon oder über die Grenze der Malerei und Poesie herausarbeitet. Vgl. Marc Caduff, Revision und Revolte. Zu Robert Walsers Frühwerk (Paderborn: Wilhelm Fink, 2016), 89-102. Eine verbindliche Haltung Walsers lässt sich jedoch schwerlich behaupten; Walser verschreibt sich auch in diesem Kontext dem Asystematischen: „Eine einheitliche, stringente Theorie lässt sich aus den Aufzeichnungen des Malers allerdings nicht extrahieren, seine Überzeugungen changieren vielmehr von einem theoretischen oder literarischen Versatzstück zum nächsten." Caduff, 95 f.

$207 \mathrm{Zu}$ diesem Begriff im Werk Walsers und der Verortung im zeitgenössischen Diskurs vgl. Peter Utz, Tanz auf den Rändern. Robert Walsers "Jetztzeitstil“ (Frankfurt am Main: Suhrkamp, 1998).

208 Für eine solche Haltung vgl. Marie-Laure Ryan, „The Modes of Narrativity and Their Visual Metaphors“, Style 26, Nr. 3 (1992): $368-387$.

209 Vgl. dazu Utz, Tanz auf den Rändern; Jörg Kreienbrock, Kleiner. Feiner. Leichter. Nuancierungen zum Werk Robert Walsers (Zürich: Diaphanes, 2010); Tamara S. Evans, Robert Walsers Moderne (Bern, Stuttgart: Francke, 1989). Jüngst auch wieder Moritz Baßler, „Robert Walsers Moderne“, in Robert Walser-Handbuch. Leben - Werk - Wirkung, hg. von Lucas Marco Gisi (Stuttgart: Metzler, 2015), 68-72. Für Benne ist Walser „[i]n der deutschen Literatur [...] der Autor mit den ausgeprägtesten Affinitäten und Parallelen zu den poetischen Verfahren des Surrealismus.“ Christian Benne, „,Schrieb je ein Schriftsteller so aufs Geratewohl?' Der surrealistische Robert Walser“, in Surrealismus in der deutschsprachigen Literatur, hg. von Friederike Reents (Berlin, New York: De Gruyter, 2009), 5o. So schon Petersen: „Robert Walsers letztes Werk Der Räuber [...] hingegen läßt 
Das Kapitel gliedert sich in vier Teile. Zunächst werden drei Verfahren des prekären Erzählens in den Blick genommen: Mit Seymour Chatmans Texttypen-Theorie wird die Differenz von Erzählung und Beschreibung untersucht. Als zweite Strategie rückt die Digression ins Zentrum: Das Konzept der Digression, die walserschen Ausgestaltungen derselben und die Konsequenzen für erzähltheoretische Grundlagen werden diskutiert. Anschließend wird die Performanz als zentrale Erzählstrategie analysiert. Zum Schluss wird ein Perspektivenwechsel vollzogen und mit dem Essens-Motiv eine spezifische Figuration des Erzählens in den Blick genommen. ${ }^{210}$

\section{1 $\quad$ Erzählung und Bild}

Robert Walsers Affinität zur bildenden Kunst ist bekannt. ${ }^{211}$ Besonders in seiner Berliner Zeit hatte er Umgang mit bildenden Künstlern und war,

sich ebensogut als surrealer Beschreibungsroman klassifizieren." Jürgen H. Petersen, Der deutsche Roman der Moderne. Grundlegung, Typologie, Entwicklung (Stuttgart: Metzler, 1991), 286.

210 Hier sei auf die methodische Schwierigkeit der Festlegung des Korpus bei Robert Walser hingewiesen. Bei über 1000 publizierten Texten besteht die Gefahr, dass zwar breite Analysen vorgenommen werden, jedoch die Tiefe verlorengeht und ein gewisser Eklektizismus Raum greift, bei einem Fokus auf zu wenige Texte hingegen droht eine Verallgemeinerung und Nivellierung des Werks. Diesem Problem soll dadurch begegnet werden, dass zwar wenige Texte im Zentrum der Analyse stehen, diese jedoch unter präzisen Gesichtspunkten und mit theoretischer Schärfe gelesen werden. Durch diese Methodik soll eine Vielfalt an Verfahren und Varianten des prekären Erzählens herausgearbeitet werden können. Der Versuchung, sich zu sehr von Robert Walsers überaus zitierfähigen Stellen leiten zu lassen, soll auch dadurch entgangen werden, dass Texte immer als Ganzes gelesen und die Zitate in den Kontext des Gesamttextes gestellt werden. Besonderes Gewicht erhalten Der Spaziergang in beiden Fassungen von 1917 und 1919 und der „Räuber“-Roman, den Walser im Sommer 1925 geschrieben hat sowie Prosastücke aus der Bieler und der Berner Zeit, an denen sich die verschiedenen Inhalte und Verfahren des prekären Erzählens deutlich zeigen lassen. Textgrundlage ist, so weit greifbar, die Kritische Ausgabe sämtlicher Drucke und Manuskripte (KWA), alternativ die Sämtlichen Werke (SW), die Berner Ausgabe (BA) sowie die Edition der Mikrogramme Aus dem Bleistiftgebiet (AdB).

211 Peter Utz dient in seiner grundlegenden Studie Tanz auf den Rändern eine Lektüre von Walsers Belgische Kunstausstellung, ein Feuilleton vom August 1926, als Einstieg in den Themenkomplex. Walser konzentriert sich im Text auf ein Bild der Ausstellung Rogier van der Weydens Christusgemälde Pietà - genauer auf ein Detail dieses Bilds, ein Baumgerippe, das sprachlich dynamisiert wird und so „die Bildlandschaft aus ihrer Totenstarre" weckt. Utz, Tanz auf den Rändern, 9.

2014 richtete das Aargauer Kunsthaus eine Ausstellung zum Thema „Robert Walser und die bildende Kunst“ aus. Vgl. dazu den Katalog: Madeleine Schuppli, Thomas 
wahrscheinlich durch Vermittlung seines Bruders Karl, kurzzeitig Sekretär der Berliner Secession und dessen Geschäftsführer Paul Cassirer. Sein Interesse an der bildenden Kunst hat sich in zahlreichen Texten niedergeschlagen. Walser hat Texte zu einzelnen bildkünstlerischen Werken verfasst sowie zahlreiche „Dichterporträts“ geschrieben. ${ }^{212}$ Vielfach dienen Gemälde auch als Ausgangspunkt von Prosastücken. Die Auseinandersetzung mit dem Bildhaften ist bei Walser auch als Verfahren wichtig. In unzähligen Prosastücken wird das Geschehen nicht handlungsorientiert, sondern als Beschreibung aufgefangen.

Vor dem Hintergrund der Frage nach Walsers Ordnungsverfahren sticht die Beziehung zwischen Bild und Erzählung hervor. Diese Praxis Walsers ist im Folgenden als Ordnungsleistung und gleichzeitig als Subversion von Ordnung zu ergründen. In der Analyse der Grenzen zwischen Erzählen und Bild leistet die Texttypen-Theorie von Seymour Chatman große Dienste. Dieser Ansatz erlaubt es, das Erzählerische an einem Text im Kontrast zu den Texttypen der Beschreibung und Argumentation zu verstehen. ${ }^{213}$ Chatman begreift einen Text medienübergreifend als einen strukturierten Verbund von Zeichen, der jeweils einem Texttypus zugeordnet werden kann. So kann ein Bild in medialer Hinsicht dem Typus der Argumentation, ein philosophischer Text der Erzählung und ein fiktionaler Text der Beschreibung zugeordnet werden und in dieser Anwendung der Standardeinteilung widersprechen. Mit diesem Instrumentarium können Walsers Texte gerade in ihrer Thematisierung der

Schmutz und Reto Sorg, Hrsg., Ohne Achtsamkeit beachte ich alles. Robert Walser und die bildende Kunst (Sulgen: Aargauer Kunsthaus Aarau / Benteli, 2014).

Vgl. zum Thema Intermedialität bei Walser: Ulf Bleckmann, „Thematisierung und Realisierung der bildenden Kunst im Werk Robert Walsers", in Intermedialität. Vom Bild zum Text, hg. von Ulf Bleckmann und Thomas Eicher (Bielefeld: Aisthesis Verlag, 1994), 29-58; Anna Fattori und Margit Gigerl, Hrsg., Bildersprache, Klangfiguren. Spielformen der Intermedialität bei Robert Walser (Paderborn: Wilhelm Fink, 2008); Tamara S. Evans, „Ein Künstler ist hier gezwungen aufzuhorchen' Zu Robert Walsers Kunstrezeption in der Berliner Zeit“, in Bildersprache, Klangfiguren. Spielformen der Intermedialität bei Robert Walser, hg. von Anna Fattori und Margit Gigerl (Paderborn: Wilhelm Fink, 2008), 107-116; Kerstin Gräfin von Schwerin, „Im weitverzweigten Lebensgarten. Robert Walsers Gedicht ,Der verlorene Sohn' und Rembrandts Bild ,Die Rückkehr des Verlorenen Sohnes“', in Bildersprache, Klangfiguren. Spielformen der Intermedialität bei Robert Walser, hg. von Anna Fattori und Margit Gigerl (Paderborn: Wilhelm Fink, 2008), 129-141.

212 Sowohl zu Walsers Texten zur bildenden Kunst wie zu Walsers Dichterporträts hat Bernhard Echte Anthologien zusammengestellt. Vgl. Robert Walser, Vor Bildern. Geschichten und Gedichte, hg. von Bernhard Echte, Insel-Bücherei (Frankfurt am Main: Insel, 2006); Robert Walser, Dichteten diese Dichter richtig? Eine poetische Literaturgeschichte, hg. von Bernhard Echte (Frankfurt am Main, Leipzig: Insel, 2002).

213 Die Texttypen-Theorie hat ihren Ursprung in der Textlinguistik und wurde von verschiedenen Narratologen für die Narratologie fruchtbar gemacht. Andere Theoretiker, etwa Mieke Bal, schlagen auch vier oder mehr Typen vor. 
Grenzziehung analysiert werden. Das Konzept der Texttypen öffnet also gleichsam den Rahmen für das Erfassen der Ordnungskritik. Das Verhältnis von Bild und Erzählung wird zum Politikum der Grenzziehung.

Im Folgenden wird das Verhältnis von Bild und Erzählung als Mittel der Problematisierung von Grenzziehungen an Prosastücken Robert Walsers verhandelt; eine ausführliche intermediale Interpretation der Texte, die auch kunstkritische Differenzierungen einzubringen hätte, kann hier nicht geleistet werden. Überblickt man Walsers Beschäftigung mit Bildern, fällt auf, dass sich die Art und Weise der Auseinandersetzung wandelt. Sind im Frühwerk die Gegensätze zwischen Bild und Erzählung relativ statisch und als Setzungen fixiert, so vermengen sie sich im Verlauf seines Schaffens mehr und mehr. Damit entsprechen sie der feststellbaren Zunahme der Bedeutung des Dynamischen in seinem Werk. Im Vordergrund steht das Bildliche als Grenzbereich des Erzählens, das Walser paradoxerweise in seinem Erzählen integriert.

Zunächst wird Seymour Chatmans Texttypen-Theorie dafür genutzt, in die Problematik der Differenzierung zwischen Bild und Erzählung einzuführen. An Walsers frühem Text Seltsame Stadt (1905) wird gezeigt, wie die Erzählung in einem statischen Bild aufgefangen und blockiert wird. Am zweiten Textbeispiel, zwei aufeinander bezogenen Texten von 1912 und 1918, die beide einem Gemälde Vincent van Goghs gewidmet sind, wird sichtbar, wie sich diese Verfahren verändern. Anschließend werden zwei Texte betrachtet, die sich demselben Gemälde des Rokoko-Malers Jean-Honoré Fragonard zuwenden. Zum Schluss wird untersucht, wie ein Text seine bildliche Vorlage dramatisiert.

\subsubsection{Erzählen-Beschreiben-Argumentieren (Chatman)}

Die Ausdifferenzierung und das Zusammenspiel der Texttypen der Narration, Beschreibung und Argumentation sind komplex. Seymour Chatman sieht keine Hierarchie zwischen den Texttypen vor, wie etwa Gérard Genette es tut. ${ }^{214}$ Trotz dieser Distinktheit sind die Texttypen aufeinander angewiesen; sie integrieren die anderen Typen für ihre Zwecke. Das heißt, es gibt keine Texttypen „in Reinform“. ${ }^{215}$ Ein Text kann auf der Oberfläche als Beschreibung

214 Vgl. Genette: „[D] escription might be conceived independently of narration, but in fact it is never found in a so to speak free state; narration cannot exist without description, but this dependence does not prevent it from constantly paying the major role. Description is quite naturally ancilla narrationis, the ever-necessary, ever-submissive, neveremancipated slave." Gérard Genette, „Frontiers of Narrative“, in Figures of Literary Discourse, übers. von Alan Sheridan (New York: Columbia University Press, 1982), 134.

215 Dies rührt unmittelbar an das Problem der Definition von events (Ereignis), die in ihrer Verkettung die story bilden, als Zustandsänderung, die auf eine Beschreibung angewiesen ist. 
erscheinen und in der Tiefenstruktur eine Erzählung sein. ${ }^{216}$ Chatman zufolge besteht das Kooperationsverhältnis der Texttypen in einem Dienstverhältnis: „The text-types routinley operate at each other's service."217 Er veranschaulicht deren Kooperation an Alain Robbe-Grillets Text La chambre secrète und zeigt, wie ein Text an der Oberfläche eine Bildbeschreibung sein kann und trotzdem einen starken narrativen Gehalt hat. ${ }^{218}$ Dieses Konzept macht Sinn, gerade bei Texten des nouveau roman, die ihre Handlung über extensive Beschreibung vermitteln. ${ }^{219}$

Für die Beschreibung des Texttypus der Narration, dem Chatman die größte Aufmerksamkeit zukommen lässt, kombiniert er zwei klassische Definitionen, die zum einen über die story und zum anderen über die Vermittlung, das heißt das Vorhandensein eines Erzählers in einem Text, laufen. ${ }^{220}$ Er bestimmt die Möglichkeit einer Unterscheidung von story und discourse als Hauptmerkmal der Erzählung. Das distinkte interne Merkmal der Narration ist nach Chatman dessen „doppelte temporale Logik“:221

As has been clearly established in recent narratology, what makes Narrative unique among the text-types is its ,chrono-logic, its doubly temporal logic. Narrative entails movement through time not only ,externally' (the duration of the presentation of the novel, film, play) but also ,internally' (the duration of the sequence of events that constitute the plot). The first operates in that dimension

Vgl. dazu Schmid, Elemente der Narratologie, 3f. Vgl. auch Monika Fludernik, „Description and Perspective. The Representation of Interiors", Style 48, Nr. 4 (2014): 461-478.

216 Roman Jakobson findet in seinem Kommunikationsmodell eine ähnliche Lösung. Jeweils eine der sechs Funktionen seines Modells ist die dominante. Vgl. Roman Jakobson, „Die Dominante“, in Linguistik und Poetik. Ausgewählte Aufsätze 1921-1971, hg. von Elmar Holenstein und Tarcisius Schelbert (Frankfurt am Main: Suhrkamp, 1979), 212-219; Roman Jakobson, „Linguistik und Poetik“, in Poetik. Ausgewählte Aufsätze 1921-1971, hg. von Elmar Holenstein und Tarcisius Schelbert (Frankfurt am Main: Suhrkamp, 1979), 83-121.

217 Seymour Chatman, Coming to Terms. The Rhetoric of Narrative in Fiction and Film (Ithaca, London: Cornell University Press, 199o), 10. Hervorhebung i. O.

218 Die Texttypen-Theorie lässt sich systemtheoretisch leicht umformulieren: So kann Chatmans service-Konzept als ein re-entry des nichtdominanten Texttyps in den dominanten Texttyp beschrieben werden.

219 Susanne Andres vergleicht Walsers Erzählweise eher oberflächlich mit Alain RobbeGrillet und Samuel Beckett: „Der Diskurs über das Erzählen rückt mehr und mehr ins Zentrum des Erzählens." Susanne Andres, Robert Walsers arabeskes Schreiben (Göttingen: Cuvillier-Verlag, 1997), 155.

220 Vgl. dazu Schmid, Elemente der Narratologie, 1-11.

221 Vgl. dazu Alexandra Georgakopoulou, „Text-Type Approach“, in Routledge Encyclopedia of Narrative Theory, hg. von David Herman, Marie-Laure Ryan und Manfred Jahn (London: Routledge, 2010).: "The boundaries of narrative have mostly been determined in terms of text-internal criteria (i.e., form and content) and at the expense of text-external (i.e., functional, socio-cultural) criteria." 
of narrative called Discourse (or récit or syuzhet), the second in that called Story (histoire or fabula). In traditional narratives, the internal or story logic entails the additional principle of causality (event $a$ causes $b, b$ causes $c$, and so on) or, more weakly, what might be called, contigency' ( $a$ does not directly cause $b$, nor does $b$ cause $c$, but they all work together to evoke a certain situation or state of affairs $x) .^{222}$

Was den narrativen Texttypus also auszeichnet, ist seine doppelte Temporalität: die erzählte Zeit - story-time - und die Erzählzeit - discourse-time. Die Texttypen der Argumentation und Deskription verfügen nach Chatman über keine erzählte Zeit, keine „internal time sequence“223, wohl aber über eine externe, weil es Zeit braucht, sie zu lesen oder zu betrachten. Die argumentative und deskriptive Textstruktur ist laut Chatman atemporal. Chatman definiert Narrativität damit im Grund wiederum über die story. Er argumentiert, dass alle Texte, also auch Bilder, notwendigerweise eine discourse-Ebene aufweisen, nicht aber eine story als zeitlich und logisch organisierte Abfolge von events.

Die Texttypen-Theorie ermöglicht es, die spezifische Grenzwertigkeit eines Erzählens beschreibbar zu machen, das sich am Rand des Narrativen bewegt und diese Grenzwertigkeit auch zu seinem Inhalt macht. ${ }^{224}$ Die Subversion von Erzählen wird so fassbar als ein Zitieren, ein Inszenieren oder eine tatsächliche Transformation in einen anderen Texttypus. Wie Chatman in seiner Studie aufzeigt, kann die Spannung zwischen Texttypen zu einem produktiven Faktor werden, der selbst zum Inhalt einer Erzählung wird.

Die Durchlässigkeit der Texttypen bringt auch eine Verunsicherung der Grenzen mit sich. Es stellt sich die Frage nach dem Typus des Textes, der nicht mehr klar gegeben ist, wenn mehrere Texttypen sich in einer Konkurrenzsituation befinden. Nach Chatmans Ansatz bestimmt die Tiefenstruktur die Identität des gesamten Textes - die Antwort läge im erwähnten Konzept der Dienstbarkeit: „The text-types routinley operate at each other's service. ${ }^{225}$ Ein Texttyp dient dem anderen, wie im Textbeispiel von Robbe-Grillet, indem die

222 Chatman, Coming to Terms, 9. Hervorhebung i. O.

223 Chatman, 9.

224 Marie-Laure Ryan kritisiert, dass die Grenzziehungen in Texttypen-Theorien zur Vermischung pragmatischer und semantischer Kriterien führen würde. Bezogen auf Chatman argumentiert sie, dass Narration und Beschreibung über den Inhalt definiert seien. Argumentation, deren Grundlage das Überzeugen sei, sei eine pragmatische Definition: „As long as the text-type approach remains unable to make a choice between semantic apples and pragmatic oranges, it will not lead to a satisfactory definition of narrative." Marie-Laure Ryan, „Toward a Definition of Narrative“, in The Cambridge Companion to Narrative, hg. von David Herman (Cambridge: Cambridge University Press, 2007), 27.

225 Chatman, Coming to Terms, 10. Hervorhebung i. O. 
Deskription der Narration ,dient‘. Der ,dienende“ Texttyp befindet sich nur an der Oberfläche und greift nicht auf die Tiefenstruktur ein, die den Typus des gesamten Textes bestimmt. Angenommen, die Tiefenstruktur sei vom Typus der Narration, dann müsste diese folglich auch die deskriptiven Elemente mit der narrativen „double chrono-logic“ versorgen, um die Durchgängigkeit und Einheit des Textes zu gewähren. Dies wiederum wirft die Frage auf, worin sich die narrativen und deskriptiven Elemente dann noch unterscheiden, wenn beide von der "double chrono-logic“ bestimmt sind, die ja gemäß Chatman das distinkte Merkmal der Narration darstellt.

Alle drei Texttypen Chatmans verfügen über in gewissem Maß durchlässige Grenzen. Bezüglich des Typus der Argumentation ist zu bemerken, dass grunsätzlich jeder Text ideologisch gefärbt ist und in dieser Hinsicht jeder Text für gewisse Positionen argumentiert. Chatman führt Beispiele auf, die die Grenze zur Argumentation betonen, wie etwa Fabeln mit einer expliziten Handlungsanweisung. ${ }^{226}$ Ausschlag über den Status der Argumentation gibt nach Chatman die Explizitheit der Argumentation: „[I]t is important to distinguish between the implication of an ideology and the urging of a thesis. ${ }^{227}$ Es bleibt also ein Abwägen, wann von einer impliziten Ideologie oder einer explizit geäußerten These gesprochen werden kann. ${ }^{228}$ So kann beispielsweise in einem eindeutig narrativen Text eine Figur auftreten, die in einem Monolog eine klare Argumentation für oder wider eine Ansicht äußert. Gleichzeitig gibt es argumentative Texte, die ihre Argumentation hinter so viel Rhetorik verstecken, dass diese kaum mehr direkt wahrgenommen wird.

Chatmans Modell des ,Dienens' hat zwar eine große pragmatische Plausibilität, ist aber in der Anwendung nicht ganz konsistent. Die Inkonsistenz des Modells rührt von der Schwierigkeit der Grenzsetzung her, bzw. der Grenzen selbst und deren narrativem Potenzial. Das Markieren und sich Bewegen auf der Grenze des Narrativen, sowie das Aushandeln der Grenzen des Erzählens ist gerade Antrieb vieler Texte Robert Walsers. Konflikte um die Vorherrschaft

226 Hier stellt sich die Frage, ob es bei der Unterscheidung der Texttypen nicht hauptsächlich um die Perspektive geht, die auf einen Text geworfen wird. Gerade Fabeln können als Erzählungen und als Argumentationen gelesen werden. Chatman weist in diese Richtung, wenn er sagt, die Bestimmung des Typus hänge auch davon ab, welche Lesart „interessanter" sei für die Interpretation: „We understand it as subservient to Narrative when the text makes more overall sense and rewards us more richly as a narrative than as a description." Chatman, 21.

227 Chatman, 11.

228 Gerade der Umstand, dass Texte, salopp gesagt, andere Dinge tun können, als sie zu tun vorgeben, ist grundlegend für die Dekonstruktion. Vgl. Paul de Man, Allegorien des Lesens, übers. von Werner Hamacher und Peter Krumme (Frankfurt am Main: Suhrkamp, 1988). 
von Texttypen sind vorprogrammiert. Das Modell des ,Dienens', das eine klare Hierarchie unter den Texttypen innerhalb eines Textes voraussetzt und eine Harmonie und Geschlossenheit des Textes suggeriert, greift hier zu kurz. Bei Walser kommt hinzu, dass u. a. mit der komplexen Thematik um die Beziehung von Herr und Diener auch inhaltlich eine Diskussion um Machtverhältnisse geführt wird. Die Art und Weise, wie bei Walser der Diener, etwa durch Überanpassung die Machtverhältnisse subtil umdreht, stellt ein subversives Spiel dar, das in zahlreichen Variationen in Walsers Werk zu finden ist.

Die Differenzierung zwischen Texttypen als textinterne Aushandlung ist außerordentlich produktiv. Die Unsicherheit der Grenzen und die Widerständigkeit einer eigenständigen Grenzziehung sind für die Texte Robert Walsers zentral. Wie im Folgenden deutlich werden wird, ist Walsers Grenzsetzung in verschiedener Hinsicht anti-systemisch. Gerade dadurch, dass er die Ordnung der Texte in Bewegung bringt und keine harmonische DienerHerrscher-Ordnung repräsentiert, provoziert Walser Ordnungsvorstellungen. In den Analysen ausgewählter Prosastücke wird die Differenz von Erzählung und Beschreibung in der medientechnischen Umsetzung als Schreiben und Malen greifbar.

\subsubsection{Das Einfrieren der Erzählung im Bild. Seltsame Stadt}

Im frühen Text Seltsame Stadt, der 1905 in der Zeitschrift Die Freistatt und 1914 im Band Geschichten des Kurt Wolff Verlags erschien, wird eine paradiesische Stadt geschildert, in der es keine Differenz zwischen der Oberfläche des Scheins und der Tiefe des Seins gibt. Mit einem märchenhaften Beginn setzt die Erzählung ein: „Es war einmal eine Stadt.“ (SW 2, 29) Die Stadt ist deshalb seltsam, weil in ihr „die Menschen darin [...] bloß Puppen“ (SW 2, 29) sind. Sie bewegen sich geisterhaft und sind stets bester Laune. „Sie sagten nicht nur: Guten Morgen, oder: Gute Nacht, sie meinten es auch, und zwar herzlich. Herz hatten diese Menschen." (SW 2, 29) In dieser Stadt folgen die "jungen Männer" dem „Lockenden“ und "Sittlichen“ und den Frauen „langsam, wie träumend, ohne in hastige, gierige Bewegungen zu verfallen" (SW 2, 30). Die „Vergnügungsorte“ der Stadt sind die Kirchen: „Lust war diesen Menschen eine heilige, tiefe Sache“, wobei man selbstverständlich „reinlich" bleibt (SW 2, 31). Unter diesen Voraussetzungen ist Kunst nicht mehr nötig, weil sie Menschen „nichts Erhebendes, Neues mehr zu sagen gewußt“ hätte, man hat „selber feine, laufende, wache und zitternde Empfindung" (SW 2, 31).

Es wird das Bild einer Stadt erzeugt, die einem Gemälde gleicht. Die Erzählung beginnt gleichsam nicht als Erzählung, sondern mit der Exposition einer solchen, die sich an sozialistische, lebensreformerische und feministische 
Utopien der Zeit anlehnt.. ${ }^{29}$ Dann tritt das Erzähler-Ich auf, der Urheber dieser Fantasie, der bisher den Vorgaben des Märchens gemäß unmarkiert war.

Alles was geschah, geschah lebhaft. So? Wirklich? Was für ein dummer Kerl ich bin! Nein, mit dieser Stadt und diesen Menschen ist es absolut nichts. Das hat keine Wirklichkeit. Das ist aus der Luft gegriffen. Fahr ab, Bursche!

Da ging der Bursche spazieren und setzte sich auf eine Gartenbank. Es war Mittag. Die Sonne schien durch die Bäume und machte Flecken auf den Weg, auf die Gesichter der spazierenden Menschen, auf die Hüte der Damen, auf den Rasen, es war spitzbübisch. [...] Es war wie ein Traum, wie ein bloßes Spiel, wie ein Bild. Der Bursche lehnte seinen Kopf in seinen Ellenbogen und ging auf in dem Bild. Plötzlich stand er auf und ging weg. Nun, das ist seine Sache. Dann kam der Regen und verwischte das Bild. (SW 2, 31f.)

Zunächst wird hier die Erzählerfigur eingeführt, die als geistige Urheberin der Stadt auftritt. Die Stadt wird selbst als Fiktion kenntlich. Dann jagt sich der Erzähler und Erfinder der Stadt selbst aus der Geschichte, worauf die Geschichte in der dritten Person weitererzählt wird. Der vormalige homodiegetische Erzähler wird selbst zur Figur in der nun heterodiegetischen Erzählung. Schließlich wird der „Bursche“ Element der Beschreibung des Parks. Er passt perfekt ins Bild. In einem wörtlichen Sinn „verwischt[]“ der Regen das Bild - es verschwindet - und mit ihm endet die Erzählung.

An diesem Schluss irritieren - neben der Metalepse - zwei Elemente. Zum einen, wie Assoziationen freigesetzt werden, indem das normalerweise statische „Bild“ mit den dynamischen Elementen Traum und Spiel in eine Reihe gesetzt wird. Irritierend ist zum anderen, dass der Text mit dem Weggehen des Burschen auch abbricht. Das Bild wird vom Regen „verwischt[]“, als sei es tatsächlich ein Gemälde und keine Erzählung. Mit dem Verschwinden des Bilds verschwinden auch der alte Erzähler und der neue Erzähler.

Sozusagen durch die Hintertür evoziert dieser Schluss mit dem vom Regen verwischten Bild ein neues Bild: In einer mise en cadre wird die Erzählung als Gemälde greifbar, das vom Regen verwischt wird. Diese Spiegelung von Erzählung und Bild ist das dynamische Moment der Erzählung. Auf diese Weise wird das Ereignishafte auf die Verfahren übertragen. „[S]pitzbübisch“ (SW 2, $3^{2}$ ), wie es heißt, werden zentrale Ordnungspfeiler durcheinandergebracht. ${ }^{230}$

229 Vgl. für Walsers frühe Begeisterung für den Sozialismus die vier Briefe an Robert Seidel, Herausgeber der Arbeiterstimme zwischen März und Juni 1897 (BA 1, 11-15, Nr. 1-4).

230 Im Text Der Waldbrand, der ebenfalls 1914 im Band Geschichten erschien, wird die Opposition von Bild und Erzählung noch einmal anders gewendet. Der Waldbrand beschreibt eine Brandkatastrophe, die selber statisch geschildert wird und mit einem Gemälde des Waldbrandes, angefertigt von einem „Trunkenbold und [...] Verächter aller guten und wohlgefälligen Sitten“ (SW 2, 38), endet. Eine ähnliche Dynamisierung von 
In Seltsame Stadt entfaltet sich also eine erzählerische Dynamik aus einem Bild heraus und in ein solches zurück. Von einer prototypischen Erzählform dem Märchen -, einer Erzählform, die hier iterativ ausgeführt und inhaltlich als konfliktlos präsentiert wird, kommt die Erzählung erst durch eine Metalepse in Gang. Das Märchen ohne Konfliktpotenzial funktioniert nur so lange, als seine Vermittlung neutral scheint und der Erzähler unmarkiert bleibt. Durch das Kenntlichmachen der Erzählstimme wird die Künstlichkeit der erzählten Ordnung wie der Erzählordnung offenbar. Bezeichnenderweise besteht der im traditionellen Theorieverständnis durch seine Irreversibilität im eigentlichen Sinn narrative Akt hier aus einer Metalepse, die das Erzählen selbst ins Zentrum rückt. ${ }^{231}$ Was in diesem frühen Text noch etwas pointenhaft aufgesetzt wirkt, wird später mehr und mehr die Struktur der Texte durchdringen.

\subsubsection{Bilder von van Gogh. Zu der Arlesierin von Van Gogh und Das Van Goghbild}

Von einem existierenden Gemälde handeln die Texte Zu der Arlesierin von Van Gogh (1912) und Das Van Goghbild (1918). Vincent van Gogh hat als Ikone der modernen Malerei auch Robert Walser beeindruckt. Das Gemälde L'Arlésienne von 1888, Gegenstand beider Texte, hat Walser wahrscheinlich im Sommer 1912 in der Jahresausstellung der Berliner Secession gesehen. ${ }^{232}$ Das Prosastück Zu der Arlesierin von Van Gogh erschien in der Zeitschrift Kunst und Künstler gleich im Anschluss an eine Besprechung der Ausstellung durch Karl Scheffler, die neben vielen anderen Reproduktionen auch von einer des Gemäldes von van Gogh begleitet wurde. ${ }^{233}$

Bild und Erzählung wie in Die seltsame Stadt findet sich etwa in Zwei Bilder meines Bruders (SW 4, 37-40).

231 Vgl. dazu die Diskussion des Ereignis-Begriffs bei Peter Hühn, „Event and Eventfulness“, in The Living Handbook of Narratology, hg. von Peter Hühn u. a. (Hamburg: Hamburg University, 2018), http://www.lhn.uni-hamburg.de/article/event-and-eventfulness. Wolf Schmid nennt fünf Bedingungen, die eine Zustandsveränderung erfüllen muss, um als Ereignis zu gelten: Relevanz, Imprädikabilität, Konsekutivität (gemeint sind damit die Konsequenzen der Figurenhandlungen, die gegeben sein müssen), Irreversibilität und Non-Iterativität. Schmid, Elemente der Narratologie, 14-19.

232 Gerade während Walsers kurzzeitiger Funktion als Sekretär der Berliner Secession und deren Geschäftsführer Paul Cassirer veranstaltete dieser im Winter 19o1/1902 die erste van Gogh-Ausstellung in Deutschland überhaupt, gab van Goghs-Briefe heraus und übte maßgeblichen Einfluss auf die Kunstrezeption aus. Vgl. dazu Margit Gigerl, „Bang vor solchen Pinsels Schwung - Robert Walsers Lektüre der Bilder van Goghs“, in Bildersprache, Klangfiguren. Spielformen der Intermedialität bei Robert Walser, hg. von Anna Fattori und Margit Gigerl (Paderborn: Wilhelm Fink, 2008), 118.

233 L'Arlésienne existiert in insgesamt sieben Varianten. Es sind Porträts von Madame Ginoux, der Café-Besitzerin in Arles, wo van Gogh von Mai bis Mitte September 1888 gewohnt hat. 
In $\mathrm{Zu}$ der Arlesierin von Van Gogh von 1912 ist die Bildbeschreibung greifbarer: Bild und Text sind in ihrer Medialität deutlich markiert. Es ist klar, dass es sich um eine Bildbeschreibung, einen Text $z u$ einem Bild handelt, wie es schon im Titel deutlich gemacht ist. In Das Van Goghbild von 1918 löst schon der Titel mehrdeutige Assoziationen aus: ein bestimmtes Gemälde van Goghs, der vorliegende Text als ein Bild sowie das zeitgenössische Bild van Goghs im Sinn der diskursiven Imagination; das Verhältnis von Bild und Erzählung ist komplexer. Im Van Goghbild berichtet der Ich-Erzähler darüber, wie ihm ein Gemälde, das er in einer Ausstellung gesehen hat, und das sich als L'Arlésienne herausstellt, gefallen und ihn beeindruckt hat. Der Erzähler verbindet Bewertungen - das Bild ist eine "starke Arbeit“ (KWA III.3, 88) und „eine Art Meisterwerk" (KWA III.3, 89) - mit Bildbeschreibungen und Reflexionen zum Kunstmarkt. Er stellt sich vor, wer die abgebildete Frau sein könnte, was sie erlebt und erlitten hat. Während der Erzähler sich dieses reale Vorbild hinter dem Abbild imaginiert, wird die erzählte Zeit zunehmend dem Erzählzeitpunkt angenähert. Vergleiche und rhetorische Fragen im Präsens erzeugen die Illusion einer zeitnahen Nacherzählung.

Das Bild von Van Gogh wirkte wie eine ernste Erzählung auf mich. Die Frau fing mit einmal von ihrem Leben an zu reden. Einst war sie ein Kind und ging zur Schule. [...] Wie oft wird sie nicht mit den Händen ein Fenster geöffnet oder eine Türe zugedrückt haben. Solches und ähnliches tuen ich und du täglich, nicht wahr, und hierin liegt Geringfügigkeit, doch auch Größe. (KWA III.3, 89f.)

Hier wird vorgeführt, wie ein Bild, genauer ein Porträt, zu einer Erzählung werden kann. ${ }^{234}$ Im Van Goghbild wird diese Transformation so erzeugt, dass die Porträtierte „zu reden“ beginnt. Ihre Erzählung, die der Erzähler gleichsam aus dem Bild vernimmt, hat geringen Ereignischarakter, da sie in iterativer Erzählweise wiedergegeben wird. Es werden abstrakte Stationen und Handlungen beschrieben, die sich dadurch auszeichnen, dass sie sehr allgemein

Fünf der sieben Bilder stammen aus dem Jahr 189o. Die zwei Bilder, um die es hier geht, sind 1888 entstanden, variieren in der Farbgebung und zeigen Madame Ginoux mit unterschiedlichen Gegenständen. Madame Ginoux mit Büchern ist in Kunst und Künstler vor Walsers Beitrag abgedruckt, vgl. Karl Scheffler, „Berliner Secession“, Kunst und Künstler 10, Nr. 9 (1912): 435 .

234 Dies ist auch insofern erstaunlich, als das Gemälde offenkundig keine Szene darstellt, wie dies beim später besprochenen Gemälde Le baiser à la derobée von Fragonard der Fall ist. Porträts gelten als die am wenigsten narrativen bildkünstlerischen Werke. Werner Wolf, „Framing of Narrative in Literature and the Pictorial Arts“, in Storyworlds across Media. Toward a Media-Conscious Narratology, hg. von Marie-Laure Ryan und Jan-Noël Thon (Lincoln, London: University of Nebraska Press, 2014), 136. 
sind und die Frau als „[e]in[en] Mensch[en], wie wir alle“ (KWA III.3, 9o) kennzeichnen. Die Erzählung ist also nicht die Repräsentation von Ereignissen, sondern zeichnet sich durch ihre Ereignislosigkeit aus. ${ }^{235}$ Die Erzählung lässt die Dinge sprechen. Dies hat zur Folge, dass sie sich ihre eigene Form suchen muss und nicht in vorgegebene Schemen hineinpasst. ${ }^{236}$ Gerade die alltäglichen Geschichten brauchen eine Form, die sie erzählenswert macht. Wie lässt sich ein solches Leben erzählen? Deutlich gibt diese Narration mit ihrer Aufmerksamkeit für die kleinen Dinge, die Bereitschaft des Horchens und Angesprochenwerdens des Erzählers zu erkennen, dass es auch um die Ordnung des Sprechens und Schweigens geht. ${ }^{237}$

Die Herausarbeitung des Erzählhaften, das Ansprechen des Rezipienten, in diesem Fall über den Erzähler vermittelt, der mit dem Bild spricht, beruht

235 Vgl. dazu Tamara Evans, die die Typisierung bei Walser betont: „Doch [...] gerät Walser, von van Goghs Wahl des Stoffes angetan, ins Erzählen und Phantasieren. Das Spannendste an Walsers Bildbeschreibung ist das, was sie dem Leser vorenthält: das Stillleben am unteren linken Bildrand mit dem Tisch und den zerlesenen Taschenbuchromanen, ein Sujet, das van Gogh, der ein besessener Leser war, des öfteren gemalt und womit er immer wieder auf seine Identifikation von Leser/Leserin und Maler-Leser verwiesen hat. Madame Marie Ginoux wurde auf dem Bild von 1888 als zeitgenössische, in Gedanken versunkene Leserin porträtiert. Walser hingegen behandelt das Stillleben als Leerstelle, und so wird aus van Goghs Leserin eine ,Frau schlechtweg', eine ,Frau aus dem täglichen Leben' und zuletzt eine ,Dulderin'“" Evans, „Walsers Kunstrezeption“, 115. Dabei scheint mir, dass gerade diese Entwicklung hin zum Typus durchaus als Motiv der Moderne und insbesondere des Expressionismus gelten kann, in dessen einschlägigen Zeitschriften Walser auch publiziert hat. Vgl. Baßler, „Robert Walser in den ,Weißen Blättern““. Walser hat in der Berliner Zeit durchaus „eine Affinität zum Expressionismus“. Bernhard Malkmus, „Berliner Zeit (19051913)“, in Robert Walser-Handbuch. Leben - Werk - Wirkung, hg. von Lucas Marco Gisi (Stuttgart: Metzler, 2015), 119 .

Tamara Evans liest Robert Walsers „Arlesierin“ gleichzeitig auch als Porträt von van Gogh selbst, indem sie die religiöse Grundierung der Porträtierten als Anspielung auf van Goghs Selbstidentifikation mit Christus liest. Schließlich beleuchtet Evans auch die politischen Implikationen von Walsers Kunstkritik im Kontext der reaktionären Bewegung gegen die moderne Kunst: „Über Liebermann und van Gogh zu schreiben, bedeutete, Farbe bekennen“. Evans, „Walsers Kunstrezeption“, 116.

236 Vgl. dazu Einmal erzählte Einer in dem das Verschwinden des „Voreingenommene[n]“ (KWA III.1, 253) begrüßt wird. Siehe Kap. 3.2.7 Disruptive Digression. Einmal erzählte Einer, S. 157 ff. unten.

237 Margit Gigerl liest den Text mit Peter Utz' „Ohralitäts“-Konzept: „Alles, was die „Dulderin“ Madame Ginoux ,still' für sich behält, wird stimmhaft, ihr Schweigen zur Sprache gebracht." Gigerl, „Walsers Lektüre van Goghs“, 121. Walsers spätes Gedicht Van Gogh von 1927, publiziert 1933 in der Prager Presse - der dritte Walser-Text, der sich um van Gogh dreht - versteht Gigerl schließlich als differenzierte Kritik auf den zeitgenössischen Hype um Vincent van Gogh und in diesem Sinn als einen „in Walsers Rezeption [...] markante[n] Bruch“. Gigerl, 117 . 
auf dem Kunstwerk und dem Künstler, der es geschaffen hat. Die Haltung des Künstlers ist im Falle von L'Arlésienne laut dem Erzähler deutlich zu erkennen.

Eines Tages sagt ihr ein Maler, der auch nur ein armer schaffender Mensch ist, daß er sie gerne malen wolle. Sie sitzt ihm, läßt sich gelassen porträtieren. Sie ist ihm kein gleichgültiges Modell; denn ihm ist keinerlei Erscheinung gleichgültig. Er malt sie wie sie ist, ganz schlicht und wahr. Ohne viele Absicht kommt jedoch etwas Großes und Hohes in das einfache Bild hinein, ein Seelenernst, den man unmöglich übersehen kann. (KWA III.3, 9o) 238 $^{33}$

Die Vorurteilsfreiheit wird zu der Bedingung, dass wirklich erzählt werden kann. Aus etwas Kleinem wird etwas "Großes und Hohes“. Diese Denkfigur, dass das Kleine durch die richtige Betrachtung und Bearbeitung ,groß` wird, lässt sich bei Walser vielfach beobachten. ${ }^{239}$

Eine neue Wendung bringt der Schluss des Textes, in welchem auf den sechs Jahre zuvor publizierten Text $\mathrm{Zu}$ der Arlesierin von Van Gogh Bezug genommen wird.

Nachdem ich mir das Bild sorgsam eingeprägt hatte, ging ich nach Hause und schrieb einen Aufsatz darüber für die Zeitschrift „Kunst und Künstler“. Der Inhalt des Aufsatzes ist mir entflogen, weshalb ich ihn zu erneuern wünschte, was hierdurch geschehen ist. (KWA III.3, 90)

Die Rekonstruktion des sechs Jahre zuvor produzierten Textes Zu der Arlesierin von Van Gogh ist das Anliegen von Das Van Goghbild. Zur ,Erneuerung' des frühreren Textes kommt es erst mit diesen Schlusssätzen, die in keiner Weise zwingend aus dem Vorhergehenden folgen. Vielmehr formuliert Das Van Goghbild geradezu seine Unabhängigkeit, wenn er wie folgt beginnt: „Vor einigen Jahren sah ich in einer Gemäldeausstellung ein in gewissem Sinne

238 Vgl. dazu das Prosastück Sie schreibt, in dem ein Aktmodell ihrem Maler in einem Brief vorwirft, kein Künstler zu sein, weil er sie als Modell und Objekt seiner Kunst zu wenig achtet. Dabei wird gleichsam ein Gegenmodell zu van Gogh gezeichnet, wie er in Das Van Goghbild erscheint. „Du kannst hundert, ja tausend Aktbilder von und nach mir verfertigen, es wird immer nur ein kläglich Studieren, nie aber, versteh mich, ein Schaffen, ein Hervorbringen von etwas Köstlichem sein. [...] Mit einem Wort: solange du nicht etwas finden kannst zum Abmalen, wovor du zitterst, bleibst du ein Stümper. [...] Du bist ein Geschäftemacher, ein Fabrikant von Haufen von Bildern, aber kein Maler." (SW 15, 93f.)

239 In Walsers Konzeptualisierung des ,Kleinen` findet sich durchaus eine Portion Ironie. Dies zeigt sich etwa in Der Spaziergang, wo der Erzähler zur Unterstützung seines Loblieds auf das Kleine eine Vielzahl von Gegenständen aufzählt, die durch diese Aufzählung gerade ins Bedeutungslose fallen. In diese Richtung zielt auch Kreienbrock, Kleiner. Feiner. Leichter. Nuancierungen zum Werk Robert Walsers. 
hinreißendes und kostbares Bild, die ,Arlesierin', von Van Gogh“ (KWA III.3, 88) - formuliert der Text sein eigenes Recht.

Wie erwähnt ist für den sechs Jahre früher publizierten Text Zu der Arlesierin von Van Gogh die stärkere Trennung zwischen dem Bild und der Erzählung auffällig. Zwar ist die Wirkung des Bilds auf den Ich-Erzähler ebenfalls sehr groß, jedoch weniger als erzählerischer Nukleus, wie im späteren Text, denn als einfache Affektion. Es fehlen auch jegliche Verweise und Reflexionen auf den Erzählgehalt des Bilds, was später dominant und textbestimmend werden wird. Die beiden Texte geben in dieser Hinsicht Hinweise auf die Entwicklung der Erzählverfahren - die Tendenz zum Asystematischen, zur zunehmenden Verwebung von Motiven und Themen sowie den stärker ausgeprägten Reflexionsgehalt. Die Differenz zwischen Bild und Text ist in der frühen Erzählung auch an den zahlreichen Nennungen der medialen Differenz abzulesen: „Bild“ kommt insgesamt zwölfmal vor.

Walser speist sein Erzählen also aus dem Material verschiedener Medien. Der narrative Gehalt entsteht dabei insbesondere aus dem emotionalen und vorurteilsfreien Bezug des Erzählers zu seinem Gegenstand. In der diachronen Entwicklung von Walsers Erzählen ist eine Komplizierung der dargestellten Beziehung zwischen Erzählung und Bild festzustellen. In Das Van Goghbild werden disparate Elemente miteinander verknüpft - eigene und fremde Kunstwerke, Malerei und Schrift sowie die Themen Individualität und Allgemeinheit - und in eine selbstbezügliche textuelle Ordnung gebracht. Erzählenswert ist das Allgemeine und Unspezifische nicht per se. Haltung und Affektion des Künstlers, der im Dispositiv von Das Van Goghbild immer auch Erzähler ist, sind für die Narration ausschlaggebend.

\subsubsection{Das dramatisierte Bild. Apollo und Diana von Lukas Cranach}

Der Text Apollo und Diana von Lukas Cranach erschien 1920 ebenfalls in der Zeitschrift Kunst und Künstler. Der Untertitel Ein Gedicht führte wohl dazu, dass der eigentlich dramatische Text, ein Dialog zwischen Apollo und Diana, seinen Weg in die Abteilung Gedichte von Jochen Grevens Sämtlichen Werken (SW 13) fand. Walser dramatisiert das Gemälde Apoll und Diana in waldiger Landschaft (1530) von Lucas Cranach dem Älteren (1472-1553), das in Kunst und Künstler innerhalb der Erzählung Walsers abgedruckt wurde. ${ }^{240}$

240 Vgl. Robert Walser, „Apollo und Diana von Lukas Cranach. Ein Gedicht“, Kunst und Künstler, Nr. 2 (November 1920): 67. Von dem Bild Cranachs gibt es drei Versionen und einige Kopien. Sie unterscheiden sich hauptsächlich durch Apollos Haltung des Bogens und den Gesichtsausdruck Dianas. Dasjenige in den Musées royaux des Beaux-Arts de Belgique in Brüssel zeigt Apollo mit nach oben gerichtetem, schussbereitem Bogen, auf der Version der Royal Collection in London zielt Apollo geradeaus. Dasjenige, welches in Kunst und 
Im Dialog versucht Diana Apollo von der Jagd abzubringen und ihn für die Kunst zu begeistern. Dies scheint ihr am Ende zu gelingen, Apollo schwört den „rohen Zerstreuungen“ (SW 13, 78) ab und will sich der Schönheit Dianas zuwenden. Diese schickt ihn jedoch fort. Im Text wird der bildliche Inhalt des Gemäldes dynamisiert und in eine Handlung mit erzählter Zeit und Erzählzeit nach Seymour Chatmans „doubly temporal logic ${ }^{\text {"241 }}$ verwandelt. Den beiden Gestalten im Gemälde werden Sätze in den Mund gelegt. Die Handlungen bleiben sprachlicher Natur. Der Konflikt zwischen Bild und Narrativ, Wirklichkeit und Wort wird explizit aufgenommen, wenn Apollo zu Diana sagt:
Da ich dich finde, ist die Jagd mir herrlich, und ich preise sie, denn nie ist mir ein schöneres, entzückenderes Wild erschienen. Nur ist dies nicht das rechte Wort: Bild - hätt' ich eher sagen sollen. $(\mathrm{SW}$ 13, 77)

Was hier Bild und was Wild, was Jagd und was Kunst ist, ist ambivalent. Das Wild bezieht sich auf den geschossenen Rehbock, auf dem Diana sitzt und gleichzeitig referiert das „entzückende[] Wild“ auf Diana, als in der Liebesjagd erbeutete Trophäe. Mit dem zweiten Begriff, dem Reimwort Bild, wird ebenfalls in übertragener Sprechweise auf Diana verwiesen, indem ihre Schönheit betont wird. Zum anderen fungiert das Bild als eine mise en abyme oder sogar als eine Metalepse des Gemäldes Apoll und Diana von Cranach dem Älteren, das den Anstoß zu Walsers Prosastück gegeben hat und aus dem nun die Figuren Apollo und Diana sozusagen befreit und befähigt werden, das Bild selbst zu betrachten und es eben „entzückend“ zu finden.

Künstler abgedruckt ist, zeigt Apollo, wie er den Bogen nicht mehr gespannt hat, sondern mitsamt den Pfeilen in der linken Hand hält. Es ist dieses Gemälde, das Walser auch zu seiner Zeit in Berlin gesehen haben muss, da es sich seit Anfang des 19. Jahrhunderts in der Gemäldegalerie in Berlin befindet. Für das Gemälde in Berlin, vgl.: „Apoll und Diana in waldiger Landschaft von Lucas Cranach (der Ältere)“, Bildindex der Kunst \& Architektur, zugegriffen am 2. Mai 2020, https://www.bildindex.de/document/objo2554118. Für London: „Lucas Cranach the Elder (1472-1553) - Apollo and Diana“, Royal Collection Trust, zugegriffen am 2. Mai 2020, https://www.rct.uk/collection/407294/apollo-anddiana. Für das Gemälde in Brüssel: „Apollo und Diana“, Cranach Digital Archive. The research resource, zugegriffen am 2. Mai 2020, http://lucascranach.org/BE_MRBAB_393o. 241 Chatman, Coming to Terms, 9. Siehe Kap. 3.1.1 Erzählen - Beschreiben - Argumentieren (Chatman), S. $97 \mathrm{ff}$. oben. 
Diana versucht im Anschluss an Apollos Rede diesen von der Jagd abzubringen und ihn zur Kunst zu führen:
$\mathrm{O}$, kehr dich ab von solcher Art, beklage die verlorne Zeit, die du hinbracht'st mit Jagdgelüsten, leg' ab den Bogen, greif' zur Leier und widme dich der holden Kunst. $\left(\mathrm{SW}_{13}, 78\right)$

Die Jagd ist hier sowohl bildlich als auch wörtlich ein zielgerichtetes Verfahren, das auf ein deutliches Ereignis hinausläuft. Das erlegte Tier ist sozusagen die Pointe der Jagd. Dem setzt Diana die Leier entgegen, zu derem Spiel sie Apollo überreden will. Dianas Überzeugungskünste gelingen und Apollo versichert, dass er „denn jetzt nichts mehr tun [will], als / was herzlich ist“ (SW 13, 79). Daran anschließend gibt es eine weitere mise en abyme, in der Diana als Lied bezeichnet wird, das Apollo nachahmen soll.

Diana: Ich glaub dir's.

Sing' nur recht schöne Liebeslieder.

Apollo: Du selber bist das schönste Lied.

Diana: So suche mich denn nachzuahmen.

(SW 13, 79)

Hier zeigt sich die vielfach gespiegelte und paradoxe Auseinandersetzung mit Bild und Text in konzentrierter Form. Diana wird mit der Bezeichnung Lied zur Personifikation ,romantischer' Dichtung. Gedoppelt wird dies in der Konnotation von Diana als Bild, das noch mitschwingt. Apollo macht sich von Diana in diesem Sinn ein musikalisch-lyrisches Bildnis. Dieses gilt es nun nachzuahmen, wobei Nachahmung hier nicht im aristotelischen Sinn als Mimesis einer Handlungskette zu verstehen ist. Apollos Dichtung soll etwas anderes sein als die zielgerichtete Jagd und das handlungsorientierte Erzählen. Das Ziel der Rede der beiden ist ein Erzählen ohne Pointe, wobei die Pointe gerade darin liegt: Die selbstbezügliche Struktur ist zugleich Antrieb und Ziel des Textes und hält den Inhalt dennoch aktuell.

Neben dieser Umkehrung der Hierarchie von Abgebildetem und Abbildung, dem Vermischen von Medialitäten und Texttypen, wird auch inhaltlich einiges durcheinandergebracht. Die deutliche Liebessemantik zeigt die Irrelevanz der Verwandschaftsbeziehung Dianas und Apollos auf. Auch mit den Attributen der Götter wird spielerisch verfahren. Die Zuständigkeitsbereiche derGötterfiguren werden umgekehrt, wie es schon bei Cranach zum Teil vorweggenommen 
ist. So wäre Diana nach dem Vorbild der griechischen Artemis die Göttin der Jagd und gleichzeitig „Herrin und Schützerin des vegetativen Lebens, bes. des Wildes" sowie "Schützerin des weiblichen Lebens und seiner Funktionen“, 242 und Apollo, dessen „originäres Wesen [...] nach wie vor in dichtes Dunkel gehüllt" ist, ${ }^{243}$ der Gott der Musik und der Dichtkunst, zu denen Diana ihn in Walsers Erzählung bewegt. Gleichzeitig ist er der „schreckliche Bogenschütze[] mit den lautlosen Pfeilen“. ${ }^{244}$ Ohne tiefer in die Geschichte und Bedeutung dieser Figuren der antiken Mythologie einzugehen, bleibt hier festzuhalten, dass Walser eine narrative Dynamik in Cranachs Gemälde hineinliest, die mit einem stofflichen Anspielungsreichtum, wie schon bei Simon. Eine Liebesgeschichte gesehen, kulturelle Kontexte und Genres aufruft und sie neu arrangiert. Dieses lyrische Sprechtheater erinnert an Walsers frühe Märchendramolette. ${ }^{245}$ Statt das Handlungspotenzial, das im Bild angelegt ist, in der medialen Übersetzung zum sprachlichen Text herauszuarbeiten, wird auf einer inhaltlichen Ebene gerade zur Reflexion und sprachlichen Handlung aufgerufen. Nicht die Jagd ist das Ziel, sondern das intertextuell und metanarrativ akzentuierte Erzählen. ${ }^{246}$

\subsubsection{Das „Fragonardhafte“. Narrativität als Gestus und Haltung}

Robert Walser widmete in seiner Berner Zeit dem Gemälde Le Baiser à la dérobée (1768) des französischen Rokoko-Malers Jean-Honoré Fragonard

242 Werner Eisenhut, „Diana“, in Der Kleine Pauly. Lexikon der Antike in 5 Bänden, hg. von Konrat Ziegler und Walther Sontheimer, Bd. 1 (München: Deutscher Taschenbuch Verlag, 1979), Sp. 1511.

243 Wolfgang Fauth, „Apollon“, in Der Kleine Pauly. Lexikon der Antike in 5 Bänden, hg. von Konrat Ziegler und Walther Sontheimer, Bd. 1 (München: Deutscher Taschenbuch Verlag, 1979), Sp. 441.

244 Fauth, Sp. 442.

245 Vgl. zu Walsers Märchendramoletten: Andrea Hübner, Ei', welcher Unsinn liegt im Sinn? Robert Walsers Umgang mit Märchen und Trivialliteratur, Stauffenburg Colloquium 36 (Tübingen: Stauffenburg, 1995); Andrea Hübner, „Das Märchen ja sagt ...' Märchen und Trivialliteratur im Werk von Robert Walser", in Robert Walser und die moderne Poetik, hg. von Dieter Borchmeyer (Frankfurt am Main: Suhrkamp, 1999), 167-186; Dieter Borchmeyer, „Robert Walsers Metatheater. Über die Dramolette und szenischen Prosastücke“, in "Immer dicht vor dem Sturze ...". Zum Werk Robert Walsers, hg. von Paolo Chiarini und Hans Dieter Zimmermann (Frankfurt am Main: Athenäum, 1987), 129-143; Marion Gees, Schauspiel auf Papier. Gebärde und Maskierung in der Prosa Robert Walsers, Philologische Studien und Quellen (Berlin: Erich Schmidt, 2001); John David Pizer, „The Disenchantment of Snow White. Robert Walser, Donald Barthelme and the modern/ postmodern anti-fairy tale“, Canadian Review of Comparative Literature 17 (1990): 330-347.

246 Unten wird diese Form des Erzählens auch als Digression greifbar. Digression ist in diesem Kontext als präzises Gegenmodell zur Jagd kenntlich. Siehe Kap. 3.2.1 Zum Begriff der Digression, S. 117ff. unten. 
(1732-1806) zwei Texte: ${ }^{247}$ Ein Bild von Fragonard ${ }^{248}$, das in der Druckfassung in Carl Seeligs Auswahlband Stille Freuden von 1944 sowie in einer MikrogrammFassung überliefert ist und eine spätere Reinschrift unter dem Titel Der Kuß $\beta^{249}$. Wie bei zahlreichen Arbeiten hat Robert Walser den Mikrogramm-Text für die Druckvorlage gekürzt. ${ }^{250}$

Fragonards Gemälde Le Baiser à la dérobée zeigt eine festlich gekleidete junge Dame, die sich gegen einen jungen Mann, der sie auf die Wange küsst,

247 Das Gemälde wird auch im „Räuber“-Roman erwähnt, wo es heißt: „[D]er Räuber hatte vielleicht tags zuvor im Schaufenster einer Buch- und Kunsthandlung eine Reproduktion des Bildes ,Le baiser dérobé von Fragonard gesehen. Dieses Gemälde mußte ihn begeistern. Es ist ja wirklich auch eins der graziösesten Bilder, die je gemalt wurden." (AdB 3 , 22) Der Maler wird auch erwähnt in Fidelio (KWA III.3, 184-187).

248 Jochen Greven datiert die Entstehungszeit des Textes auf die Jahre zwischen 1928 bis 1933, Bernhard Echte und Werner Morlang vermuten Sommer 1927. Vgl. Grevens Kommentar in SW 20, 451 und die Übersichtstabelle in AdB 6, 750. Die Reinschrift, die Carl Seelig für Stille Freuden von Lisa Walser erhalten haben muss, ist nicht erhalten.

249 Bei Jochen Greven als Der Kuß (III) geführt und auf 193 o datiert; keine bekannten Drucke vor Grevens Das Gesamtwerk.

250 An dieser Stelle muss Robert Walsers Schreibverfahren vergegenwärtigt werden. Hat er seine frühen Texte, die er schließlich auch als Druckvorlagen versandte, gleich mit Tinte verfasst, so entwickelte er ab 1918 das „Bleistiftsystem“, wie er es in einem vielzitierten Brief an Max Rychner nennt, mit dem er die erste Fassung notiert, um sie dann abzuschreiben und zu variieren; dieses „Abschreibesystem“ verzögere den Schreibprozess (BA 2, 299, Nr. 758 vom 20.6.1927). Als „zur Publikation von Texten führende poetische Produktionsanordnung scheint die Mikrographie tatsächlich erst gegen Ende 1924 ,wirksam' geworden zu sein." Christian Walt, Improvisation und Interpretation. Robert Walsers Mikrogramme lesen (Frankfurt am Main: Stroemfeld, 2015), 19. Als Mikrogramme werden jene $5^{26}$ Blätter unterschiedlichen Formats und unterschiedlicher Art bezeichnet, auf denen Robert Walser mit Bleistift in einer Kleinstschrift seine Texte notiert hat. In einem zweiten Schritt übertrug er diejenigen Mikrogramme, die er an Zeitungen und Zeitschriften versandte, mit Feder und Tinte in eine normalgroße Schrift und veränderte sie auch mehr oder weniger stark. Christian Walt vergleicht dieses Verfahren mit Aufnahmen von Improvisation im Jazz als first und second/alternate takes. Walt, 28. Für eine Diskussion dieses Schreibverfahrens sowie einer ausführlichen Besprechung des Briefs an Rychner, vgl. Walt, 10-29. Vgl. zur editorischen Problematik der Zeitungstexte: Barbara von Reibnitz, „Erstdrucke in Zeitungen. Zur editorischen Kontextdokumentation am Beispiel von Robert Walsers Feuilletons", in Text-Material - Medium. Zur Relevanz editorischer Dokumentationen für die literaturwissenschaftliche Interpretation, hg. von Wolfgang Lukas, Rüdiger Nutt-Kofoth und Madleen Podewski (Berlin: De Gruyter, 2014), 219-235. Diejenigen Mikrogramme, von denen eine Reinschrift oder ein Druckbeleg vorhanden ist, werden in der neuen Kritischen Ausgabe sämtlicher Drucke und Manuskripte (KWA) erstmalig ediert. In der bislang maßgebenden, sechsbändigen Edition der Mikrogramme Aus dem Bleistiftgebiet von Bernhard Echte und Werner Morlang (AdB) sind nur von einzelnen Texten, die schon publiziert und also in den Sämtlichen Werken ediert wurden, die Mikrogramm-Fassungen wiedergegeben. 
lehnt oder ihn kokettierend wegschiebt. Die Frau blickt dabei durch eine halb offene Tür, hinter der eine Tischgesellschaft versammelt ist. In Walsers Ein Bild von Fragonard wird zuerst eine Bildbeschreibung des Gemäldes L'escarpolette (Die Schaukel, 1767) von Fragonard gegeben und danach auf Le Baiser à la dérobée eingeschwenkt. Doch zunächst beginnt der Text mit einer Aufschiebung, genauer, der Text selbst wird zu einer Aufschiebung, wie sie in den Texten der Berner Zeit häufig zu beobachten ist:

Diese ganze Zeit über gingen mir Gedichtstrophen durch den Kopf, und obschon ich jetzt zur Absolvierung eines Besuches verpflichtet wäre, scheine ich ihn aufzuschieben im Sinne zu haben, indem mich ein Künstler interessiert, über den ich zu sprechen Lust habe, und von dem ich übrigens noch nie ein Original erblickte. (SW 20, 40)

Auffällig ist an dieser Einführung, dass bereits auf eine Vielfalt der Künste und Gattungen hingewiesen wird: Gedichtstrophen, ein Gemälde und der vorliegende Prosatext. In der Mikrogramm-Fassung kommt hinzu, dass der Erzähler den Vorsatz hat, einen „Essay“ über Fragonard zu verfassen:

Er, von dem ich spreche, scheint es mir leicht zu machen, einen Essay über ihn [zu] riskieren. Da mir seine näheren Umstände, Erlebnisse unbekannt sind, brauche ich sie nicht zu erwähnen und gestaltet sich meine Arbeit um so zwangloser. (AdB 6, 553)

In der bei Seelig wiedergegebenen Fassung ist von einem Essay nicht mehr die Rede. Der Erzähler will über den Maler „referieren“ (SW 20, 40). Der Umstand, dass ihm die Lebensumstände Fragonards unbekannt sind, hindert ihn nicht am Schreiben, im Gegenteil, er stellt fest, dass dies es ihm sogar einfacher mache: Das Fehlen von gesicherten Informationen ermöglicht es dem Erzähler, die eigene Geschichte zu erzählen. Wie schon in Das Van Goghbild geht es weniger um die Individualität des Gegenstands, als um den Bezug des Erzählers zum Kunstwerk und um das Erzählerische, das aus dieser Beziehung erwachsen kann. Der Erzähler identifiziert sich mit der Malweise des Bilds, was zunächst erstaunen mag, wenn die Unterschiedlichkeit der künstlerischen Epochen in Betracht gezogen wird. Was ihm jedoch vor allem die enge Bezugnahme ermöglicht, ist das Erzählerische in Fragonards Bildern:

Fragonard war ein malender Erzähler, und er scheint mir's nicht schwer und doch auch wieder nicht leicht zu machen, über ihn zu referieren. [...] Mein Betragen besaß vielleicht etwas Fragonardhaftes, item, jeder Laden, jeder öffentliche Platz, jedes Fenster erzählten mir Geschichten, waren etwas wie Musik für mich, dem zeitweise ein Mädchen in Bernertracht starken Eindruck machte. (SW 2O, 40) 
In diesem Satz, der in der Mikrogramm-Fassung fehlt, wird das „Fragonardhafte[]" als ein Erzählen von Geschichten bestimmt. Der Erzähler deutet es als eine Haltung, die von einer gewissen ,Aufnahmefähigkeit', einer ,Offenheit' für Gegenstände und Geschichten geprägt ist. Die Geschichten, die Personen, Orte und Gegenstände wie hier „Laden“, „Platz“ oder „Fenster“ erzählen etwas. Sie sind - in einer intermedialen Erweiterung von Narrativität „etwas wie Musik“ (SW 2O, 40). Mit der Musik findet auch das Gehör, das Hören und Horchen Beachtung. ${ }^{251}$ Das Motiv des Bilds ist nicht deshalb narrativ, weil eine Kette von Ereignissen darin angelegt ist und sich so eine Spannung ergibt, sondern weil es so etwas wie einen Möglichkeitsraum bietet, eine Art Stimmung, die die Geschichten erst sehen und hören lässt.

Die Narrativität eines Bilds ist durch ihre mediale Verfasstheit prinzipiell anders, weil sie keine erzählte Zeit darstellen kann, wohl aber eine Szene, die vorherige und nachherige Ereignisse erahnen lässt. Ein bildkünstlerisches Werk kann Diachronie nicht beinhalten, aber den Betrachter dazu anregen, sich die vorherige und nachherige Situation auszumalen und einen Bezug herzustellen. ${ }^{252}$ Es ist tatsächlich so, dass Fragonards Le Baiser à la dérobée ein hohes Maß an Narrativität besitzt und in den Begriffen von Seymour Chatman eher dem Texttyp der Narration denn der Deskription zugeordnet werden müsste. ${ }^{253}$

251 Vgl. grundlegend zur Bedeutung des Hörens für Walsers Poetik Utz, Tanz auf den Rändern, 243-294.

252 Natürlich kann ein Gemälde mehrere Szenen enthalten, die deutlich in einem narrativen Verhältnis stehen. Fragonards Gemälde zeigt aber nur eine Szene. Die Verwandlung von Raum in Zeit findet bloß auf einer medialen Ebene statt und nicht auch formal, wie Tamara S. Evans es als „practice of transmuting space into time“ beschreibt. Nach Evans steht dieses bildtechnische Verfahren in scharfem Kontrast zu Walser, der auf Verfahren der Transformation von Zeit in Raum setzt. Tamara S. Evans, „Robert Walser: Writing Painting“, in Robert Walser and the Visual Arts, hg. von Tamara S. Evans (New York: The Graduate School and University Center, The City University of New York, 1996), 3 .

Vgl. dazu grundsätzlich Wolf, „Framing of Narrative in Literature and the Pictorial Arts“.

253 Dies zeigt folgende Bildbeschreibung an: „It looks as though she has just been searching in the little gueridon table for a hair ribbon, and is about to put on a silk shawl when she is surprised by a young man who draws her toward him through an open side door to ,steal a kiss. [...] [T] he entire scene is suggestive of a play unfolding on a stage." Colin B. Bailey, The Age of Watteau, Chardin, and Fragonard. Masterpieces of French Genre Painting (New Haven: Yale University Press, 2003), 296.

In der Nomenklatur der cognitive narratology ließen sich mit Werner Wolf die Elemente, die den Frame des Erzählens evozieren, benennen. Wolf ist der Ansicht, "that narrative is a major cognitive frame whose application is elicited by certain clues, ,keys,' or ,framings,' typically and preferably at the outset of a reception process." Wolf, „Framing of Narrative in Literature and the Pictorial Arts“, 126. Hervorhebung i. O. Gemäß Wolf erzeugen in der Literatur verschiedene framings den Rahmen der Narrativität: 
Walsers Erzähler interessiert sich jedoch nicht für diese handlungsorientierte Narrativität des Bilds. Der Text verweigert sich im Anschluss an obige Stelle, an der das „Fragonardhafte[]“ skizziert ist, gleichsam dieser Form der Narration und fokussiert stattdessen auf die Haltung des Erzählens in medialer Proliferation. Neben der Musik wird auch die Lyrik wieder als Medium aktiviert: Die Gedichtzeilen, die dem Erzähler zu Beginn des Textes durch den Kopf gehen und die den Text über Fragonard anstoßen, werden wieder aufgenommen, als es heißt, dass Le baiser à la dérobée „wie ein Gedicht anmutet" (SW 20, 40).

In der Mikrogramm-Version fehlt dieser explizite Vergleich mit dem Gedicht, stattdessen gibt es eine äquivalente Analogie:

Vielleicht kommt einem die Eleganz um so eleganter, die Kunst um so künstlerischer, die Liebe um so lieblicher, die Frauen um so fraulicher und eine Freude um so freudig[er] vor, je mansärdeliger man wohnt. (AdB 6, 554)

"[M]ansärdelig“ verweist hier als bloßer Gestus auf den „Dachkammerdichter". ${ }^{254}$ In der Fassung, die Seelig in Stille Freuden abgedruckt hat, fehlt dieses Wort, nicht jedoch die implizite Ansicht, dass die Intensität des Lebens als das Poetische mit der Bescheidenheit des Lebensstils zunehme. „[M]ansärdelig“ hat eine ironische Wirkung, ebenso wie das „Fragonardhafte[]“, das in beiden Fassungen vorkommt: „Meine Gesamtaufführung war fragonar[d] haft. Jedes Fenster, jeder Laden, jeder öffentliche Platz erzäh[1]te mir etwas und ich ihnen." (AdB 6, 554)

An solchen Stellen inszeniert sich der Erzähler als Performer ${ }_{\text {„ }}[\mathrm{m}] \mathrm{eine}$ Gesamtaufführung"), womit auch die Gattungsreferenz des Theaters eingeführt wäre. ${ }^{255} \mathrm{Zu}$ Walsers erzählerischer Bezugnahme ist zu bemerken, dass

Charaktere, Orte, Kausalitäten der Handlung - Elemente der story-Ebene - wie auch die Kommunikationssituation, das epische Präteritum, der Umstand, das ein vergangenes Ereignis berichtet wird, sowie paratextuelle, kontextuelle und intertextuelle Momente.

254 Robert Walser hat sich als typischen „Dachkammerdichter“ inszeniert und wurde auch in der Rezeption lange gemäss diesem Stereotyp behandelt. Peter Utz spricht von der „Legendenfigur in der Dachkammer“. Peter Utz, „Robert Walser“, in Deutsche Dichter des 20. Jahrhunderts, hg. von Hartmut Steinecke (Berlin: Erich Schmidt Verlag, 1994), 197.

Auch Marc Caduff tritt entschieden gegen diese Legende an: „Sollte also immer noch das klischierte und romantisierte Bild von Robert Walser als unbelesenem Dichterjüngling, der sich in der zurückgezogenen Dachkammer seiner eigenen Fantasie überantwortet, vorherrschen, so gilt es dieses endgültig zu verabschieden“ Caduff, Revision und Revolte, 21.

255 Die Gattungsbezeichnungen lassen sich bei Walser nicht systematisieren. Ordnung wird nicht über die Gattung hergestellt, sondern, wie hier argumentiert wird, über Performanz. Vgl. zu der Gattungsfrage bei Walser: Carsten Dutt, „Was nicht in den Rahmen 
die Motive, die der Erzähler aufzählt - Fenster, Laden, öffentlicher Platz keine Motive des Rokoko-Malers Fragonard waren. Der Erzähler übergeht die historische Distanz und adaptiert das Motiv in den eigenen poetischen Kosmos der Stadt.

Erzählen wird im Text also deutlich als medienübergreifendes Verfahren gezeichnet, das nicht auf die Verknüpfung von Ereignissen reduziert und eng an einen Erzähler gebunden ist, sondern als etwas, das durch die Herstellung eines eigenen Bezugs zum Dargestellten gelingt, wodurch eine Selbstreferenz auf das Erzählen gelegt wird.

Im Text Der Kuß, der ebenfalls Fragonards Le baiser à la dérobée zum Ausgangspunkt nimmt, wird die Beziehung zwischen Bild und Erzählung noch einmal anders gewendet. In Der Kuß ist der junge Mann auf Fragonards Gemälde der Protagonist. Walser nennt ihn einen „Pagen“. Auch hier geht es dem Erzähler nicht darum, die im Gemälde festgehaltene Szene in einem klassischen Sinn zu rekonstruieren, sondern darum, mit dem gebotenen Material einen Bezug zum eigenen Erzählen herzustellen. Ein ,Lebendigmachen' der Figuren, die Darstellung einer individuellen Persönlichkeit mit eigener Geschichte ist nicht das Ziel.

Die Menschheit war noch kilometer- oder meilenweit von der Elektrizität entfernt. Fortbildungsschulen waren für den Pagen ein totales Rätsel, über den ich hier mit des Lesers Erlaubnis einige Worte sagen will. Er lebt heute nur noch in einem unsterblichen Bild, das vor mehr als hundert Jahren zustande gekommen ist. (SW 20, 144)

Diese Zeilen haben zwei Implikationen. Zum einen suggerieren sie, dass der Page zu einem vergangenen Zeitpunkt tatsächlich lebte, das heißt auch außerhalb des Bilds eine Existenz besessen haben soll. Dem Gemälde wird ein dokumentarischer Charakter zugesprochen. Zum anderen hat das Gemälde auch konservatorische Eigenschaften, die das Weiterleben des Pagen im Gemälde ermöglichen.

Gemäß dem Erzähler sei die Geschichte hinter der Kussszene die, dass die „Herrin des Hauses [...] ihm [dem Pagen] von Zeit zu Zeit Blicke voll Aufmerksamkeit“ (SW 20, 145) zuwerfe und ihm schließlich „ihr Gesicht [...] zur zärtlichen Berührung" (SW 2O, 146) darbiete. Der Page wird - ob dadurch oder durch einen anderen Vorfall - seiner „kleine[n] Küchenfee“ (SW 20, 146)

passt. Anmerkungen zu Robert Walsers Gattungsreflexion“, in Bildersprache, Klangfiguren. Spielformen der Intermedialität bei Robert Walser, hg. von Anna Fattori und Margit Gigerl (Paderborn: Wilhelm Fink, 2008), 49-61. 
untreu. Walser erfindet also einen konkreten Kontext zu dieser Szene, während er in Das Van Goghbild lediglich einen allgemeinen Rahmen erzeugte.

In einer biografischen Lektüre wäre hier hervorzuheben, dass Walser in einem Brief an Therese Breitbach, einer Briefpartnerin in den Jahren 1925 bis Ende 1932, davon spricht, wie er sich innerhalb kurzer Zeit in zwei Frauen verliebt habe. ${ }^{256}$ Jedenfalls ist es ein Motiv, das in vielen Texten Walsers Verwendung findet. Auch dies macht deutlich, wie Walsers Erzählen weniger auf Ereignisse und deren Verknüpfung, denn auf deren Bezug zum erzählerischen Kosmos angewiesen ist.

Erzählung und Bild werden in Der Kuß eng zusammengedacht. Die Beschreibung des Bilds liefert die Basis für die Erzählung der Geschichte des Erzählers. Aus der Bearbeitung von Bildern entsteht keine Nacherzählung, keine Zusammenfassung oder Erweiterung, sondern eine eigene, selbstreflexive Erzählung, in der die Bilder als Material verwendet werden. Der Erzähler projiziert sich hinein, findet die eigene Erzählung im Bild, dem er sich, durchaus im Sinn der Produktionsmetapher des Raubes im „Räuber“Roman, bemächtigt. ${ }^{257}$

Erzählen wird so zu einer Haltung, die es ermöglicht, in allem das Erzählerische zu sehen. Das „Fragonardhafte[]“ bedeutet bei Walser nicht die galante Welt und die besondere Darstellungsweise dieser galanten Welt, für die Fragonard berühmt ist, sondern eine Art und Weise des Umgangs mit Materialien, diese zum Sprechen zu bringen und für das eigene Erzählen, das unabhängig von der story ist, produktiv zu verwenden: Im Ausreizen von medialen Ambivalenzen wird das Erzählen hier prekär.

\subsection{Digression als prekäres Ordnungsverfahren}

Wenn von Robert Walsers Texten die Rede ist, dann fällt rasch das Adjektiv digressiv. Der Begriff bezeichnet die Sprunghaftigkeit, das Zusammenhanglose und die Abschweifungen in Robert Walsers Erzählen. Digression hat aus dieser Perspektive etwas ,Zerstörerisches' an sich, etwas Chaotisches. Im Folgenden steht weniger die gemeinhin attestierte Verzögerung bzw. Verhinderung des Erzählens im Zentrum des Interesses, als vielmehr der produktive Aspekt der vielfältigen Verknüpfungsmöglichkeiten, die die Digression als Verfahren

256 Vgl. BA 2, 148f., Nr. 659, undatiert, vermutlich September/Oktober 1925.

257 Siehe Kap. 3.2.6 Der raubende Spaziergänger, S. 146ff. unten. 
bietet. ${ }^{258}$ Zunächst wird auf den Begriff der Digression und dessen paradoxe Struktur eingegangen, um dann mit dem Spaziergang (1917/1919) in die Analyse einzusteigen. Sodann wird der Übergang vom Spaziergänger zum Räuber im „Räuber“-Roman (verfasst 1925) verfolgt; schließlich stehen die Prosastücke Einmal erzählte Einer (1931) und Der heiße Brei (verfasst 1926/1927) im Zentrum der Argumentation.

\subsubsection{Zum Begriff der Digression}

So häufig der Begriff der Digression auch gebraucht wird, die Konzepte dahinter sind doch nicht fest genug umrissen. Narratologische Studien zum Begriff existieren kaum. ${ }^{259}$ Digression ist weder in der Routledge Encyclopedia of Narrative Theory ${ }^{260}$ noch im Handbook of Narratology ${ }^{261}$ aufgeführt. Häufiger als in theoretischen Zusammenhängen wird der Begriff direkt in Textanalysen und Interpretationen verwendet. ${ }^{262}$

In der antiken Rhetorik ist die digressio eine „Unterbrechung der geradlinigen Weiterführung der Rede“ zum Zweck der „Erfrischung und Erheiterung“. 263 Analog definiert das Reallexikon der deutschen Literaturwissenschaft Digression als eine „[r] $]$ hetorische Figur der Abschweifung vom direkten Gang der Rede oder Erzählung." ${ }^{264}$ Auch der Oxford Dictionary of Literary Terms stellt Digression als Unterbruch dar, als „temporary departure from one subject to

$25^{8}$ Vgl. dazu Samuel Frederick, der Walsers Schreibweise als ",plotless' writing“ bezeichnet: Samuel Frederick, Narratives Unsettled. Digression in Robert Walser, Thomas Bernhard, and Adalbert Stifter (Evanston: Northwestern University Press, 2012), 65.

259 Vgl. dazu Rhian Atkins Sammelband: „Digression is a narrative device that has often been sidelined in literary criticism. It has been seen by some as an authorial error or as an undesirable element of the text." Rhian Atkin, Hrsg., Textual Wanderings. The Theory and Practice of Narrative Digression (Leeds: Legenda, 2011), ix. Ausnahmen sind: Atkin, Textual Wanderings; Ross Chambers, Loiterature (Lincoln: University of Nebraska Press, 1999); Alexis Grohmann und Caragh Wells, Hrsg., Digressions in European Literature. From Cervantes to Sebald (London: Palgrave Macmillan, 2011); Olivia Santovetti, Digression. A Narrative Strategy in the Italian Novel (Oxford u. a.: Peter Lang, 2007).

26o David Herman, Manfred Jahn und Marie-Laure Ryan, Hrsg., Routledge Encyclopedia of Narrative Theory (London, New York: Routledge, 2010).

261 Im Handbook wird Digression in mehreren Artikeln gestreift, aber nie ausführlich besprochen. Vgl. Peter Hühn u. a., Hrsg., The Living Handbook of Narratology (Hamburg: Hamburg University, 2016), http://www.lhn.uni-hamburg.de/.

262 Etwa im Sammelband Grohmann und Wells, Digressions in European Literature. Srikanth Reddy, „Changing the Sjuzet. Lyn Hejinian's Digressive Narratologies“, Contemporary Literature 5o, Nr. 1 (2009): 54-93.

263 Josef Martin, Antike Rhetorik. Technik und Methode (München: C. H. Beck, 1974), 89.

264 Hans Esselborn, „Digression“, in Reallexikon der deutschen Literaturwissenschaft. Neubearbeitung des Reallexikons der deutschen Literaturgeschichte gemeinsam mit Harald 
another more or less distantly related topic before the discussion of the first subject is resumed. ${ }^{\text {"265 }}$ Was in den ersten beiden Definitionen suggeriert wird, ist in der letzten ausgesprochen, nämlich die temporäre Beschränkung und anschließende Rückkehr zum ursprünglichen Thema bzw. Hauptstrang. Ein Festhalten an dieser Definition der Wiederaufnahme des ursprünglichen Fadens ist auch bei verwandten narratologischen Konzepten festzustellen, beispielsweise den Katalysen des frühen Roland Barthes ${ }^{266}$ oder den satellites Seymour Chatmans ${ }^{267}$, die zwischen die Kardinalfunktionen oder kernels geschaltet werden.

Digression wird demnach als ,Abwesenheit' der Erzählung, als deren Suspendierung, mithin als Gegenstück verstanden. ${ }^{268}$ Erst wenn die Digression beendet ist, fährt die Erzählung fort. Bei Roland Barthes haben die Katalysen zwar die Funktion, einen effet de réel herzustellen, sie haben aber darüber hinaus für den narrativen Gehalt kaum Bewandtnis. Im Extremfall des Strukturalismus der 196oer-Jahre wurde, zugespitzt formuliert, versucht, die Erzählung als Formel zu verstehen. So jedoch muss die Erzählung selbst verschwinden, weil das, was zwischen Anfang und Ende steht, nur mehr als Störung des direkten Wegs erscheint. Die Abweichung vom direktesten, eben formelhaften Weg ist jedoch ein konstitutives Element jedes Erzählens.

Erzählen heißt immer auch Umwege gehen. ${ }^{269}$ Nicht umsonst wird Digression häufig in Verbindung mit Gehen, Spazieren und Flanieren gebracht.

Fricke, Klaus Grubmüller und Jan-Dirk Müller. Bd. 1, hg. von Klaus Weimar (Berlin, New York: De Gruyter, 2007), 363 .

265 Chris Baldick, „Digression“, in Oxford Dictionary of Literary Terms (Oxford, New York: Oxford University Press, 2008).

266 Roland Barthes, „Einführung in die strukturale Analyse von Erzählungen [franz. 1966]“, in Das semiologische Abenteuer, übers. von Dieter Hornig (Frankfurt am Main: Suhrkamp, 1988), 102-143.

267 Chatman, Story and Discourse, 53-56. In der Texttypen-Theorie des späteren Chatman ist die Rede davon, dass sich die Digression jeweils auf einen nicht aktualisierten Texttypus beziehe: „Narrators of novels routinely digress to describe or argue, describers to narrate or argue, and arguers to narrate or describe." Chatman, Coming to Terms, 10. Dabei ist unklar, wodurch die Texttypen definiert sind, was Chatman also unter einem „describer“ und einem "arguer" versteht.

268 Vgl. dazu Genettes Definition von Pause als ein Weiterlaufen der discours-Zeit, während die histoire-Zeit stehen bleibt.

269 Vgl. dazu schon Posers Studie zum abschweifenden Erzähler: „Die Rede als zeitliche Abfolge, welche in dem geschriebenen bzw. gedruckten Werk eine örtliche Komponente hinzugewinnt, hat von Anbeginn die Metapher des Weges, der Fahrt oder Reise nahegelegt." Michael von Poser, Der abschweifende Erzähler. Rhetorische Tradition und deutscher Roman im achtzehnten Jahrhundert, Respublica Literaria. Studienreihe zur europäischen Bildungstradition vom Humanismus bis zur Romantik (Bad Homburg: Gehlen, 1969), 138. Dies führt Poser zunächst an Homer, dann an Sternes Tristam Shandy 
Ross Chambers spricht von Loiterature - eine Wortzusammensetzung aus to loiter (herumlungern) und literature. ${ }^{270}$ Chambers unterscheidet zwei grundlegende Techniken der Digression: das etcetera-principle und das time-out. Ersteres beschreibt die Strategie, prinzipiell unendliche Kontexte an eine Erzählung anzuschließen. Dies zeigt sich konkret bei Robert Walser, der stets weitere Szenen, Ereignisse, Exkurse und Sätze als „und dann“-Konjunktionen anfügt. Mit dem Prinzip des time-out veranschaulicht Chambers die Beobachtung, dass digressive Texte häufig eine klare Begrenzung auf story-Ebene haben, innerhalb der sich die Digression ausbreiten kann. ${ }^{271}$

Wie es offenkundig ist, dass Erzählungen nicht ohne Aufschübe auskommen, ist es auch zweifellos, dass Digression dem Erzählen nicht prinzipiell hinderlich sein muss. Spannungseffekte wie Cliffhanger sind nichts anderes als Digressionen, die gezielt eingesetzt und als Stützen der Narration eingefügt werden und so der Gesamtintention des Textes zur Manifestierung verhelfen. Der Aspekt der Wiederaufnahme ist für diese Art systemstützender Digression essenziell.

Wenn jedoch die Rede von digressiven Texten ist, dann sind damit nicht Texte gemeint, für die dieses für das Erzählen überhaupt konstitutive Aufschieben wichtig ist, sondern Texte, die von ihrem plot abweichen. Bei vielen Texten, die als extrem digressiv verstanden werden, so auch bei Walser, fehlt es jedoch an diesem plot, von dem abgewichen und zu dem wieder zurückgefunden werden kann. Vielmehr besteht der Text aus einzelnen Versatzstücken von stories, die aufgegriffen, fallengelassen und im Sinn einer Montage, deren Verknüpfung einzig auf der Kontiguität der Syntax beruht, nebeneinandergestellt werden. ${ }^{272}$ Radikale Digression führt so zu einer Störung

aus, um dann für die deutschsprachige Literatur (Wieland, Musäus, Jean Paul) die Auflösung dieser Metapher zu konstatieren: „Bei den deutschen Autoren schrumpft die Reise zum Spaziergang ein, dessen auf Nebenwege lockende Hauptattraktion das unerwartete Blümlein ist." Poser, 139 .

270 Chambers, Loiterature.

271 Die Narratologin Marie-Laure Ryan spricht vor diesem Hintergrund von „diluted [verwässerter] narrativity“. In diesem Modus stehe die Erzählung in Konkurrenz zu "nonnarrative elements“, wie ausführlichen Beschreibungen, Erzählkommentaren und sonstigen Digressionen. Ryan, „The Modes of Narrativity and Their Visual Metaphors“, 375. Interessanterweise führt Ryan Digression einzeln auf und benutzt den Begriff nicht als Überbegriff für die verschiedenen Formen von Abweichung, wie die sonst genannten. Ryan nennt dabei als typische Exponenten dieser Erzählform Klassiker des narrativen Genres, wie Gustav Flauberts Madame Bovary, Tolstois Anna Karenina und auch Prousts A la recherche du temps perdu.

272 Christine Angela Knoop diskutiert ausgehend von der Differenz von „zentralen “ und „peripheren" Teilen der Erzählung den Nutzen des Konzepts Digression für Texte, die weder über ein Thema („theme“) noch über eine Handlung („plot“) zusammengehalten werden. 
jenes Systems, das Erzählen in engen Grenzen kausaler Verknüpfung verortet. Diese Form der Digression wirkt der Erzählordnung, den klaren Hierarchien der narrativen Ebenen und der Priorisierung von Ereignissen subversiv entgegen. Wie bei Walser zu sehen sein wird, kann Digression auch personifiziert werden und in Figuren auftreten, die analog zur Störung der Erzählordnung die soziale Ordnung subvertieren. Dies ist bei den Figuren des Spaziergängers und insbesondere des Räubers der Fall. Die Subversion ist dabei nicht zwangsläufig als Zweck der Digression, sondern primär als Effekt dieser Erzählform zu sehen. Anhand von Walsers Der Spaziergang, der sozusagen zu einem Prototyp des modernen digressiven Erzählens geworden ist, werden diese Überlegungen nun ausgeführt.

\subsubsection{Die Pointen des Spaziergangs. Zur Rezeption}

Bei Erscheinen der Auftragsarbeit Der Spaziergang 1917 in der erfolgreichen Reihe Schweizerische Erzähler im Frauenfelder Verlag Huber \& Co. war die Aufnahme der Rezensenten größtenteils positiv. 273 Mit drei Auflagen und insgesamt 11600 gedruckten Exemplaren darf Der Spaziergang von 1917 als Walsers erfolgreichstes Buch gelten. ${ }^{274}$ Die drei Jahre später erschienene, sprachlich stark bearbeitete Fassung des Spaziergangs im Band Seeland, stieß auf bedeutend weniger Aufmerksamkeit. Nur gerade sieben Besprechungen zu Seeland sind bekannt, während es bei Der Spaziergang in der Reihe Schweizerische Erzähler 18 Artikel sind. ${ }^{275}$ Die Rezensenten hoben 1917 das Poetische am Text hervor, die vielen Facetten und sprachlichen Register, die

Sie fragt sich, „whether this suggestion of textual hierarchy is, in fact, necessarily suitable for literary texts at large“. Christine Angela Knoop, „Is Digression a Viable Concept for Literary Studies", in Textual Wanderings. The Theory and Practice of Narrative Digression, hg. von Rhian Atkin (Leeds: Legenda, 2011), 113.

273 Vgl. Barbara von Reibnitz, „Editorisches Nachwort“, in Robert Walser. Kritische Ausgabe sämtlicher Drucke und Manuskripte, hg. von Wolfram Groddeck und Barbara von Reibnitz, Bd. I.8: Prosastücke. Kleine Prosa. Der Spaziergang, hg. von Barbara von Reibnitz (Frankfurt am Main, Basel: Stroemfeld, Schwabe, 2016), 270.

274 Vgl. Reibnitz, 26of.; Reto Sorg, „Der Spaziergang (1917)“, in Robert Walser-Handbuch, hg. von Lucas Marco Gisi (Stuttgart: Metzler, 2015). Vgl. auch André Salathé, Staatsarchivar des Kantons Thurgau, der den Briefwechsel der Brüder Walser mit dem Frauenfelder Huber Verlag herausgab. André Salathé, „Man muss nicht hinter alle Geheimnisse kommen wollen." Robert und Karl Walsers Briefwechsel mit dem Verlag Huber Frauenfeld (1916-1922) samt einer Biografie von Verleger Walther Lohmeyer (1890-1951) (Frauenfeld: Historischer Verein d. Kantons Thurgau, 2013).

275 Matthias Sprünglin, „Editorisches Nachwort“, in Robert Walser. Kritische Ausgabe sämtlicher Drucke und Manuskripte, hg. von Wolfram Groddeck und Barbara von Reibnitz, Bd. I.11: Seeland, hg. von Matthias Sprünglin (Frankfurt am Main, Basel: Stroemfeld, Schwabe, 2018), 215-217; Reibnitz, „Editorisches Nachwort“, 270-276. 
gezogen würden, die überraschenden Einfälle und immer wieder die Heiterkeit der Erzählung. Eduard Korrodi, damaliger Feuilletonchef der Neuen Zürcher Zeitung, nannte den Spaziergang ein „heitere[s], kleine[s] Meisterwerk[]“.276 Anerkennung zollte man dem "Spielerische[n] des Inhaltes“. 277 Die Erzählung wurde beschrieben als eine "tändelnde, liebliche Plauderei“278

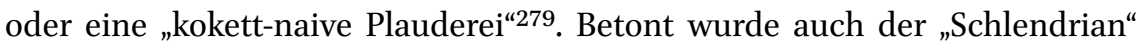
des Autors, dessen „Fabulieren“ und die „Kindlichkeit“ seines Werks. ${ }^{280}$ Dies sind freilich alles Eigenschaften, die aus dem digressiven Verfahren herrühren. Was die meisten Rezensenten positiv bewerteten als ein Erzählen, das in der Tradition der Romantik und der romantischen Ironie steht, ist auch negativ charakterisiert worden als ein Fehlen von Handlung und Konsequenz, Notwendigkeit und Kohäsion. ${ }^{281}$ So vom Rezensenten unter dem Kürzel E. J., das gemäß Barbara von Reibnitz wahrscheinlich für Ernst Jenny steht: „[I]mmer hofft man: Aha, jetzt kommts! und es ist wieder nichts und verläuft im Sand

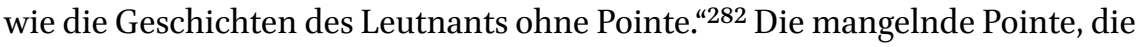
hier kritisiert wird, zielt auf das Fehlen eines deutlichen Konfliktes. Just dies ist in einer story-orientierten Definition von Erzählung zentral. Dabei ist bemerkenswert, dass der Erzähler in Der Spaziergang sein Sprechen, durchaus im Bewusstsein um diese andere Form der Textkohäsion, als ein „Erzählen und Plaudern“ (KWA I.8, 192) darstellt. ${ }^{283}$

276 Eduard Korrodi, „Der Spaziergang [1917]“, in Über Robert Walser, hg. von Katharina Kerr, Bd. 1, 3 Bde. (Frankfurt am Main, 1978f.), 113f. Teilweise abgedruckt in: KWA I.8, 271.

277 Hans Müller-Bertelmann, „Die zweite Reihe“, in Thurgauer Zeitung, Nr. 157, 7.7.1917, S. 1. Teilweise abgedruckt in: KWA I.8, 271.

278 Hans Müller-Bertelmann, „Neue Schweizer Prosa II“, in Die Schweiz, Jg. 21, Nr. 11, November 1917, S. 669-673. Teilweise abgedruckt in: KWA I.8, 273.

279 Carl Müller-Rastatt, "Von neuer Schweizer Dichtung“, in Hamburgischer Correspondent, Jg. 187, Nr. 636, 13.12.1917, Abendausgabe Ausgabe B, S. 2. Teilweise abgedruckt in: KWA I.8, 273.

28 o H. R., „Schweizerische Erzähler“, in Das Werk, Jg. 4, H. 8 [August] 1917, S. XIII. Teilweise abgedruckt in: KWA I.8, 272.

281 Digression als permanente Parekbase ist zentral in Schlegels Bestimmung der romantischen Ironie. Interessanterweise beinhaltet der Begriff der Parekbase bei Schlegel im Sinn des Heraustretens eine metanarrative Komponente, welche die Digression als solche zwar häufig auch aufweist, jedoch im heutigen Theorieverständnis dem performativen Erzählen entstammt.

282 E. J. [evtl. Ernst Jenny], „Neue Novellen und Romane“, in Sonntagsblatt der Basler Nachrichten, Jg. 12, Nr. 50, 16.12.1917, S. 199. Teilweise abgedruckt in: KWA I.8, 274. Ob die „Geschichte des Leutnants ohne Pointe“ sich auf Arthur Schnitzlers Lieutenant Gustl bezieht, kann nicht mit Bestimmtheit gesagt werden.

283 Eine Entgegensetzung von Erzählen und Plaudern findet dagegen im unveröffentlichten Prosatext Literarische Revue (laut Jochen Greven um 1928/1929 verfasst) statt, die jedoch ihrerseits durch die untergründige Ironie ambivalent bleibt: „Ich erkläre vorliegenden 
Die digressiven Eigenheiten von Der Spaziergang wurden schon beim Erscheinen des Buchs festgestellt und, je nach literaturästhetischem Empfinden des Rezensenten, positiv als Kunstfertigkeit oder negativ als Mangel an Form und Spannung gewertet. Die polarisierende Wirkung auf die zeitgenössische Kritik kann durchaus als weiteres Indiz für dessen Modernität gesehen werden. ${ }^{284}$ Diese Polarität prägt auch die spätere Rezeption, in der Walsers Bieler Zeit nicht selten zur Zeit des Idyllikers erklärt ${ }^{285}$ und, in der Folge der normativ aufgeladenen Betrachtung, die Texte der Berner Zeit als Zeugnisse seiner geistigen Umnachtung beschrieben wurden, um sie dann in jüngerer Zeit wiederum als Postmoderne avant la lettre zu lesen.

\subsubsection{Kohäsion und Konsequenz im Spaziergang}

Inhaltlich erzählt Der Spaziergang einen Gang durch eine Kleinstadt mit ländlicher Umgebung, wobei der Erzähler immer wieder kommentierend und den Erzählakt betonend in den Gang der Erzählung eingreift. Es ist in Genettes Terminologie eine autodiegetisch extradiegetische Erzählung, in der der Erzähler gleichzeitig Protagonist ist. Die Episoden, Erzählerkommentare, Ereignisse und Beobachtungen sind über den zurückgelegten Weg des Spaziergängers miteinander verknüpft. Eine Zusammenfassung des Textes zu geben, gestaltet sich schwierig. Gerade weil die Episoden in keiner klaren Hierarchie zueinanderstehen, würde eine Auswahl beliebig erscheinen. ${ }^{286}$ Um ein Gefühl für den Text zu bekommen, sollen hier trotzdem einige relativ abgeschlossene Episoden in der Reihenfolge ihrer Wiedergabe genannt werden: Aufbruch des Spaziergängers aus dem "Schreib- oder Geisterzimmer“ (KWA I.8, 167), provozierender Besuch bei einem Buchhändler mit Gespräch über Literatur,

Essay für eine Erzählung, und ich tu dies deshalb, damit, was ich da darbringe, nicht als Schwatzhaftigkeit, als Plauderei aufgefaßt wird. Ein Erzähler erzählt, er spricht nicht, und so erzähle ich denn mit großem Anstand, mit einer Gediegenheit sondergleichen und mit einer Ruhe, die, könnte man sie erblicken, eine Sehenswürdigkeit bildete, daß ich der Meinung sei, ein Poet sei verpflichtet, sich poetisch zu kleiden und eine möglichst poetische Wohnung zu bewohnen, damit allen Menschen sogleich bewußt wird: ,Aha, das ist ein Poet', und jede Verwechslung ausgeschlossen ist." (SW 19, 238)

284 Reto Sorg spricht vom Spaziergang als einem „Schwellentext der Moderne“. Reto Sorg, „Der Spaziergang (1917)“, 15 o.

285 In den Carl Seeligs Wanderungen nennt Walser die Bieler Zeit „hirtenbübelig“. Seelig, Wanderungen mit Robert Walser, 21.

286 Dies ist der Fall bei Claudia Albes, die eine fünfseitige Aufzählung der Stationen der Erzählung gibt. Vgl. Claudia Albes, Der Spaziergang als Erzählmodell. Studien zu JeanJacques Rousseau, Adalbert Stifter, Robert Walser und Thomas Bernhard (Tübingen, Basel: Francke, 1999), 221-226. 
Entgegennahme eines Preises des Vereins Gemeinnütziger Frauen in der Bank, Begegnung mit einer vermeintlichen Schauspielerin, der er von seiner Herkunft erzählt, Begegnungen mit dem Riesen Tomzack, mit einer Sängerin, Mittagessen bei Frau Aebi, Einwurf und Rekapitulation eines Beschwerdebriefes, Besuch bei einem Schneider, den er beschimpft, seinen Anzug nicht passend gemacht zu haben, Vorsprechen beim Steuerbeamten mit Bitte um eine Herabsetzung seiner Steuerschuld, Gang über die Bahnschranke, der "Höhepunkt" (KWA I.8, 208), Erleben einer Jesus-Epiphanie, Schimpfen über einen gefällten Baum, Erinnerung an einen Toten und an eine vergangene Liebe und schließlich Entschluss zum Heimweg, da es dunkel wird. Einige dieser Episoden weisen biografische Bezüge zu Walser auf, wie die Geldspende - Walser hat 1914 seine einzige Auszeichnung vom Frauenbund zur Ehrung rheinländischer Dichter erhalten - oder den Bericht über die Rückkehr aus einer Großstadt - Walser kehrte 1913 aus Berlin zurück nach Biel. Die Abfolge der Episoden gehorcht keiner Entwicklung. Ihren Platz in der Erzählung erhalten sie durch die Kontiguität des Spaziergangs sowie die zahlreichen Spiegelungsverhältnisse und Variationen von Figuren, Ereignissen und Motiven.

Die Spannung zwischen der Intentionslosigkeit, die einen Spaziergang im Grunde ausmacht und den deutlichen Absichten und Verabredungen des Spaziergängers wurde aus den vorherigen Beschreibungen sichtbar. Mag die Ansprache an den Hund und das Gespräch mit der Sängerin dem Zufall geschuldet sein, so sind die Verabredung des Spaziergängers zum Mittagessen bei Frau Aebi geplant, ebenso der Gang aufs Steueramt und der Besuch beim Schneider. Keineswegs kann der Spaziergänger mittags länger bei Frau Aebi verweilen, weil er, wie er erklärt, „gewisse wichtige Dinge zu erledigen hätte, die ich nicht aufschieben dürfte." (KWA I.8, 195) Die geplanten Ereignisse geben dem Spaziergang vielleicht ansatzweise einen Zweck, reichen jedoch nicht aus, alle Episoden in einen Zusammenhang mit durchgängiger Motivation zu stellen. ${ }^{287}$ Sie bleiben kontingent.

Aus den oben aufgeführten Beobachtungen und einigen der Rezensionen lässt sich eine erste Bestimmung der Digression als scheinbar mangelhafte Form der Verknüpfung ziehen: Digressive Erzählungen sind solche, deren

287 Der Narratologe Peter Hühn schlägt zwei Typen von Ereignissen vor: event type I und event type II. Erstgenannten zeichnet das formale Kriterium der Zustandsänderung aus, letzterer meint ein Ereignis in einem umfassenderen Sinn, wie es etwa Jurij Lotman als Überschreitung einer semantischen Grenze definiert. Diese Ereignisdefinitionen sind jedoch nicht auf die spontanen und geplanten Ereignisse im Spaziergang übertragbar. Vgl. Hühn, „Event and Eventfulness“. 
Ereignisse nicht über eine (pseudo-)kausale Verknüpfung zu einem Ganzen gefügt werden, sondern deren Elemente in kontingenter Weise nebeneinanderstehen. Eine durchgehende Motivierung in Form einer integralen und integrierenden story fehlt. ${ }^{288}$

Statt der narrativen Logik übernehmen andere Merkmale die Funktion der Kohäsion: Das ausufernd kommentierende Erzähler-Ich und sein Figuren-Ich, die Kontiguität des Spazierens im Raum, die Spiegelung von Erzählprozess und Spazieren sowie zahlreiche Spiegelungen von Motiven, Figuren und Szenerien. Der Erzähler erzeugt mit seinen Erzählkommentaren metanarrative Klammern, in Prolepsen weist er auf Kommendes hin oder macht mittels Analepsen Vergangenes gegenwärtig, wodurch die Erzählung strukturiert wird. Hinzu kommen Sinnangebote, die sich als übergeordnete Metaerzählung anbieten, die gleichsam die unsystematische Verknüpfung der Episoden erklären können. Beispiele solcher Sinnangebote sind etwa die Erledigungen und Verpflichtungen während des Spaziergangs als Grund desselben, der Spaziergang als Ausdruck eines Leides, wie ihn der Spaziergänger gegenüber der Sängerin darstellt oder schließlich die Rahmung des Textes als unglückliche Liebesgeschichte, wie sie am Ende des Spaziergangs aufscheint. Diese Angebote sind jedoch in keiner Weise zwingend. Allein deren Suggestion durch unsystematische Hinweise erzeugt Klammern, die dem Text als Ganzes Stabilität und Konzentration geben. ${ }^{289}$

Durch die ausgeprägte Markierung des Erzählers im Spaziergang entsteht eine deutliche Erzählerillusion. ${ }^{290}$ Diese wird durch wiederkehrende Verweise auf die erzählte Zeit und die Erzählzeit, bzw. auf die erzählte Handlung und das Erzählen selbst erzeugt. Der Erzähler wechselt kontinuierlich die narrativen Ebenen - springt vom Spaziergänger-Ich der Vergangenheit zum Erzähler-Ich der Gegenwart. So heißt es eingangs: „Soviel ich mich erinnere, befand ich mich, als ich auf die offene, helle Strasse trat, in romantisch-abenteuerlicher Gemütsverfassung, die mich beglückte." (KWA I.11, 79) ${ }^{291}$ Hier wird eine

288 Vgl. Martinez und Scheffel, Einführung in die Erzähltheorie, 111-118.

289 In Bezug auf Gérard Genettes Unterscheidung von Fiktion und Diktion kann gesagt werden, dass Der Spaziergang stark durch die Kohäsionskraft der Diktion organisiert ist. Vgl. Gérard Genette, Fiktion und Diktion, übers. von Heinz Jatho (München:Wilhelm Fink, 1991).

290 Zur Erzählerillusion vgl. Nünning, „Mimesis des Erzählens“. Siehe Kap. 3.3 Performatives Erzählen, Metanarration und Metafiktion, S. 168ff. unten.

291 In der Fassung von 1917 heißt es leicht variiert und komplizierter: „So viel ich mich heute, wo ich dieses alles schreibe, noch zu erinnern vermag, befand ich mich, als ich auf die offene helle und heitere Straße trat, in einer romantisch-abenteuerlichen Gemütsverfassung, die mich tief beglückte." (KWA I.8, 167) Dies beschreibt just das Programm des 
klassische Erzählsituation evoziert, in der ein Erzähler ein vergangenes Ereignis berichtet.

Diese so deutliche Evokation der prototypischen Erzählsituation wird im Verlauf der Erzählung vielfach gebrochen. Durch Ironie, Übertreibungen, Widersprüche und Sprünge im Verlauf zeigt sich der Erzähler in seiner Funktion als ordnende Instanz unzuverlässig. Der konzeptionellen Fragilität des Erzählers zum Trotz vermag es die Stimme, wie oben gezeigt, die Kohäsion des Textes zu garantieren, gerade auch durch Verfahren, die die realistische Erzählordnung in Frage stellen. Die Unverwechselbarkeit der Stimme spiegelt sich dabei in der Kontiguität der Episoden, die sich durch die Topografie des Spaziergangs auf einer Art Bahn befindet, die eben diese Kontiguität sicherstellt.

Es sind die inhaltlichen und formalen Klammern, die den Spaziergang in Bezug auf die Konvention der Erzählordnung aufbrechen und neu zusammenhalten. Die aneinandergereihten Episoden sind zwar kontingent, verfügen aber über einen Zusammenhang jenseits logischer Verknüpfung. Indem der Text als Ganzes wiederkehrend auf der Metaebene des Erzählerkommentars diskutiert wird und sich dadurch fortlaufend selbst als zusammenhängender Text in Szene setzt, entsteht mit der Leichtigkeit, die von den zeitgenössischen Rezensenten gerühmt wird, ein kohäsiver Text, der als Einheit wahrgenommen wird.

\subsubsection{Digression als Aufschub, Ausweichen und Abweichen}

Robert Walser ist ein Meister des Aufschiebens. Die Digression als Aufschub hat - genau wie als Ausweichen und als Abweichen - Konsequenzen, insbesondere auch für den Anfang und das Ende der Erzählung. Der Anfang des Spaziergangs ist insofern ein Glanzstück, als der Aufschub mit dem Vorsatz sich zu beeilen einhergeht und im bloßen Konjunktiv gehalten ist. In der Fassung von 1917 lautet der Beginn des Textes:

Ich teile mit, daß ich eines schönen Vormittags, ich weiß nicht mehr genau, um wieviel Uhr, da mich die Lust, einen Spaziergang zu machen, ankam, den Hut auf den Kopf setzte, das Schreib- oder Geisterzimmer verließ, die Treppe hinunterlief, um auf die Straße zu eilen. Beifügen könnte ich, daß mir im Treppenhaus eine Frau begegnete, die wie eine Spanierin, Peruanerin oder Kreolin aussah. Sie trug etwelche bleiche, welke Majestät zur Schau. Ich muß mir jedoch auf das strengste verbieten, mich auch nur zwei Sekunden lang bei dieser Brasilianerin oder was sie sonst sein mochte, aufzuhalten; denn ich darf weder Raum noch Zeit verschwenden. So viel ich mich heute, wo ich dieses alles schreibe, noch zu

Spaziergangs als romantisch einerseits und abenteuerlich andererseits. Interessanterweise wird die Modernität gleichsam bloß in der Form mitgedacht und nicht in konkreter Bildlichkeit. 
erinnern vermag, befand ich mich, als ich auf die offene helle und heitere Straße trat, in einer romantisch-abenteuerlichen Gemütsverfassung, die mich tief beglückte. (KWA I.8, 167)

Indem der Erzähler behauptet, sich beeilen zu müssen und keine Zeit zu verschwenden sei, schiebt er den Beginn der Erzählung auf. Es ist nicht nur ein Aufschub, sondern auch eine performative Aufhebung des Vorsatzes, sich zu beeilen. Der Aufschub vollzieht sich auf verschiedenen Ebenen. Schon die Wendung „auf die Straße zu eilen“ verzögert durch die Konditionalkonstruktion die Ankunft auf der Straße - die Figur befindet sich erst im Treppenhaus. Der Erzähler friert gleichsam den Spaziergänger beim Hinabeilen auf der Treppe ein und schiebt so den Beginn des Spaziergangs auf. Der folgende Satz, der die Frau im Treppenhaus einführt, wird auf der discourse-Ebene als Erzählerkommentar mitgeteilt. So ist die Nennung der Frau im Konjunktiv („beifügen könnte ich“) eine Form des Möglichkeitserzählen, was insofern ein Paradox darstellt, als das Gesagte nicht nicht hätte gesagt werden können. Mithin ist diese denarration eine bloße Inszenierung des Möglichen. ${ }^{292}$ Der Aufschub äußert sich auch im zusätzlichen Einschub „oder was sie sonst sein mochte“ und der Vielzahl der Adjektive auf der Mikroebene des Satzes. ${ }^{293}$ Indem der

292 Dieser erzählerische Konditional ist eine spezifische Form der denarration, ein Begriff, den Brian Richardson im Rückgriff auf Brian McHales Konzept des disnarrated in Bezug auf mögliche, jedoch nicht verwirklichte Ereignisse geprägt hat. Richardson redet von „a kind of narrative negation in which a narrator denies significant aspects of her narrative that had earlier been presented as given.“ Brian Richardson, „Denarration in Fiction: Erasing the Story in Beckett and Others“, Narrative 9, Nr. 2 (2001): 168. Vgl. dazu auch Brian Richardson, „Denarration“, in Routledge Encyclopedia of Narrative Theory, hg. von David Herman, Marie-Laure Ryan und Manfred Jahn (London: Routledge, 2010); Brian McHale, Postmodernist Fiction (London, New York: Routledge, 1987).

293 Samuel Frederick arbeitet anschaulich heraus, wie sowohl auf der story-Ebene wie auch auf der discourse-Ebene ein Ereignis verweigert wird: „The opening words immediately foreground the act of telling that defines Walserian narration: the narrator both tells us he is telling and performs this telling at the same time. The first sentence that these words introduce, however, does not take us far before Walser begins employing his apophatic mode. Already in the second sentence he takes a narrative detour to tell of an insignificant encounter in the stairwell. This sentence revealingly starts with the subjunctive mode, which cues the description that follows as something that does not happen. The event that does not actually occur, however, is not the encounter with the woman, but rather the narrator's aside, the aside that would narrate this same encounter. This aside, which is an event on the level of discourse, not story, does not, the narrator says, actually take place (because, the narrator makes clear, he could add that narrative detail, but does not want to waste the time doing it). Paradoxically, however, in the apophatic act of saying that it will not take place, this aside actually occurs. Walser thereby narrates something by refusing to narrate it; though this refusal, as part of Walser's ironical playfulness, is 
Erzähler sich selbst zur Disziplin aufruft („ich muß mir jedoch verbieten“), macht er deutlich, dass er sich der Wirkung des Aufschubs bewusst ist und zögert den Anfang doch auch damit weiter hinaus.

Ein anderes Beispiel der aufschiebenden Wirkung der denarration und damit für das Verfahren der Negation von Möglichkeiten wird im Spaziergang geschildert, wenn die Option zur Einkehr in ein Wirtshaus durchdacht wird.

Es käme jetzt und träte hervor ein Wirtshaus, und zwar ein sehr feines, reizendes, schmeichelhaftes, ein Wirtshaus, nah am Rand des Waldes gelegen, aus dem ich soeben erst herauskam [...]. [...] Ein Glas Bier oder Wein wäre sicher auch nicht schlecht; aber der Mensch, der hier spaziert, besinnt sich rechtzeitig, daß er sich ja auf keinem gar so sehr anstrengenden Ausmarsch befindet. [...] Handelt es sich doch hier mehr um zartes, sanftes Spazierengehen als um eine Reise und Wanderung, und mehr um einen feinen Rundgang als um einen Gewaltritt und -Marsch, und daher verzichtet er gerechter- so gut wie vernünftigerweise auf den Eintritt ins Lusthaus und Erquickungshaus und nimmt Abgang. Alle ernsthaften Leute, die dies lesen, werden seinem schönen Entschluß und seinem guten Willen gewiß reichen Beifall zollen. (KWA I.8, 188)

Dieses Erzählen in der Möglichkeitsform ist in einem doppelten Sinn digressiv. Der Erzählerkommentar schiebt einerseits auf der discourse-Ebene den Fortgang des Spaziergangs auf der story-Ebene auf. Solange darüber gesprochen wird, was sein könnte, aber de facto nicht ist, kann die Geschichte nicht vorankommen. Diese Form der Digression schiebt andererseits aber auch den discourse als solchen auf und zwar insofern, als sich diese Möglichkeitsform letztlich negiert. Es zeigt sich hier deutlich, wie im Text Erzählen und Spazieren jeweils in einer paradoxen Simultanität dargestellt werden. Die Benutzung des Konditionals („käme jetzt und träte hervor ein Wirtshaus“) anstelle der Indikativ-Form (bspw. ,jetzt taucht ein Wirtshaus auf"), akzentuiert also die aufschiebende Wirkung.

Dass der Spaziergänger plötzlich nicht mehr als Ich, sondern in der dritten Person erzählt wird („der Mensch, der hier spaziert“), ist ein Zitat der klassischen Erzählordnung, in der Erzähler und Figur, anders als im Spaziergang üblich, deutlich voneinander getrennt sind. Durch die konjunktivische Erzählform wird die Erzählordnung weiter aufgegliedert, woraus ein eigenartiger Schwebezustand entsteht, der den engen Zusammenhang von Digression und performativem Erzählen im Spaziergang deutlich macht.

also not a refusal, but that which makes possible narrative inclusion. Walser therefore denies two events their place in the narrative (one, the actual occurrence of encountering someone [story level]; and two, the narratorial aside [discourse level]), but in doing so sanctions them both." Frederick, Narratives Unsettled, 42. Hervorhebung i. O. 
Die Digression, die in story-orientierten Erzählmodellen die kausale Verknüpfung von Ereignissen aufschiebt, lässt sich auch als Form der Verknüpfung verstehen, die nicht auf Kausalität abzielt. Als eine Aneinanderreihung von Ereignissen und Episoden - Ross Chambers' etcetera-principle - lässt sich Digression darüber hinaus als ein Ausweichen von narrativer Logik, genotypischen Erwartungen und anderen Ordnungsverfahren verstehen. ${ }^{294}$ Die Digression übernimmt die Funktion des Ordnens auf paradoxe Weise. Der Widerstand gegen die Kausalität in der spezifischen Form des Ausweichens ist ein häufig angewandtes Verfahren Robert Walsers. Narrative Ordnungsmuster werden zitiert und anschließend umgangen, wodurch deren Künstlichkeit und Irrelevanz aufgezeigt wird. Deutlich zeigt sich dieserWiderstand im Modus des Ausweichens bei der Begegnung des Spaziergängers mit dem Riesen Tomzack.

Indem ich [...] so des Weges ging [...], kam ein Mensch, ein Ungeheuer, ein Ungetüm mir entgegen, der mir die helle lichte Straße fast völlig verdunkelte, ein lang- und hochaufgeschossener unheimlicher Kerl, den ich leider nur allzu gut kannte, ein höchst sonderbarer Geselle, nämlich der Riese

Tomzack.

[...] Seine trauervolle, schauervolle Erscheinung, sein tragisches, ungeheures Wesen flößte mir Schrecken ein [...]. Ich kam mir neben ihm wie ein Zwerg oder wie ein kleines armes schwaches Kind vor. Mit der größten Leichtigkeit hätte mich der Riese zertreten oder erdrücken können. (KWA I.8, 184f.)

Der Riese Tomzack wird hier als drohendes Ungeheuer inszeniert, das dem Spaziergänger-Ich mit Leichtigkeit den Garaus machen könnte. Durch die Marker „Riese“, „Ungeheuer“, „Zwerg“ und weitere wird ein Märchenton erzeugt; doch statt nun die Erzähllogik des Märchens aufzunehmen, weicht die Erzählung diesem soeben inszenierten Erzählmuster aus. Der erwartete Konflikt zwischen Held und Widersacher bleibt aus. ${ }^{295}$ Die sonderbare Begegnung ist ohne jede Konsequenz: „Ich wich ihm aus und murmelte für mich: ,Leb wohl, und laß es dir immerhin gut gehen, Freund Tomzack.“ (KWA I.8, 186)

Dieses Ausweichen ist sowohl auf der story-Ebene als auch auf discourseEbene wirksam. Auf der story-Ebene weicht das Spaziergänger-Ich Tomzack

294 Erzählformen und die Regeln dessen, was „verständliches“ Erzählen bedeutet, sind diskursive Festlegungen, die in den jeweiligen Epochen verankert sind. Vgl. Jan Alber, "The Diachronic Development of Unnaturalness. A New View on Genre“, in Unnatural Narratives - Unnatural Narratology, hg. von Jan Alber und Rüdiger Heinze (Berlin, Boston: De Gruyter, 2011), 41-70.

295 Das Register der Abenteuergeschichte wird gleich zu Beginn des Spaziergangs aktiviert, in dem auf die "romantisch-abenteuerliche[] Gemütsverfassung“ (KWA I.8, 167) des Spaziergänger-Ich hingewiesen wird. Vgl. in Bezug auf das Märchen Vladimir Propps Funktion des Kampfes, Vladimir Propp, Morphologie des Märchens. (Frankfurt am Main: Suhrkamp, 1986). 
aus, auf der discourse-Ebene umgeht der Erzähler das Erzählmuster des Konflikts. Paradoxerweise ist das lapidare „ich wich ihm aus“ seinerseits sehr pointiert. In der Programmatik des Ausweichens ist die Ablehnung des Konflikts geradezu die Pointe.

Aus handlungslogischer Sicht gelingt es der Erzählung just mit der Ablehnung einer narrativen Verknüpfung den Spaziergang fortzuführen. Dies ist eine Form der Digression, die gerade nicht zu einem Hauptstrang zurückkehren kann, wie es im klassischen Verständnis der Digression gefordert wird. Stattdessen wird weitererzählt; die Erzählung, der Text und der Spaziergänger gehen einfach weiter. Der Figur des Ausweichens liegt also gleichzeitig eine Zuwendung zum Stoff und zur Erzählung zugrunde. Durch diese Zuwendung im Ausweichen kann die Tomzack-Episode als eine Form von Walsers ambivalenter Auseinandersetzung mit der Moderne beschrieben werden. ${ }^{296}$

Digression ist auch ein Abweichen von vorgegebenen Formen und Inhalten. Es wird vom schnellsten Weg des Erzählens der story abgesehen und gegen genrespezifische Anforderungen und allgemein klassische Erzählordnungen verstoßen. ${ }^{297}$ Es ist ein Abweichen vom normalen Gang der Erzählung. Als der Spaziergänger nach dem Wirtshaus-Schlenker im Konditional wieder auf den Hauptweg zurückkommt, heißt es: „Ich kam nämlich jetzt aus der Waldabschwenkung wieder in den Hauptweg zurück“ (KWA I.8, 189). Der Diskurs über das Gästehaus wird hier explizit als Abschwenkung bezeichnet, ein Abweichen vom gewöhnlichen Gang und Hauptweg. ${ }^{298}$

296 Der Riese Tomzack lässt sich inhaltlich verschieden interpretieren. Peter Utz liest Tomzack vor dem Hintergrund des zeitgenössischen Diskurses als Figuration von Nietzsche, als „Schatten Zarathustras“. Utz, Tanz auf den Rändern, 175. Walser hatte zum modernen Philosophen par excellence selbst ein ambivalentes Verhältnis. Reto Sorg sieht in Tomzack ein „dämonisches Alter Ego des Erzählers“. Reto Sorg, „Der Spaziergang (1917)“, 151. Tomzack ist auch als „Herold des Nichts“, der „Wortlosigkeit“ beschrieben worden. Michail Schischkin, „Walser und Tomzack“, in Ein Buchstabe auf Schnee. 3 Essays (PetitLucelle, 2019), 56. Bei Martin Roussel birgt die Moderne Monstrositäten und Gefahren für den Spaziergänger, die im Riesen verkörpert werden. Martin Roussel, „Der Riese Tomzack. Robert Walsers monströse Moderne“, in Monströse Ordnungen. Zur Typologie und Ästhetik des Anormalen, hg. von Achim Geisenhanslüke und Georg Mein (Bielefeld: Transcript, 2009), 363-40o. Vgl. zu Tomzack auch Kirsten Scheffler, Mikropoetik. Robert Walsers Bieler Prosa. Spuren in ein „Bleistiftgebiet“ avant la lettre, Lettre (Bielefeld: transcript, 2010), 213-218.

297 Dabei sei auch darauf hingewiesen, dass es durchaus genretypische Digressionen gibt, die jedoch relativ begrenzt sind und durch eine (finale) Motivierung zusammengehalten werden, wie etwa im Schelmenroman, beispielsweise bei Christoph Martin Wielands Die Abenteuer des Don Silvio von Rosalva und anderen.

298 Dass die "Waldabschwenkung" auf der Ebene des discourse gelesen werden muss, wie Albes behauptet, ist schlecht nachvollziehbar, insbesondere mit ihrem topografischen Argument: „Die ,Waldabschwenkung“ etwa, von der aus der Erzähler ,wieder auf den Hauptweg‘ zurückkehrt, kann nur als metaphorischer Hinweis auf einen narrativen 
Das Abweichen auf der Ebene von Verhaltensnormen und sozialen Rollen wird im Spaziergang ebenfalls als Digression thematisiert: Es ist ein inhaltliches Pendant zum narrativen Verfahren. Im Anschluss an das Zurückfinden auf den „Hauptweg“ heißt es: „Doch halt! und eine kleine Anstandspause gemacht. Schriftsteller, die ihren Beruf verstehen, nehmen denselben möglichst ruhig." (KWA I.8, 189) Es ist, als würde der Erzähler, der dem Spaziergänger zuvor noch die Pause abgeschlagen hat, selbst in jenes Wirtshaus einkehren, das in der story nicht über den Konditional hinaus erscheinen durfte. Als Grund dafür, dass der Spaziergänger nicht einkehrte, wurde genannt, dass es sich beim Spaziergang „mehr um zartes, sanftes Spazierengehen als um eine Reise und Wanderung" (KWA I.8, 188) handelt. ${ }^{299}$ Diese Aussage lässt sich auch auf die discourse-Ebene beziehen. Schließlich ist der Text von geringem Umfang und eher eine Novelle als ein ausufernder Roman.

Diese zur Schau gestellte Rechtschaffenheit versucht den Künstler und seine zweifelhafte Arbeitsmoral zu rehabilitieren. Auf der story-Ebene ist der Spaziergänger ,anständig‘ und trinkt nicht, wofür sich der Erzähler des Lobes der Leserschaft gewiss ist. ${ }^{300}$ Ebenso hat auch der Erzähler die Anerkennung der Bürgerlichen verdient, da er mit größter Anstrengung arbeitet: „Anhaltendes Schreiben ermüdet wie Erdarbeit." (KWA I.8, 189) Diese Rechtfertigungen kommen derart offensiv daher, dass sie als ironische Übererfüllung der Norm ad absurdum geführt werden. ${ }^{301}$

Exkurs gelesen werden, denn andernfalls wäre kaum erklärlich, wieso der Erzähler, nachdem er eben noch auf einem Aussichtshügel gestanden hat, um ,in bläulicher, weissumhauchter Ferne' das Gebirge zu betrachten, wenige Sätze später ,am ärmlichen Vorstadtfenster die jugendliche Sängerin erblicken kann." Albes, Der Spaziergang als Erzählmodell, 229 .

299 Das vollständige Zitat lautet: „Er muß sich ehrlich gestehen, daß sein Durst weder mordsmäßig noch heidenmäßig ist, da er bis jetzt verhältnismäßig nur kleine Strecken zurückzulegen gehabt hat. Handelt es sich doch hier mehr um zartes, sanftes Spazierengehen als um eine Reise und Wanderung, und mehr um einen feinen Rundgang als um einen Gewaltritt und -Marsch, und daher verzichtet er gerechter- so gut wie vernünftigerweise auf den Eintritt ins Lusthaus und Erquickungshaus und nimmt Abgang." (KWA I.8, 188) Es sei auf die Betonung des Akts in „Spazierengehen“ im Kontrast zum Spaziergang hingewiesen.

300 „Alle ernsthaften Leute, die dies lesen, werden seinem schönen Entschluß und seinem guten Willen gewiß reichen Beifall zollen." (KWA I.8, 188)

301 Die Problematik der Abweichungen von bürgerlichen Normen, die sich in Walsers Werkentwicklung verstärkt, wird weiter unten anhand des „Räuber“-Romans eingehender untersucht. Siehe Kap. 3.2.6 Provokationen der Ordnungen. Der „Räuber"-Roman, S. $141 f f$. unten.

Zur wichtigen Figur der Übererfüllung von Normen als Topos vgl. Christian Walt, „Den Lyrikern empfehl' ich dringend, / sich dem Zwang des Reims zu unterziehen ...". Zur Übererfüllung von Gattungsnormen in Robert Walsers späten Gedichten“, in „Ich 
Digression als wucherndes Textprinzip steht in einem Spannungsverhältnis zur Schließung eines Textes in der Struktur von Anfang und Ende. Indem Digression Normen, Grenzen und Ordnungen aufbricht, steht sie naturgemäß in Konflikt mit Rahmungen und ist gleichzeitig auf eine künstliche Begrenzung angewiesen, um die eigene Wirkung zu entfalten. Eine Begrenzung des Textes ist nur schon durch das Medium, eine vorgegebene Zeichenzahl oder einen anvisierten Buchumfang gegeben. Als Feuilletonist hat Walser Texte vorgegebenen Umfangs verfasst, auch Der Spaziergang hatte als beauftragte Novelle einen ungefähr festgelegten Umfang. Anfang und Ende sind der für die Rahmung notwendige Gegenpart, an dem sich Digression reibt, den sie aufschiebt und von dem sie abzuweichen versucht.

In Der Spaziergang sind Anfang und Ende sehr deutlich markiert. ${ }^{302}$ Der Anfang, welcher oben ausführlich wiedergegeben wurde, zitiert klassische Erzählordnungen und weicht doch von ihnen ab. Die eigentlich redundante Inquit-Formel der Fassung von 1917 „Ich teile mit, daß“ (KWA I.8, 167) etabliert die Kommunikationssituation zwischen Erzähler und Leser, jedoch nicht ohne eine Irritation einzubauen, die im Verb mitteilen liegt, bezieht sich dieses doch in der Regel nicht auf einen erzählerischen Kontext, sondern eher auf eine Proklamation oder einen Rapport. ${ }^{303}$ Neben dem Anfang wird auch das Ende

beendige dieses Gedicht lieber in Prosa". Robert Walser als Grenzgänger der Gattungen, hg. von Anna Fattori und Kerstin Gräfin von Schwerin (Heidelberg: Universitätsverlag Winter, 2011), 157-175.

Zur Übererfüllung von sozialen Rollen bei Robert Walser selbst vgl. Gisi, „Das Schweigen des Schriftstellers. Robert Walser und das Macht-Wissen der Psychiatrie“.

302 ",The Walk' has a beginning, middle, and end. But its design does not allow us to read it for or in terms of those structural features. They are merely markers; their functionality has been neutralized." Frederick, Narratives Unsettled, 63. Hervorhebung i. O.

303 In der umgearbeiteten Fassung von 1919 in Seeland fehlt diese Inquit-Formel. Der Spaziergang beginnt in medias res: „Eines Vormittags, da mich die Lust, einen Spaziergang zu machen, ankam, setzte ich den Hut auf den Kopf, lief aus dem Schreib- oder Geisterzimmer weg und die Treppe hinunter, um auf die Strasse zu eilen. Im Treppenhaus begegnete mir eine Frau, die wie eine Spanierin, Peruanerin oder Kreolin aussah und etwelche bleiche, welke Majestät zur Schau trug." (KWA I.11, 79) Wie oben bemerkt fehlt hier im Vergleich zur Fassung von 1917 auch der Einschub „ich darf weder Raum noch Zeit verschwenden“. So lässt sich sagen, dass die Performanz des Textes eher mit der formulierten Intention übereinstimmt. Dies führt auch zur Einschätzung, dass die zweite Version des Spaziergangs abgerundeter und gemäßigter ist. Vgl. Susan Bernofsky, „Introduction“, in The Walk Translated by Christopher Middleton with Susan Bernofsky (New York: New Direction, 2012), 3-11; Dorette Fasoletti, Selbstrevision - Neukreation: Robert Walsers Buch "Seeland“ (Würzburg: Königshausen \& Neumann, 2020); Jochen Greven, „Nachwort des Herausgebers", in Sämtliche Werke in Einzelausgaben, hg. von Jochen Greven, Bd. 7: Seeland, 2o Bde. (Zürich, Frankfurt am Main: Suhrkamp, 1986), 209-215. 
der Erzählung aufgeschoben. Schon fünf Seiten vor Schluss wird es mit einer Art Resümee eingeleitet:

Vielleicht sind da und dort Wiederholungen vorgekommen. Ich möchte aber bekennen, daß ich Natur und Menschenleben als eine ebenso schöne wie reizende Flucht von Wiederholungen anschaue, und ich möchte außerdem bekennen, daß ich eben diese Erscheinung als Schönheit und als Segen betrachte. (KWA I.8, 224)

Etwas später heißt es: „Es war nun Abend geworden, und da gelangte ich auf einem hübschen, stillen Weg oder Seitenweg, der unter Bäumen hinlief, zum See hinaus, und hier endete der Spaziergang." (KWA I.8, 224) Der Spaziergang als Erzählung führt dennoch weiter. Im prinzipiell unabschließbaren Prozess der Digression kann das Ende nur durch künstliche Grenzen oder in einer Abweichung vom Prinzip der Digression gefunden werden. In diesem Sinn ist Digression ein paradoxes Verfahren. Prinzipiell endlos angelegt, muss es, um zu einem Ende zu kommen, seine eigene Ordnung durchbrechen.

Die Problematik der Digression und ihrer textuellen Begrenzung von Anfang und Ende wird in Ross Chambers' time-out principle aufgenommen. Ein Verfahren, welches seinen Namen, so Chambers, dem Umstand verdankt, dass digressive Texte häufig innerhalb eines klaren zeitlichen Rahmens spielen. Seine Überlegungen entwickelt er an Nicolas Bakers Roman The Mezzanine (1986), einem postmodernen Angestelltenroman, in dem die Mittagspause und eine Liftfahrt das time-out vom Büroalltag markieren und eine Phase der Digression eröffnen und wieder beschließen. ${ }^{304}$

Interessanterweise weist die Bearbeitung des Spaziergangs damit eine andere Tendenz auf als andere Texte Walsers, die ein zweites Mal gedruckt wurden. So ist etwa bei den Texten im Band Kleine Prosa (1917), die mehrheitlich schon in Zeitungen und Zeitschriften publiziert wurden, festzustellen, dass diese in der Buchfassung an narrativer Komplexität und Redundanz zulegen. Erstdrucke sind als Digitalisate in der OnlineVersion der KWA greifbar. Vgl. Walser, Elektronische Edition der Kritischen Robert WalserAusgabe (KWAe).

Vgl. zu dieser Eingangssequenz auch Jörg Kreienbrock, der das „Mitteilen“ als Hinweis auf die Teilung des Anfangs liest und insofern als Ausstellen der Kontingenz des Anfangs: „Anfang der Erzählung und Anfang des Spaziergangs sind nicht identisch, sondern sind mitgeteilt. In der Wendung Ich teile mit wird anerkannt, dass der Beginn der Erzählung geteilt ist und somit auch immer anders mitgeteilt werden könnte." Kreienbrock, Kleiner. Feiner. Leichter. Nuancierungen zum Werk Robert Walsers, 49.

304 Den Text zeichnet auch eine Verschiebung vom Vertikalen des Hochhauses als paradigmatischer Relation der Bedeutung zum Horizontalen der digressiven, syntagmatischen Verknüpfung aus. Vgl. Chambers, Loiterature, 124. 
Die time-out-Situation bringt für die Erzählung den Vorteil mit sich, dass Anfang und Ende auf der Ebene der story schon gegeben sind. Durch einen thematischen Wechsel oder einen Sprung auf der narrativen Ebene kann die Digression abgeschnitten werden, ohne dass sich ein Ende aus ihr entwickeln muss. In Robert Walsers Prosa aus der Berner Zeit wird der Abschluss der radikal digressiven Kurztexte häufig durch die explizite Nennung dieses Abschlusses vollzogen, also mit einer Referenz auf die Schreibszene, die sozusagen als timeout dient, innerhalb dessen die Digression Raum greift. Dies ist natürlich eine paradoxe Eingrenzung, weil es sich dabei um eine Inszenierung einer höheren Ebene (Schreibszene) handelt. ${ }^{305}$

Auch der Spaziergang lässt sich als time-out-Erzählung beschreiben. Die Zeit von Vormittag bis zum Abend bildet den Rahmen innerhalb dessen der Spaziergang stattfindet. In dieser Zeitspanne spaziert der Protagonist durch die Kleinstadt, den nahen Wald, macht seine Besorgungen und Bekanntschaften in zwangloser Manier. In eigentümlicher Umkehrung ist dabei die Situation, von der ein time-out zum Zwecke der Digression genommen wird, eine Schreibsituation - er verließ das "Schreib- oder Geisterzimmer“ (KWA I.8, 167). Die oben zitierte Feststellung über das Ende des Spaziergangs („hier endete der Spaziergang“) artikuliert gleichzeitig die Rahmung der Erzählung und deren Kontingenz, ist es doch in ihrer Explizitheit eine künstlich wirkende Setzung - der Weg könnte ohne Weiteres weitergehen.

Die time-out-Situation ist also durch die metanarrative Erzählweise prekarisiert. Die Ebenen von Erzählen und Erzähltem werden überblendet, so dass das Spazieren, während es stattfindet, erst geschrieben wird. Das performative Erzählen verschiebt Anfang und Ende der story - also Aufbruch und Rückkehr des Spaziergängers - auf die Ebene des Erzählens. Die Begrenzungen verlieren dadurch, dass sie Setzungen des Erzählers sind, der sich als autodiegetischer Erzähler auf derselben narrativen Ebene befindet und entsprechend denselben Fiktionalitätsgesetzen untersteht, ihre Rahmenfunktion. Sie werden kontingent und künstlich. Daraus lässt sich schließen, dass die zentralen Ordnungsverfahren im Text sich nicht mehr aus der narrativen Logik der story ergeben, sondern auf der discourse-Ebene beim Erzählen selbst hergestellt werden. Die Aufschübe, das Ausweichen und Abweichen von einem geraden narrativen Weg sind dabei nicht nur Verstöße gegen herkömmliche Erzählordnungen, sondern stellen eine eigene Ordnung sicher.

305 Siehe Kap. 3.3 Performatives Erzählen, Metanarration und Metafiktion, S. 168ff. unten. 


\subsubsection{Spaziergänger, Flaneure und Vagabunden}

Der Flaneur ist seit Baudelaires kanonischem Moderne-Aufsatz Le peintre de la vie moderne und Edgar Allan Poes Man of the Crowd zu einer der zentralen Figuren der großstädtischen Moderne geworden. ${ }^{306}$ Als Figur spiegelt er in seinen Bewegungen, Reflexionen und Wahrnehmungen die Vielfalt der Großstadt, die Überwältigung der Sinne in der Moderne, die Intensität und Flüchtigkeit des Augenblicks. Von Robert Walser gibt es auch großstädtische Flaneur-Texte, wie etwa Guten Tag, Riesin! (1907/1913; SW 3, 63-67) oder Aschinger (1907/1913; SW 3, 67-70), die die Beschleunigung und die Vielfalt der Großstadt Berlin aufnehmen und abbilden. ${ }^{307}$ Der Spaziergang jedoch spielt offensichtlich nicht in einer Großstadt, sondern in einer Kleinstadt, die große Ähnlichkeiten mit Biel hat. Man könnte meinen, Walser repräsentiere eher den Typus des romantischen Naturwanderers als den modernen Flaneur, ihm gehe es eher um Kontemplation, denn um Erfahrung des Disparaten. Der Topos des Spaziergängers ist für die Rezeption von Leben und Werk des Autors zentral. ${ }^{308}$ Zweifellos ist die Bieler Zeit nach den Berliner Jahren wieder

306 Vgl. für eine Differenzierung der Flaneur-Typen: Harald Neumeyer, Der Flaneur. Konzeptionen der Moderne (Würzburg: Königshausen \& Neumann, 1999); Hans Richard Brittnacher und Magnus Klaue, Hrsg., Unterwegs. Zur Poetik des Vagabundentums im 20. Jahrhundert (Köln, Weimar, Wien: Böhlau Verlag, 2008); Annette Simonis, „Vom ästhetischen Blick zur ,bricolage؛. Zur Entstehung der modernen Kulturpoetik bei Georg Simmel und Walter Benjamin", in Unterwegs. Zur Poetik des Vagabundentums im 2o. Jahrhundert, hg. von Hans Richard Brittnacher und Magnus Klaue (Köln, Weimar, Wien: Böhlau Verlag, 2008), 9-26.

307 Vgl. insb. Walsers Sammelband Aufsätze (Leipzig: Kurt Wolff, 1913) sowie die Anthologien: Robert Walser, Berlin gibt immer den Ton an. Kleine Prosa aus und über Berlin, hg. von Jochen Greven (Frankfurt am Main, Leipzig: Insel, 2006); Robert Walser, Die kleine Berlinerin. Geschichten aus der Großstadt, hg. von Pino Dietiker und Reto Sorg (Berlin: Insel, 2018).

308 Vgl. Otto Zinniker, Robert Walser der Poet (Zürich: Werner Classen, 1947); Seelig, Wanderungen mit Robert Walser. Vgl. Guido Stefani, Der Spaziergänger. Untersuchungen $z u$ Robert Walser, Zürcher Beiträge zur deutschen Literatur- und Geistesgeschichte (Zürich, München: Artemis, 1985); Albes, Der Spaziergang als Erzählmodell; Elisabetta Niccolini, Der Spaziergang des Schriftstellers. „Lenz“von Georg Büchner, „Der Spaziergang“ von Robert Walser, „Gehen“ von Thomas Bernhard (Stuttgart: Metzler, 20oo); Rothemann, Spazierengehen - Verschollengehen. Zum Problem der Wahrnehmung und der Auslegung bei Robert Walser und Franz Kafka; Annie Pfeifer und Reto Sorg, Hrsg., „Spazieren muss ich unbedingt". Robert Walser und die Kultur des Gehens, Robert Walser-Studien 1 (Paderborn: Wilhelm Fink, 2019).

Anna Fattori definiert die zweite Phase der Rezeption von 1978 bis 2000 als „Auffächerung der Forschung“, in der „[e]tliche Arbeiten [...] versuchten, an dem herkömmlichen Bild des Autors zu rütteln, das sich Ende der 1970er Jahre gefestigt hatte." Anna Fattori, „Forschungsgeschichte“, in Robert Walser-Handbuch. Leben - Werk - Wirkung, hg. von Lucas Marco Gisi (Stuttgart: Metzler, 2015), 421f. 
stärker auf Motive der Romantik und des Ländlichen bezogen. Dennoch ist diese Referenz auf die Vormoderne immer von Modernität grundiert, wie sich an Die Indianerin aus dem Band Poetenleben zeigt.

\section{Die Indianerin aus Amerika}

Am Band Poetenleben (1917) lässt sich zeigen, wie sich in die zahlreichen neoromantischen Motive - wie Schlösser und Burgfräuleins, Natur und Schönheit die Moderne eingeschlichen hat. Im Text Die Indianerin (KWA I.9, 51-53) wird das Zusammentreffen des Erzählers mit einer rätselhaften, verfolgten Frau geschildert, indem Elemente der Romantik mit solchen der Moderne vermischt werden. ${ }^{309}$ Der Text beginnt mit der Schilderung eines, feenhaft schönen Sees, die „Träume waren wach und lebendig geworden; Geister und Gedanken bewegten sich in weichen, schleierhaften Gewändern“ (KWA I.9, 51). Eine Frau wartet auf der Terrasse vor einem Palast, in dessen Innenräumen ein Fest im Gange ist. Ihr fremdländisches Aussehen und ihre „entzückende, phantastische Schleppe“ (KWA I.9, 52) erinnern den Erzähler an eine Tänzerin. Sie deutet an, dass sie verfolgt werde. Zusammen fahren sie in einem Boot auf den See hinaus. „Das sieht ja aus wie eine Entführung“ (KWA I.9, 52), sagt sie und spielt damit auf den Topos der Entführung in der Liebesliteratur an. ${ }^{310}$ Die Figur der Tänzerin hat in diesem Setting deutliche Bezüge zur Moderne. Als Amerikanerin dürfte die Indianerin das Leben in der Großstadt gewohnt sein. Das verabredete Treffen zwischen Tänzerin und Ich-Erzähler verhindert das Wetter: „Aber andern Tags regnete es, und ich blieb zu Hause“ (KWA I.9, 53). Das Nichtzustandekommen dieses neuerlichen Treffens zeigt an, dass in der Moderne gleichsam nur Inszenierungen von Romantik möglich sind. Die Kontingenz des Wetters schlägt der Romantik in der Moderne ein Schnippchen. Mit dieser lapidaren Wende nimmt Die Indianerin Verfahren der Neuen Sachlichkeit vorweg und illustriert, wie Walser neoromantische Topoi in die Moderne überführt. ${ }^{311}$

309 Mit vielen stilistischen Veränderungen zuerst erschienen im März 1915 in der Zeitschrift Die Schweiz, Jg. 19, Nr. 3, zusammen mit Der Wanderbursche unter der Überschrift Zwei romantische Stücke. Vgl. für einen Abgleich der Fassungen die KWAe.

310 Walser hat diese romantische Entführung ironisch auch in Die italienische Novelle (KWA I.8, n1f.), erschienen in Prosastücke, modelliert. Vgl. dazu Christine Weder, „Oskar und Emma statt Romeo und Julia. Vom modernen Schicksal des Liebespaars bei Robert Walser“, Deutsche Vierteljahrsschrift für Literaturwissenschaft und Geistesgeschichte 92, Nr. 1 (März 2018): 43-61.

$311 \mathrm{Zu}$ Walsers Haltung gegenüber der neusachlichen Literaturtheorie im "Tagebuch"Fragment von 1926 vgl. Hendrik Stiemer, „Wenn das Schreiben Hand in Hand mit dem Leben geht. Zu Robert Walsers „Tagebuch'-Fragment von 1926““, Deutsche Vierteljahrsschrift für 


\section{Großstädtische Kleinstadt}

Was also zunächst als neoromantisch und idyllisch daherkommt und gattungstechnischen Vorgaben zu gehorchen scheint, entpuppt sich als ironische Inszenierung dieser Ordnungen. Ähnliches gilt auch für die vermeintliche Vormoderne der Kleinstadt im Spaziergang. Auch hier schlägt sich das Großstädtische Bahn. ${ }^{312}$ Marker einer großstädtischen Moderne sind die dargestellten unübersichtlichen Massenphänomene und die Zitationen von Werbesprüchen und Markennamen. Der Erzähler selbst scheint vor der Vielfalt kapitulieren zu müssen. ${ }^{313}$

Einige Alltäglichkeiten und Verkehrserscheinungen sind hier vielleicht ganz am Platz, nämlich etwa der Reihe nach: eine stattliche Klavierfabrik nebst andern Fabriken und Etablissementen, eine Pappelallee dicht neben einem schwärzlichen Fluß, Männer, Frauen, Kinder, elektrische Straßenbahnwagen, ihr Krächzen und der ausschauende verantwortliche Feldherr oder Führer, ein Trupp reizend gescheckter und gefleckter blaßfarbiger Kühe, Bauernfrauen auf Bauernwagen und dazugehöriges Rädergeroll und Peitschenknallen, etliche schwerbepackte, hochaufgetürmte Lastwagen, Bierwagen und Bierfässer, heimkehrende, aus der Fabrik hervorströmende und -brechende Arbeiter, das Überwältigende dieses Massen-Anblicks und -Artikels und seltsame Gedanken hierauf bezüglich [...]. Ferner nicht zu übersehen oder zu vergessen: Aufschriften und Ankündigungen wie „Persil“ oder "Maggis unübertroffene Suppenrollen" oder "Continental-Gummiabsatz enorm haltbar" oder "Grundstück zu verkaufen“ oder "Die beste Milch-Schokolade“ oder ich weiß wahrhaftig nicht, was sonst noch alles. Wollte man so aufzählen, bis alles getreulich aufgezählt wäre, so käme man an kein Ende. Einsichtige fühlen und merken das. (KWA I.8, 220f.)

In diesem Zitat werden die chaotische Mannigfaltigkeit, die Dynamik und der Rhythmus der Masse in die Sprache aufgenommen und wiedergegeben. Die Aneinanderreihung stellt ihre Künstlichkeit aus - sie zielt weniger auf eine mimetische Abbildung einer Vielheit, als auf deren Herstellung in der Sprache. In der Aufzählung wird die Individualität des Einzelnen gerade entwertet, der

Literaturwissenschaft und Geistesgeschichte 87, Nr. 1 (März 2013): 93-122, https://doi. org/10.1007/BFo3375853.

312 Vgl. dazu Peter Utz, „Wo spielt Walsers ,Spaziergang?? Stichworte zu seinem kultur- und literaturgeschichtlichen Ort", in "Spazieren muss ich unbedingt" Robert Walser und die Kultur des Gehens, hg. von Annie Pfeifer und Reto Sorg, Robert Walser-Studien 1 (Paderborn: Wilhelm Fink, 2019), 51-65.

313 Insofern ist Harald Neumeyers These, dass Walser mit der Rückkehr von Berlin nach Biel und dem Verfassen des Spaziergangs wieder "auf den Wanderer bzw. Spaziergänger [...] als Identitätsmodelle“ zurückgreife und dasjenige des Flaneurs, der sich über die Beobachtung von Masse definiert, aufgebe, wenig überzeugend. Was sich ändert, ist lediglich die Explizitheit des Settings. Neumeyer, Der Flaneur, 209f. 
Blick darauf ist kontingent. Die Beschreibung ist kein Erfassen mehr, sondern ein bloßes Benennen, das die Einzigartikeit des Objekts wiederum subvertiert. ${ }^{314}$ Dies sind charakteristische Verfahren der literarischen Moderne, die auf einer formalen Ebene avancierter sind als bei manchen Autoren, die das Setting der Großstadt explizit bedienen.

\section{Fachmann und Verdächtiger}

Noch in Franz Hessels formal wenig avancierter Spaziergänger-Literatur (Spazieren in Berlin, 1929) ${ }^{315}$ ist der Spaziergänger eine verdächtige Figur. Dass Spazieren in der Großstadt nichts Harmloses ist, zeigt sich paradigmatisch in der Erzählung Der Verdächtige. Die Flaneure werden von den sogenannten Vertretern des Anstands argwöhnisch beobachtet. Der Protagonist bei Hessel hütet den Hund einer Bekannten, um seine flânerie mit einer Intention zu tarnen. Nachdem der tierische Freund im Treppenhaus sein Geschäft erledigt hat, solidarisiert er sich mit ihm und bestätigt insofern die Abweichung von der bürgerlichen Norm. Im Vergleich zu Walsers Spaziergang, in dem die Hunde nur Streuner sind, ist dies geradezu kokett. Hessels Erzählung hat einen deutlich pädagogischen Anspruch und der Erzähler hält sich an die entsprechende Erzählordnung.

Wenn das Spazieren schon in der Großstadt Verdacht schöpft, um wie viel mehr ist es dann in der Kleinstadt suspekt. ${ }^{316}$ Im Spaziergang heißt es:

Ein Monteur auf dem Fahrrad, Kamerad vom Landwehrbataillon 134/III, ruft mir beiläufig zu: „Du spazierst wieder einmal, scheint mir, am heiterhellen Werktag." Ich grüße ihn lachend und gebe mit Freuden zu, daß er recht hat, wenn er der Ansicht ist, daß ich spaziere.

„Sie sehen es mir an, daß ich spaziere“, dachte ich im stillen und spazierte friedlich weiter, ohne mich im geringsten über das Ertapptwordensein zu ärgern, was ganz dumm gewesen wäre. (KWA I.8, 176f.) $)^{317}$

314 Weitere Beispiele dieses Verfahrens sind die Aufzählung des Erzählers vor der Zusammenkunft mit Tomzack (KWA I.8, 184f.) und die Lobrede auf das Spazieren beim Bankangestellten (KWA I.8, 202-207).

315 Franz Hessel, „Spazieren in Berlin“, in Franz Hessel. Sämtliche Werke in fünf Bänden, hg. von Hartmut Vollmer und Bernd Witte, Bd. 3: Städte und Porträts, hg. von Bernhard Echte, 5 Bde. (Paderborn: Igel Verlag, 2013).

316 Georg Simmel betonte die stärkere Selbst- und Fremdkontrolle der Bewohner einer Kleinstadt: „Je kleiner ein solcher Kreis ist, der unser Milieu bildet, je beschränkter die grenzenlösenden Beziehungen zu anderen, desto ängstlicher wacht er über die Leistungen, die Lebensführung, die Gesinnungen des Individuums, desto eher würde eine quantitative und qualitative Sonderart den Rahmen des Ganzen sprengen.“ (GG 125)

317 Robert Walser selbst war Füsilier im Landwehrbataillon 134 / III, vgl. Peter Utz, „Urkatastrophe, Ohropax und ferner Donner. Zur Literatur aus der Schweiz im Ersten 
Spazieren fällt auf. Auch wenn der Spaziergänger den Argwohn, den er hervorruft, auf die leichte Schulter zu nehmen scheint, so steht doch fest, dass er in einer Position der Abwehr ist. Das „Ertapptwordensein“ zeugt - trotz aller Freundlichkeit - von der Ächtung des Spazierens am "heiterhellen Werktag“, die nicht spurlos am Spaziergänger vorbeigeht. ${ }^{318}$

Expliziter noch werden die Vorwürfe in der Episode des Steuerbeamten vorgebracht, in der der Spaziergänger sich um eine möglichst tiefe steuerliche Einschätzung bemüht. Auf die wortreiche Erklärung und Bitte des Spaziergängers, seine „Zahlungskraft so niedrig einzuschätzen wie nur immer möglich“ (KWA I.8, 203), entgegnet der Steuerbeamte: „Man sieht Sie aber immer spazieren!“ (KWA I.8, 203). Mit dieser Antwort wird schwerlich suggeriert, dass Spazieren eine bürgerliche Tugend sei und der Beamte von entsprechenden finanziellen Mitteln des Spaziergängers ausgehe. Spazieren ist hier ein Indiz des Nichtstuns und des Schmarotzertums an der Gesellschaft.

Dem Spaziergänger ist bewusst, dass er nicht der Norm entspricht: „Bürgerliche Stellung und bürgerliches Ansehen besitze ich nicht; das ist sonnenklar.“ (KWA I.8, 203) In der anschließenden Rede zieht er zur Rechtfertigung seines Spazierens bürgerliche Normen der Arbeitsmoral und des Fleißes heran. Das Spazieren ist laut dem Spaziergänger für die Ausübung seines Berufs - er ist Schriftsteller - unentbehrlich:

Ohne Spazieren und Bericht-Auffangen könnte ich auch keinen Bericht mehr abstatten und nicht den winzigsten Aufsatz mehr, geschweige denn eine ganze lange Novelle verfassen. (KWA I.8, 203f.)

Geist, Hingabe und Treue beseligen ihn [den Schriftsteller] und heben ihn hoch über seine eigene unscheinbare Spaziergängerperson hinaus, die nur zu oft im Geruch und schlechten Rufe des Vagabundierens und unnützen Herumstreichens steht. (KWA I.8, 205)

Ich verdiene mit einem Wort mein tägliches Brot durch Denken, Grübeln, Bohren, Graben, Sinnen, Dichten, Untersuchen, Forschen und Spazieren so sauer wie irgend einer. Indem ich vielleicht die allervergnügteste Miene schneide, bin ich höchst ernsthaft und gewissenhaft, und wo ich weiter nichts als zärtlich und schwärmerisch zu sein scheine, bin ich ein solider Fachmann! (KWA I.8, 207)

Weltkrieg“, Jahrbuch der deutschen Schillergesellschaft. Internationales Organ für neuere deutsche Literatur, 2015, 276.

318 Auch Melissa Kagen liest diese Stelle so: „The interaction with his friend clearly bothers him, although he blithely admits to his seeming unproductivity and protests, too much, about how useless frustration would be [...]. Silly or not, the interaction clearly upsets the narrator, as evidenced by his repetitive assurances to the contrary.“ Melissa B. Kagen, „The Wanderer as Soldier: Robert Walser's ,Der Spaziergang', Switzerland in World War I, and Digression as Occupation“, The German Quarterly 89, Nr. 1 (1. Januar 2016): 39, https://doi. org/10.1111/gequ.10254. 
Mit dem ,soliden Fachmann' ist die denkbar größte Differenz zum ,nichtsnutzigen' Spaziergänger gezogen. Es geht hier natürlich auch um die Verhandlung der Funktion und Stellung des Künstlers in der Gesellschaft. Was die Avantgarde der literarischen Moderne sicherlich nicht war, ist eine Gruppe biederer solider Fachmänner. Der Steuerbeamte lässt sich von diesen Erklärungen zufriedenstellen und willigt ein, das Gesuch zu prüfen. Als der Spaziergänger das Gebäude verlässt, fühlt er sich wieder in Freiheit - ein ironischer Kommentar auf die soeben aufgeführte Anbiederung.

So wie der Text von der Erzählordnung abweicht, weicht der Spaziergänger von der bürgerlichen Ordnung ab und versucht doch, die Anbindung nicht zu verlieren. An einer Stelle heißt es, er sei ein „besserer Strolch, feinerer Vagabund und Tagedieb oder Zeitverschwender und Landstreicher" (KWA I.8, 184). Bei der Figur des Landstreichers und Vagabunden darf auch der streunende Hund nicht fehlen. Wie vorhin angesprochen, solidarisiert sich in Franz Hessels Spazieren in Berlin der Flaneur mit einem Hund. Er spricht von sich und dem Hund als einem wir, und sieht sich gemeinsam für den Kot im fremden Treppenhaus verantwortlich. Bei Walser nun liegen die Hunde im Weg. Im Spaziergang „erlabt“ sich schon auf der dritten Seite ein Hund an „Brunnenwasser“ (KWA I.8, 169) an einer Stelle, die bezeichnenderweise besonders deutlich die Überblendung narrativer Ebenen ausstellt. Später liegt ein Hund „quer mitten auf der Straße" (KWA I.8, 177). Und als Spiegelung dieses Hundes folgt darauf ein "gute[r], ehrliche[r], kohlrabenschwarze[r] Hund“ (KWA I.8, 216), der vom Spaziergänger mit einer Ansprache bedacht wird. Er wirft dem Hund seine Anstandslosigkeit vor, dass er nicht aufstehe, nicht grüße und keine Antwort gebe, ein "gänzlich unbelehrte[r] und unkultiverte[r] Bursche[]“" (KWA I.8, 216), ein „ruppiger Gesell“ (KWA I.8, 217) sei. Zwar distanziert sich der Spaziergänger vom Tier und beschimpft es, relativierend wird jedoch klargestellt, dass das Schimpfen "jedenfalls nicht böse gemeint sein konnte“ (KWA I.8, 217). Gerade in dieser Äußerung aber stellt sich der Spaziergänger mit dem Hund auf eine Ebene, macht sich vergleichbar und wird - in dieser Logik - selbst zum Gesellen des Streuners. ${ }^{319}$

319 Diese Lesart wurde auf problematische Weise in einem weiteren Schritt auf Robert Walser selbst übertragen. Zum Beispiel im Essay von William H. Gass: „Er [Robert Walser] verfügt über die perfekte Streunerpsychologie.“ William H. Gass, „Robert Walser“, in Über Robert Walser. Zwei Essays, übers. von Jürg Laederach (Salzburg, Wien: Residenz Verlag, 1997), 7. Dieser Kurzschluss zwischen Figur, Erzählverfahren und Pathologie des Autors war bis in die 1970er-Jahre verbreitet. Martin Jürgens hat sich in einem einflussreichen „Exkurs“ dagegen verwehrt. Jürgens, Robert Walser. In der psychiatrisch-medizinischen Forschung gibt es nach wie vor Arbeiten, die denselben Fehlschluss begehen und aus den Schreibverfahren auf die Psyche des Autors schließen, vgl. S. Partl u. a., „,Meine Krankheit 
Dass der Spaziergänger durchaus die entsprechende Figur für die digressive Form des Erzählens ist und nicht einfach zufälligerweise einen strolchenhaften Eindruck hinterlässt, liegt auf der Hand. Erzähler und Strolch verhalten sich gegenüber Regeln und Normen ähnlich, ein Verhältnis, das demjenigen der Digression zum konventionell-ordentlichen Erzählmodell entspricht. Sie sind Eindringlinge in einem festgefügten System, das auch militärische Kontrolle aufweist. Diese Kontrolle wird nicht nur kritisiert. Die dissidenten und subversiven Seiten der Erzählung und des Protagonisten dürfen nicht darüber hinwegtäuschen, dass den Text durchaus auch reaktionäre, konservative Aspekte kennzeichnen. Zu deutlich sind die konservativen Momente, die die Subversion wiederum ambivalent halten, so dass eine eigenartig verdoppelte Ambivalenz entsteht, gerade hinsichtlich der Kriegsthematik, die sehr präsent ist. ${ }^{320}$

Im Folgenden wird zu sehen sein, wie sich vom Spaziergänger zum Räuber des „Räuber“-Romans die widerständige Haltung weiterentwickelt. Wie der Spaziergänger nicht eigentlich Spaziergänger ist, ist auch der Räuber nicht nur Räuber. Im Vergleich zum Spaziergang stellt der rund neun Jahre später verfasste Text eine aggressivere Figuration der Erzählverfahren dar.

ist eine Kopfkrankheit, die schwer zu definieren ist'. Robert Walser $(1878-1956)$ in seiner psychischen Erkrankung“, Der Nervenarzt 82 (2011): 67-78.

320 Melissa Kagen hat in einem interessanten Aufsatz den Spaziergang vor dem Hintergrund der schweizerischen Militärtaktik im Ersten Weltkrieg als „Verzögerungskrieg“ gelesen. In diesem militärischen Kontext wird Digression als Okkupation („digression as occupation“) lesbar und der Spaziergänger seinerseits erscheint als Soldat, der in den entsprechenden Episoden äußerst aggressiv agiert: „In the wartime atmosphere of Der Spaziergang, this kind of expansiveness expresses itself militantly. Digression is a technique through which Walser the author holds the reader's attention and arrests his eye movement, in the same way the Spaziergänger controls the space he's wandering and blathering through." Kagen, "The Wanderer as Soldier“, 47.

Vgl. dazu Peter Utz, der in diesem Zusammenhang auch folgenden intertextuellen Bezug herstellt: „So ist im großen Prosatext Der Spaziergang, der 1917 unmittelbar neben Faesis Füsilier Wipf in der gleichen Reihe bei Huber erscheint, der Krieg vor allem indirekt präsent, in einer Schreibweise des subjektiven Ab- und Ausschweifens, das sich der Logik der militärischen Gradlinigkeit ironisch entgegensetzt.“ Utz, „Urkatastrophe, Ohropax und ferner Donner. Zur Literatur aus der Schweiz im Ersten Weltkrieg“, 279. Vgl. auch Peter Utz, „Helvetische Heroik im Huber-Verlag. Robert Faesi, Paul Ilg, Robert Walser“, in Der Held im Schützengraben. Führer, Massen und Medientechnik im Ersten Weltkrieg, hg. von Michael Gamper, Karl Wagner und Stephan Baumgartner (Zürich: Chronos, 2014), $81-98$. 


\subsubsection{Provokationen der Ordnungen. Der „Räuber“-Roman}

Zwischen dem Spaziergang, der im August 1916 geschrieben und dem „Räuber"-Roman, der im Sommer 1925 verfasst wurde, liegen rund neun Jahre. Ersterer gilt als Höhepunkt der Bieler Zeit, letzterer ist ein zentraler Text der Berner Zeit. Der Spaziergang war ein Auftragswerk, das in einen bestimmten Kontext - die erfolgreiche Reihe Schweizerische Erzähler des Huber Verlags passen musste. Es wurde schließlich Walsers meistgedrucktes Buch. ${ }^{321}$ Vom „Räuber"-Roman, der erst 1972 in gedruckter Fassung vorlag, existiert nur die Mikrogramm-Version. ${ }^{322}$ Eine Manuskriptfassung in normalgroßer Type als Vorstufe zum Druck ist nicht bekannt. ${ }^{323}$

Eine Gegenüberstellung der beiden Texte ist nur schon durch die für Walsers CEuvre hervorstechende Länge gerechtfertigt: Abgesehen von den verschollenen Romanen Tobold (1918) und Theodor (1921) sind Der Spaziergang und der „Räuber"-Roman die einzigen umfangreicheren Texte nach den Berliner Romanen. Beide Texte reizen ihre jeweilige Gattung aus: Findet im Spaziergang eine explizite Thematisierung der Novelle statt, so steht im „Räuber"-Roman die Romanform im Zentrum und wird zum Versuchsfeld. ${ }^{324}$ Während die Berliner Romane noch an den Ordnungsmustern der Biografie und des Bildungsromans ausgerichtet waren und diese Referenzsysteme

321 Salathé, Robert und Karl Walsers Briefwechsel; Reibnitz, „Editorisches Nachwort“. Siehe Kap. 3.2.2 Die Pointen des Spaziergangs. Zur Rezeption, S. 12off. oben.

322 Das Mikrogramm wurde von Jochen Greven und Martin Jürgens entziffert und zunächst im Kossodo Verlag und später im Suhrkamp Verlag herausgegeben. 1988 erschien die revidierte und bis heute gültige Entzifferung durch Werner Morlang und Bernhard Echte in ihrer sechsbändigen Transkription Aus dem Bleistiftgebiet als AdB 3. Eine neuerliche Transkription wird im Rahmen der Kritischen Ausgabe erarbeitet. Eine FaksimileAusgabe haben schon Bernhard Echte und Werner Morlang 1986 herausgegeben: Robert Walser, Der Räuber-Roman. Faksmilie der 24 Manuskript-Seiten in Robert Walsers Mikrogramm-Schrift, hg. von Bernhard Echte und Werner Morlang (Zürich: Suhrkamp, 1986).

323 Vgl. zu Walser Schreibverfahren der Mikrogramme Walt, Improvisation und Interpretation, 7-69.

324 Vgl. zur Novelle Peter Utz, „Italianismen vom Kollegen Kartoffelstock. Robert Walsers Auseinandersetzung mit der Novellentradition", in Bildersprache, Klangfiguren. Spielformen der Intermedialität bei Robert Walser, hg. von Anna Fattori und Margit Gigerl (Paderborn: Wilhelm Fink, 2008), 33-48. Zum Roman: Samuel Frederick: „[T] he novel becomes for Walser the site of some of his most extreme digressivity, an occasion for him to test to what degree and to what length plotlessness can be maintained without a collapse into non-narrative.“ Samuel Frederick, „Stealing the Story. Robert Walser's ,Robber'-Novel“, in Digressions in European Literature. From Cervantes to Sebald, hg. von Alexis Grohmann und Caragh Wells (London Palgrave Macmillan, 2011), 131. 
modifizierend ausreizten, fallen sowohl im Spaziergang als auch im „Räuber“Roman diese Ordnungen zugunsten einer Vielzahl von Versatzstücken weg. ${ }^{325}$

Hinsichtlich der formalen Gestaltung der Erzählverfahren lässt sich feststellen, dass im „Räuber"-Roman die im Spaziergang herausgearbeiteten prekären Eigenschaften zugespitzt werden. Im „Räuber"-Roman sind die narrativen Ebenen enger verflochten, die Übergänge sind unvermittelter, arbiträrer, die Verknüpfungen der Ereignisse vollziehen sich assoziativer und freier. Prolepsen und metanarrative Kommentare kommen häufiger vor und sind um ein Vielfaches unzuverlässiger, Triviales wird exzessiver ausgebreitet, scheinbar Wichtiges schneller liegengelassen, so dass die Unterscheidung von Peripherie und Zentrum des Textes umso mehr untergraben wird. ${ }^{326}$

Im Spaziergang bietet der Gang durch die Kleinstadt und den Wald hin zum See die Grundlage für die Verknüpfungen der Ereignisse und erzeugt eine gewisse Grundstruktur. Der Spazierweg hält das Erzählen und die Erzählung in gewissen Bahnen. Zwar ist dies eine Ordnung, die vergleichsweise wenig

325 Vgl. dazu Rüdiger Campes These des Institutionenromans bei Walser und Kafka, der den Bildungsroman als Konzept ablösen soll: Rüdiger Campe, „Robert Walsers Institutionenroman ,Jakob von Gunten“', in Die Macht und das Imaginäre. Eine kulturelle Verwandtschaft in der Literatur zwischen Früher Neuzeit und Moderne, hg. von Rudolf Behrens und Jörn Steigerwald (Würzburg: Königshausen \& Neumann, 2005), 235-250; Rüdiger Campe, „Kafkas Institutionenroman. Der Proceß, Das Schloß“, in Gesetz. Ironie. Festschrift für Manfred Schneider, hg. von Rüdiger Campe und Michael Niehaus (Heidelberg: Synchron. Wissenschaftsverlag der Autoren, 2004), 197-208.

326 Zu den Strukturen und Themen des Räuber-Romans vgl. Ulrich Binggeli, „Intertextualität und Lektüresemiotik. Der ,Räuber'-Roman von Robert Walser", Zeitschrift für Semiotik 24, Nr. 2 (2002): 231-26o; Thomas Bolli, Inszeniertes Erzählen. Überlegungen zu Robert Walsers „Räuber"-Roman, Basler Studien zur deutschen Sprache und Literatur (Bern: Francke, 1991); Thomas Bürgi-Michaud, Robert Walsers „mühseligkeitenüberschüttetes Kunststück“. Eine Strukturanalyse des „Räuber“-Romans (Bern, Berlin, Frankfurt am Main u. a.: Peter Lang, 1996); Melissa De Bruyker, Das resonante Schweigen. Die Rhetorik der erzählten Welt in Kafkas „Der Verschollene“, Schnitzlers "Therese“ und Walsers „Räuber“-Roman (Würzburg: Königshausen \& Neumann, 2008); Constance Colwell, Robert Walser, „Der Räuber". A Study of the Narrative Structure (Ann Arbor, 1979); Jens Hobus, Poetik der Umschreibung. Figurationen der Liebe im Werk Robert Walsers (Würzburg: Königshausen \& Neumann, 2011); Heinz Schafroth, „Wie ein richtiger Abgetaner. Über Robert Walsers ,Räuber'-Roman“, in Über Robert Walser, hg. von Katharina Kerr, Bd. 2, 3 Bde. (Frankfurt am Main: Suhrkamp, 1978f.), 286-307; Hubert Thüring, „Der Commis, der Räuber und ihre Geschwister. Robert Walsers erkenntnispoetische Figuren erkunden die Normalität“, in Literatur des Ausnahmezustands (1914-1945), hg. von Cristina Fossaluzza und Paolo Panizzo (Würzburg: Königshausen \& Neumann, 2015), 45-67; Peter Villwock, Räuber Walser. Beschreibung eines Grundmodells, Epistemata Literatur (Würzburg: Königshausen \& Neumann, 1993); Urs Widmer, „Der Dichter als Krimineller. Robert Walsers im Nachlaß entdeckter Roman ,Der Räuber ' 1974]“, in Über Robert Walser, hg. von Katharina Kerr, Bd. 2, 3 Bde. (Frankfurt am Main: Suhrkamp, 1978f.), 21-25. 
fixiert ist und auch keine Notwendigkeit der Verknüpfung von Ereignissen bieten kann, aber doch eine, die der Erzählstimme Leitplanken vorgibt, über deren Kontiguität die Ereignisse verknüpft sind. Der „Räuber"-Roman dagegen verfügt über keine solchen Orientierungshilfen und Strukturierungen. Es lässt sich weder die Folie einer biografischen Erzählung noch die einer Abenteueroder Liebesgeschichte über den Roman legen.

\section{Prinzip Digression. Benennung und Ausübung}

Im „Räuber"-Roman wie im Spaziergang ist die Erzählstimme dominant. Sie formuliert jedoch in viel stärkerem Maße als im Spaziergang Versprechungen und kündigt die spätere Schilderung von Inhalten an - Auf- bzw. Verschiebungen, die in zahlreichen Fällen nicht realisiert werden. Bereits der Beginn des Romans verdeutlicht diese Aspekte:

Edith liebt ihn. Hievon nachher mehr. Vielleicht hätte sie nie zu diesem Nichtsnutz, der kein Geld besitzt, Beziehungen anbahnen sollen. Es scheint, daß sie Abgeordnetinnen, wie sollen wir sagen, Kommissärinnen nach ihm aussendet. Er hat überall so seine Freundinnen, aber es ist nichts mit ihnen, und vor allen Dingen ist wieder nichts mit diesen sozusagen berühmten hundert Franken. Einst ließ er aus nichts als Nachgiebigkeit, aus Menschenfreundlichkeit hunderttausend Mark in den Händen andrer liegen. Wenn man ihn auslacht, so lacht er mit. Schon das allein könnte als recht bedenklich an ihm erscheinen. Nicht einmal einen Freund hat er. Während ,all dieser Zeit', die er hier unter uns zubringt, ist es ihm, zu seinem Vergnügen, nicht gelungen, sich unter der Herrenwelt Wertschätzungen zu erwerben. (AdB 3,11$)$

In dieser Anfangssequenz wird das digressive Erzählprinzip des Romans vorgeführt. Der Roman hebt an, eine Geschichte zu erzählen („Edith liebt ihn“), nur um sie sogleich abzubrechen und zu verschieben („[h]ievon nachher mehr"). Mit den ersten beiden kurzen Sätzen demonstriert der Text gleichsam sein Programm. ${ }^{327}$

Es ist aber nicht so, dass im „Räuber"-Roman nichts geschieht. Im Gegenteil, die Ereignisse überschlagen sich im Roman geradezu:Es kommen zwar Liebesund Eifersuchtsgeschichten, Mordversuche, Diebstähle, Geständnisse und zahlreiche weitere, eigentlich folgenreiche Ereignisse, vor. Jedoch sind diese

327 Zurecht schreibt Samuel Frederick dazu: „With the most extreme economy, these opening two sentences of the novel enact a limit-case of digressive storytelling in announcing and performing in its first six words the novel's governing principle." Frederick, „Stealing the Story“, 135. Frederick liest den „Räuber“-Roman als Geschichte von Nichts und über Nichts, in dem er auch die zahllosen Negationen und Negierungen herausarbeitet. Stattdessen bleibe die Narration sozusagen im Bereich des Möglichen mit unzähligen „possible plot seed[s]“, die der Roman ausbreitet. Frederick, 134. Hervorhebung i. O. 
Elemente, die in einem herkömmlichen Sinn als Ereignisse zu bezeichnen sind und die durchaus über eine tellability verfügen, auf der discourse-Ebene kaum von Trivialitäten zu unterscheiden. ${ }^{328}$ Der Text ist noch viel weniger als der Spaziergang an der narrativen Ordnung einer homodiegetischen extradiegetischen Erzählung ausgerichtet. Dieses Gerüst, das einen Erzähler vorsieht, der seinerseits als Figur an der erzählten Geschichte teilhat, wird im "Räuber"-Roman vielfach zitiert, jedoch nicht konsequent angewandt; viel eher sorgt es für Verwirrung und die Unterwanderung dieser Ordnungen.

\section{Anfang und Ende. Der umkehrbare Rahmen}

Wie oben erwähnt verfügt Der Spaziergang mit dem Spaziergang als einem inszenierten, zwischen Schreibbewegung und körperlicher Bewegung der Figur oszillierenden Inhalt, über eine Rahmung, die der „Räuber“-Roman entbehrt. Zwar besitzt auch dieser einen Anfang und ein Ende, die keineswegs beliebig sind, sondern sich selbstreflexiv auf die Geschichte beziehen. Anfang und Ende sind jedoch im „Räuber"-Roman unter Einbezug der stets mitformulierten Metanarration jeweils als Umkehrung des ganzen Romans lesbar, so dass sich ein vielfach überblendeter, redundanter und gespiegelter Inhalt ergibt.

$\mathrm{Zu}$ Beginn werden, wie Jens Hobus formuliert, „in einer Art Exposition die Hauptfiguren und die für diesen Roman zentralen Diskurse benannt: die Liebe zwischen Edith und dem Räuber, Ökonomie, Ästhetik und die soziale Ordnung.“329 Der Anfang ist zugleich eine Abschweifung und ein NichtAnfangen, indem aufgezählt wird, was jetzt nicht erzählt wird. ${ }^{330}$ Ähnliches findet sich, wie bereits ausgeführt, zu Beginn des Spaziergangs, wo der Gang

328 Tellability ist ein Begriff, der ursprünglich aus der Linguistik stammt und für die Erforschung mündlicher Konversation entwickelt wurde. In der Narratologie wird er in der Regel im Sinn von Erzählwürdigkeit verwendet, also zur Charakterisierung eines Ereignisses, das im kulturellen Rahmen als bedeutend genug erachtet wird, um erzählt und gehört zu werden. Robert Walsers Ereignisse sind zum Teil durchaus von einer großen Erzählwürdigkeit, wie im Spaziergang die Begegnung mit einem Riesen oder im „Räuber“Roman der abgegebene Schuss auf den Räuber. Diese Ereignisse werden jedoch nicht anders behandelt als Trivialitäten und ziehen keine Konsequenzen nach sich. Vgl. zum Konzept: Raphaël Baroni, „Tellability“, in The Living Handbook of Narratology, hg. von Peter Hühn u. a. (Hamburg: Hamburg University, 2014), http://www.lhn.uni-hamburg.de/ article/tellability.

329 Jens Hobus, „Räuber-Roman (verfasst 1925)“, in Robert Walser-Handbuch. Leben - WerkWirkung, hg. von Lucas Marco Gisi (Stuttgart: Metzler, 2015), 182. Hinzuzufügen wäre hier auch die Etablierung der Erzählsituation, die zwischen metafiktionalem Bekenntnis und homodiegetischer Erzählung changiert. Zu den zentralen Diskursen wäre derjenige über das Erzählen anzufügen.

330 Frederick betont die Bedeutung der Negation. „She means, nothing" to the narrator and to his story, and yet he writes about her, again suggesting that in some way ,nothing itself is 
des Spaziergängers durch das Treppenhaus jedoch eine räumliche Rahmung vorgab.

Beim „Räuber"-Roman kann der erste Abschnitt als eine chronologische Umkehrung des gesamten Romans gelesen werden. Er hebt an mit der Behauptung von Ediths Liebe, die aber erst am Ende des Romans im Schuss auf den Räuber aus Eifersucht eingelöst wird und endet mit der Einführung des Protagonisten und der Thematik der öffentlichen Anerkennung: „Und daß ihm Direktoren die Hand geben. Ist das nicht sehr eigentümlich? Diesem Räuber?" (AdB 3, 12) Diese Worte wiederum werden im fünfunddreißigsten und letzten Segment des Romans in einer Umkehrung des Handlungsverlaufs aufgenommen. Der vielzitierte Wunsch des Erzählers und letzte Satz des Romans lautet, „daß man den Räuber angenehm finde und daß man ihn von nun an kenne und grüße" (AdB 3, 150), worin sich der Schluss des allerersten Absatzes spiegelt. Dies erzeugt den Eindruck, dass die Geschichte tatsächlich mit einer klassischen Abrundung beendet wird. Wenn sich dieser Wunsch auf den Räuber richtet, was der Erzähler vorgibt, so ist er reichlich unwahrscheinlich, ist jener doch erst gerade in eine Heilanstalt eingetreten. Bedenkt man die metanarrative Ebene, so wird die Lektüre plausibel: Es handelt sich um die Geschichte des Räubers, mithin um den Roman und damit auch um dessen Verfasser, den Erzähler, der sich in einem übertragenen Sinn die Anerkennung von Professoren durch und für dieses Buch wünscht. ${ }^{331}$ Mit dieser Volte wird das Ende wiederum zu einem Anfang, geht es doch nun darum, das Buch über den Räuber so zu rezipieren bzw. neu zu lesen, dass dem Autor, das heißt dem Erzähler im „Räuber"-Roman, die Anerkennung zuteil wird, die er zu verdienen meint. ${ }^{332}$

that which is mysteriously and productively significant for the novel.“ Frederick, „Stealing the Story", 137.

331 Auch die Bedeutung der Professoren ist eine der vielen möglichen Gemeinsamkeiten zwischen dem Spaziergang und dem „Räuber“-Roman, man denke nur an Professor Meili, der den Spaziergänger gerade nicht grüßt (vgl. KWA I.8, 168). Und während es zu Beginn des Spaziergangs im Treppenhaus „eine Spanierin, Peruanerin oder Kreolin“ (KWA I.8, 167) ist, die den Gang des Erzählens aufhält, ist im „Räuber“-Roman der Räuber selbst ein „Peruaner" (AdB 3, 11). Vgl. dazu Wolfram Groddeck, „Begegnung mit einem ,Gelehrten' in Robert Walsers ,Spaziergang'“, in Gelehrte in der deutschsprachigen Literatur. Physiognomien, Gattungen, Kontexte, hg. von Robert Leucht u. a. (Wien, Hamburg: new academic press, 2019), 103-111; Peter Utz, „Professoren und andere Zerstreuungen. Auf einem ,Universitätsbummel' mit dem literarischen Feuilleton“, in Gelehrte in der deutschsprachigen Literatur. Physiognomien, Gattungen, Kontexte, hg. von Robert Leucht u. a. (Wien, Hamburg: new academic press, 2019), 127-147.

332 Ein früher Referenztext dieser metafiktionalen Anlage, in der die Figuren den Roman lesen können, in dem sie erzählt werden, ist natürlich Cervantes' Don Quijote, wo Don Quijote sich im zweiten Teil auf den ersten beziehen kann. Wie schon bei Cervantes bedeutet diese Metafiktion nicht, dass „nichts“ erzählt wird, wie Andres behauptet: „Der 
Aus diesen zirkulären Verknüpfungen und der prekären Rahmung ergibt sich denn auch die „quälende Lektüre“ dieses „Stück[s] literarischer Rücksichtslosigkeit“. ${ }^{333}$ Es ist die Erzählerstimme selbst, die den Text zusammenhält, der Sprechakt, der gewährleistet, dass gewisse Elemente, Figuren und Versatzstücke von Erzählsträngen immer wieder auftauchen und der dennoch immer wieder mittels Überblendungen und durch Untergraben der Sprechposition verunsichert wird. Im Folgenden soll nun die Bewegung vom Spazieren zum Rauben nachgezeichnet werden, die nicht nur in der erzählten Geschichte vollzogen wird, sondern auch in der narrativen Poetik ihren Niederschlag findet.

\section{Der raubende Spaziergänger}

Robert Walsers Räuber fungiert als negative Projektionsfläche zeitgenössischer sozialer Normen: Der „Räuber"-Roman ist eine Auseinandersetzung mit bürgerlichen Werten. ${ }^{334}$ Diese Auseinandersetzung findet bereits im Spaziergang statt, wird in den Jahren bis 1925 und darüber hinaus jedoch stärker akzentuiert, der Ton wird kritischer und angriffiger. ${ }^{335}$ Räuber wie Spaziergänger nehmen als gekennzeichnete Sonderfälle, als Vagabunden der Moderne, innerhalb der sozialen Ordnung eine spezifische Beobachterposition gegenüber dieser

Inhalt wird gleichsam auf Null reduziert und die Sprache, das Schreiben selbst wird Inhalt." Andres, Robert Walsers arabeskes Schreiben, 145.

333 Martin Jürgens, „Nachwort“, in Robert Walser. Der Räuber, hg. von Jochen Greven und Martin Jürgens (Frankfurt am Main: Suhrkamp, 1986), 201.

334 Häufig wurde die gesellschaftliche Randständigkeit des Räubers betont, sein Ausgeschlossensein aus der Gesellschaft. Vgl. Schafroth, „Wie ein richtiger Abgetaner. Über Robert Walsers ,Räuber'-Roman“, 295; Evans, Robert Walsers Moderne, 153; Utz, Tanz auf den Rändern, 418; Jürgens, Robert Walser, 137, 14of.

335 Hubert Thüring stellt die Räuber-Figur in Beziehung zum Commis. Während der Commis als eigentliche Verkörperung der Normalität gesehen werden muss, die dennoch über ihre subtilen Widerstandsmechanismen verfügt, stellt der Räuber mit Foucault das Skandalon der Unbestimmtheit jenseits der Normalität dar. „Für die normalistische Normalität ist die dynamische Produktion von Abweichung aus der Normalität selbst heraus konstitutiv. Dies führt der Walsersche Räuber als immer schon dagewesenes Janus-Gesicht des Commis vor." Thüring, „Der Commis, der Räuber und ihre Geschwister“, 63f. Interessant ist dabei insbesondere auch, dass der Räuber in der sexuellen Perversion zu einer „Synthesefigur von Verbrechen und Wahnsinn“ wird. Thüring, 64. Mit Giorgio Agamben macht ihn dies laut Thüring zur Ausnahme: „Er [der Räuber] ist die Ausnahmefigur, die als Gesandter der Gesellschaft neue Gebiete jenseits des Normalen auskundschaften soll.“ Thüring, 67. Hervorhebung i. O.

Mit dieser spezifischen Unbestimmtheit beschäftigt sich auch Jael Bollag, „Unbestimmtheit. Robert Walsers Poetik der Saumseligkeit“, in Goldenes Anfängliches. Neue Beiträge zur Robert Walser-Forschung, hg. von Lukas Gloor und Rebecca Lötscher, Robert Walser-Studien 4 (Paderborn: Wilhelm Fink, 2020), 53-63. 
Ordnung ein. ${ }^{336}$ So lässt sich in diesen Figuren und Texten zeigen, wie Ordnung überhaupt hergestellt wird. Bei Robert Walser geschieht dies insbesondere auf einer formalen Ebene, indem Erzählordnungen sichtbar gemacht werden, wie dies für den Spaziergang aufgezeigt wurde. Ähnliches gilt für den „Räuber“Roman, wobei in diesem Fall die zitierten Ordnungen so schnell gewechselt, variiert und verworfen werden, dass es schwieriger wird, deutliche Episoden festzulegen, innerhalb derer eine Erzählordnung verhandelt wird. Das zeigt sich in den Überblendungen von story und discourse, von Figur und Erzähler, wie denjenigen der Figuren untereinander.

Augenfälliger Hinweis auf die Zuspitzung derThematik findet sich in derVerschiebung der Funktionsbezeichnung. Erhält im Spaziergang der Protagonist, der Spaziergänger, 337 seine Namensbezeichnung noch durch das Ausüben seiner Tätigkeit, so ist die Funktionsbezeichnung Räuber im „Räuber"-Roman eine reine Zuschreibung durch den Erzähler. Sind die Vergehen des Spaziergängers gegen die bürgerlichen Normen noch potenziell, so befindet sich der Räuber in einem anderen Modus. Seine Bezeichnung ist eindeutig: Ein Räuber ist jemand, der einen Raub beging. Die Figur erhält keine Gelegenheit, sich zu dieser Funktionsbezeichnung zu verhalten; seine Identität ist durch die Namensbezeichnung definiert und rückt an Stelle eines Eigennamens. Der Räuber ist ein Räuber, weil er so genannt wird.

Diese Deutlichkeit der Benennung ist umso irritierender, wenn man bedenkt, dass sich dieser gar keine Vergehen zu Schulden kommen lässt. ${ }^{338} \mathrm{Er}$ mag

336 Es handelt sich also um "spezifische Beobachtertypen“ der „Erfahrung der Moderne“, die geprägt ist "von der Wahrnehmung der Kontingenz und Dissoziation, des Transitorischen und des Zerfalls“. Simonis, „Vom ästhetischen Blick zur ,bricolage““, 9. Systemtheoretisch reformuliert wären dies Beobachtungen zweiter Ordnung.

337 An vier Stellen wird der Spaziergänger in eigentümlichem Bruch zur ansonsten homodiegetischen Erzählung tatsächlich vom Erzähler so genannt. Dies unterstreicht, nebenbei bemerkt, wieder die Wichtigkeit, dass Erzähler und Figur auch in homodiegetischen Erzählungen in ihrer Funktion deutlich unterschieden werden. - „Ein radfahrender [...] Stadtchemiker [...] fährt [...] dicht am Spaziergänger, nämlich an mir, vorüber“ (KWA I.8, 168). - „Es war so feierlich im Wald, daß schöne und feierliche Einbildungen ganz von selber sich des empfindlichen Spaziergängers bemächtigten." (KWA I.8, 187) - Während der Ansprache an den Steuerbeamten: „Naturkunde und Landeskunde öffnen sich [...] vor den Sinnen und Augen des aufmerksamen Spaziergängers“ (KWA I.8, 204). - „Bei dieser Gelegenheit sei darauf hingewiesen, wie sehr der Spaziergänger [...] wünschte, wieder ein Kind [...] sein zu dürfen“ (KWA I.8, 212).

338 Peter Villwock untersucht, was für die Bezeichnung Räuber und was dagegenspricht. Dabei sticht insbesondere die Rolle des Bohemiens hervor. Villwock kommt zu dem Schluss, dass es „kein eigentliches Ich [gibt] - nur ein ,Ich' oder einen ,Ich'-Komplex ohne Zentrum oder ruhenden Pol, der ständig in Komplexität, Umfang, Besetzung der Systemstellen und Besetzungsenergien variiert, pulsiert oder fließt“, der aber nicht 
ein ,Vagabund' und ,Streuner' sein und in dieser Hinsicht aus der Perspektive der Ordnung ein Verdächtiger wie der Spaziergänger, dessen Verdacht jedoch gleich das Verdikt nach sich zieht. Er hat keine gefestigte Anstellung, unternimmt viele Spaziergänge, erlebt Liebesgeschichten, Schwärmereien und Interaktionen mit verschiedenen anderen Figuren.

Das einzige, was der Räuber laut des Erzählers (be-)raubt, sind „Landschaftseindrücke“ (AdB 3, 30) und "Geschichten“ (AdB 3, 37). In der Kanzelrede im dreiunddreißigsten Absatz, in der der Räuber zum ersten Mal selbst ausführlich zu Wort kommt, sagt er über seine Geliebte Edith, dass er sie in seiner Liebe „ausbeutete“, so dass Edith „eine Geplünderte“ und „Beraubte[]“ wurde ( $A d B 3,140$ ). Diese Liebe ist insofern eine geraubte Liebe, als sie imaginiert ist: „Hätte sie mir denn verbieten können, sie [in] die Prachtstücher der Zärtlichkeit zu legen? Wenn ich bei ihr sein wollte und zu ihr sprach:,Erscheine mir', so tat sie's augenblicklich." (AdB 3, 141) ${ }^{339}$ Gleichzeitig schildert der Räuber, dass er Edith in der Wirklichkeit mied, um nicht enttäuscht zu werden, und weil er „sie für nicht ganz gescheit hielt" und Angst hatte, sich mit ihr zu „langweilen“ (AdB 3, 141). Auch Edith fühlt sich „beraubt [...] aus lauter Anhänglichkeit und Ehrfurcht" des Räubers (AdB 3, 135). Seine Imaginationen hat der Räuber zu Erzählungen verarbeitet und verkauft: „[N] un habe ich bereits Honorar in der Tasche, das davon herrührt, daß ich Geschichten über sie ersonnen habe“. (AdB 3, 143) Dies ist dann der Auslöser für Ediths Schuss auf den Räuber. Das Rauben lässt sich also als „Produktionsmetapher“ des Erzählens begreifen. ${ }^{340}$

Die Literaturproduktion als Raub zu beschreiben, steht jeglicher GenieÄsthetik diametral entgegen, welche diese als unverwechselbare, einzigartige und individuelle Praxis sieht. Der Raub von Geschichten zurWiederverwertung

„auf den Punkt gebracht werden kann.“ Villwock, Räuber Walser, 1o1f. Gemäß Villwock nimmt der Räuber eine Vielzahl von Rollen ein, die er in der Metaphorik des Raubes als gestohlene versteht: „Die Walsersche Figur zeigt sich und ist als Konstellation von gestohlenen, anderen enteigneten und sich angeeigneten Identitäten ohne die eine, eigene Identität. [...] Das Ich des Räubers ist eine Vielheit.“ Villwock, 102. Hervorhebung i. O.

339 Dieser Eindruck von Edith als einer Projektion verstärkt sich noch: „Sie war immer eine so Gefügige, wie ich sie mir nur wünschte. Sie hat nie gezögert, mir alles zu sein, und ich bin natürlich viel, viel reicher als sie, denn ich liebe sie, und dem, der liebt, wird immer gegeben, wessen er zu seiner Seligkeit nötig hat, und noch mehr, so daß er sorgen muß, nicht zu viel anzunehmen. Und dieses Mädchens Gesicht war mir schrecklich, und Sie verstehen ja nun, weshalb, denn es war das Gesicht der Beraubten." (AdB 3, 141)

340 Jens Hobus verwendet den Begriff der "Produktionsmetapher" auch in Bezug auf die Liebe. Hobus, Poetik der Umschreibung; Hobus, „,Räuber'-Roman (verfasst 1925)“, 187.

Stephan Kammer untersucht die Produktionsmetaphern in Bezug auf den Schreibprozess. Stephan Kammer, Figurationen und Gesten des Schreibens. Zur Ästhetik der Produktion in Robert Walsers Prosa der Berner Zeit (Tübingen: Max Niemeyer, 2003), 57-74. 
in eigenen Erzählungen ist in doppelter Hinsicht ein intertextuelles Konzept. ${ }^{341}$ Zum einen im Sinn eines Zitats und einer Neuschreibung einer vorhandenen Geschichte, wie Robert Walser dies mit Büchern und auch Gemälden gemacht hat. In einem zweiten Sinn ist das Rauben von Geschichten und ,Landschaftseindrücken' auch konkret zu verstehen als Aneignung von Ereignissen und Eindrücken. ${ }^{342}$

Mit der Produktionsmetapher des Raubes wird ein starker Gegenakzent zu bürgerlichen Vorstellungen von Literatur und Kunst gesetzt. Die Kunst wird zu etwas Verbotenem, Anrüchigem, sie wird antibürgerlich. Jedoch gilt gemäß dem Räuber diese Produktionsmetapher für alle Literatur: „[W]ir alle, die wir Romane und Novellen schreiben, [sind] Schurken." $\left(\mathrm{AdB}_{3}, 134\right)^{343}$ Die implizite Kritik, die sich automatisch aus der Beobachterposition der bürgerlichen Ordnung ergibt, wird zu einem Produktivitätsfaktor. Wie im Spaziergang das Spazieren in seiner metaphorischen Auffächerung zum Inhalt der Erzählung und zum Verfahren des Erzählens wird, so sind es auch die „Räubereien“ $(\mathrm{AdB} 3,25) \mathrm{im}$ „Räuber“-Roman. Aus diesen jeweiligen Systemen erwächst eine

341 Im „Räuber“-Roman werden sowohl Werke des literarischen Kanons, wie Schillers Räuber und Meyers Der Schuss von der Kanzel, verarbeitet als auch trivialliterarische Kioskromane, die Walser las. Der intertextuelle Bezug reicht dabei vom Gebrauch von Versatzstücken (wie bei Meyer) bis hin zur Übernahme von Grundstrukturen (wie bei den Räubern, wo das Brüderpaar Moor seine Entsprechung in der Aufspaltung von Erzähler und Räuber findet und auch Karl Moor erst über die Zuschreibung zum eigentlichen Räuber wird). Laut Bernhard Echte ist der „Schillersche Räuber Karl Moor [...] für den jungen Walser eine der ersten wirklichen Identifikationsfiguren aus dem Bereich der Kunst gewesen." Bernhard Echte, „Nachwort“, in Aus dem Bleistiftgebiet, hg. von Bernhard Echte und Werner Morlang, Bd. 3: „Räuber“-Roman. „Felix“-Szenen, 6 Bde. (Frankfurt am Main: Suhrkamp, 1986), 210.

342 Jens Hobus systematisiert vier Aspekte, die in der Bezeichnung „Räuber“ zusammenfallen: „1. die ästhetische Praxis der Weltaneignung; 2. die Transformation dieser Erfahrung in Literatur; 3. die spezifisch literarische Praxis der intertextuellen Bezugnahme; 4. die vermeintlich widerrechtliche Aneignung und Generierung von Eigentum durch diese Verfahren. Alle diese Aspekte diskreditieren den Schriftsteller als vermeintlich unproduktiven Außenseiter und legitimieren in gewissem Sinne dessen Bezeichnung als ,Räuber'. ,Räuber' ist er also nicht nur durch gesellschaftliche Zuschreibungen, sondern auch im metaphorischen Sinne nach seinem Selbstverständnis.“ Hobus, „,Räuber'-Roman (verfasst 1925)“, 185. Wichtig ist hier die Aufspaltung von Räuber und Erzähler: Es ist ausschließlich der Erzähler, der den Räuber als solchen bezeichnet.

343 Der Räuber spricht dies zu „Ediths Beschützer“, der den Räuber auf dessen Eröffnung, „er helfe einem Schriftsteller an einem Roman“, der Edith gelte, als „Schurke“ beschimpft. Das Zitat lautet ausführlicher: „,Streng genommen', erwiderte der Räuber, ,sind ja wir alle, die wir Romane und Novellen schreiben, insofern Schurken, als wir mit rücksichtsvoller Rücksichtslosigkeit, zarter Kühnheit, unerschrockener Erschrockenheit, leidender Lustigkeit und lustigem Leid beim Abdrücken unserer Gewehre, will sagen beim Zielen auf unsere hochgeschätzten Modelle vorgehen. So ist es einmal in der Literatur.“ (AdB 3, 134) 
Gefahr für die Norm, wie sie im Spaziergang in der Episode um den Steuerbeamten besonders deutlich wird, und sich im „Räuber"-Roman schon nur in der Tatsache zeigt, dass aus dem Verdacht des Vagabundentums die Funktion Räuber abgeleitet wird.

Es ist wichtig zu sehen, dass im Roman ausschließlich der Erzähler die Räuber-Figur als Räuber bezeichnet. Der Erzähler verweigert die Nennung eines richtigen Namens. Es ist auch der Erzähler, der den Räuber grundlos kritisiert, verleumdet und beschimpft. Die Außenseiterstellung des Räubers wird also durch den Diskurs des Erzählers zementiert und nicht durch Handlungen anderer Figuren. Bedeutsam ist diese Tatsache auch deshalb, weil der Ich-Erzähler ein in höchstem Maße unzuverlässiger Erzähler ist, der sich im Gegensatz zur Figur des Räubers auch tatsächlich Gesetzesbrüche zuschulden hat kommen lassen. Der homodiegetische Erzähler nutzt sein Gewicht im Text, um die Figur des Räubers hegemonial zu beanspruchen. Indem der Erzähler den Räuber als solchen benennt, entzieht er sich selbst dem Vorwurf, Strolch und Räuber zu sein und vermag es, von sich abzulenken. Mit der Exklusion des Räubers sichert er seine eigene Inklusion. ${ }^{344}$ Auch darin mag eine kulturwissenschaftlich informierte Lektüre eine Reflexion über die Ordnung und Regeln der Zuordnung feststellen.

Verwechslungsgefahr. Figur, Räuber und Erzähler

Gemäß der Produktionsmetapher des Raubes ist auch der Erzähler als Räuber zu bezeichnen: Er versichert immer wieder, wahre Geschichten zu erzählen, in der fiktiven Welt des „Räuber"-Romans hat er jedoch denselben ontologischen Status wie der Räuber. Er raubt also dessen Geschichten und verarbeitet sie, just wie der Räuber es mit Edith tut. Kommt hinzu, dass der Erzähler die Hilfe des Räubers beim Verfassen des Romans erwähnt, wobei jedoch unklar ist, wie diese Hilfe tatsächlich geleistet wurde - ob schreibend, als Auskunftsperson über sein Leben oder als erfundene Figur. Es sind also zwei Räuber die Protagonisten des Romans: Erzähler und Figur. Der bestimmende Unterschied

344 Der Umstand, dass der Erzähler den Räuber in Metalepsen als seine erschriebene und erfundene Figur darstellt, wurde nicht immer in seiner Konsequenz gesehen. Vgl. etwa Susanne Andres: „Der Erzähler sieht sich als Aufsichtspersonal, übernimmt Verantwortung, verteidigt den Räuber, zieht ihn zur Rechenschaft und vermittelt zwischen ihm und der Gesellschaft. Das Verwirrspiel zwischen Erzähler und Räuber problematisiert die Kommunikation zwischen beiden. [...] Doch das Verwirrspiel [...] ist im RäuberRoman so ausgeprägt, daß kaum mehr zu unterscheiden ist, wer raubt und wer beraubt wird. Die Trennung zwischen Autor und Protagonist ist nicht mehr nachvollziehbar. [...] Der Leser des Räuber-Roman[s] [sic] erlebt die Produktion eines Romans mit." Andres, Robert Walsers arabeskes Schreiben, 144. 
zwischen den beiden ist nach Dafürhalten des Erzählers das Geld, das er im Gegensatz zum Räuber habe. Trotz dieser Differenzierung oszillieren die Figuren in ihrer Funktion, ähnlich wie dies im Spaziergang mit dem Erzähler und dem Spaziergänger zu beobachten war, wobei es hier tatsächlich um zwei Figuren geht, während im Spaziergang bloß unterschiedliche Funktionen der Erzähler/Spaziergänger-Figur überblendet werden. Tritt der Erzähler im Spaziergang nur in kurzen, paradoxen Überblendungen in die story-Ebene ein, ohne tatsächlich Handelnder zu werden, so ist im „Räuber"-Roman der Erzähler von Beginn an als Verfasser des Romans präsent. Erzählzeit und erzählte Zeit werden vielfach überblendet. Viel deutlicher als im Spaziergang ist auch die inhaltliche Reflexion auf das Verhältnis von Figur und Erzähler.

Dieses performative Erzählverfahren, das im Folgenden noch ausführlicher besprochen wird, kann mit folgendem Ausschnitt kurz illustriert werden. ${ }^{345}$ Im Überblenden zweier narrativer Ebenen - derjenigen des Erzählers und derjenigen der Figur - stellt sich die Erzählung dar als im Prozess des Erzählens stattfindend.

Doch sprechen wir lieber im Jetztzeitstil. Hunde spazierten neben ihren Herren, und alle Bäume standen lautlos still, und die Vöglein warteten auf ihren lieben Freund, den Abend, um in seiner Kühle zu jubeln. Bis dahin würde die Sonne scheinen, die so hell die Allee durchbrach, und der Räuber gestattet uns zu sagen, daß er jetzt Kartoffelstauden anschaute, die sich über's Feld erstreckten. $(\mathrm{AdB} 3,73)$

Zunächst ist die Rede von einem Spaziergang, den der Räuber unternimmt, also einem Ereignis in der Vergangenheit, das nun erzählt wird. Dann heißt es, dass der Räuber einem „uns“ - hinter dem sich der Erzähler im Pluralis Majestatis verbirgt, vielleicht auch unter Einbezug des Lesers - "gestattet“ zu sagen, dass er ,jetzt Kartoffelstauden anschau[]e“, wobei hier wieder auf das Präteritum der story-Ebene zurückgegriffen wird. Der Räuber tritt bildlich gesprochen aus seiner Geschichte heraus, die der Erzähler berichtet, um dem Erzähler die Erlaubnis zum weiteren Erzählen zu erteilen. In dieser Metalepse überblenden sich erzählte Zeit und Erzählzeit. ${ }^{346}$ Diese Überblendung folgt unmittelbar auf die Bekräftigung, nun im "Jetztzeitstil“ zu sprechen. Mit dieser Formel ist also nicht nur die inhaltliche Auseinandersetzung mit zeitgenössischen Diskursen

345 Siehe Kap. 3.3 Performatives Erzählen, Metanarration und Metafiktion, S. 168ff. unten.

346 Zur Metalepse vgl. Alice Bell und Jan Alber, „Ontological Metalepsis and Unnatural Narratology“, Journal of Narrative Theory 42, Nr. 2 (2012): 166-192; Dorrit Cohn, „Metalepsis and Mise en Abyme“, übers. von Lewis S. Gleich, Narrative 20, Nr. 1 (2012): 105-114; Sonja Klimek, Paradoxes Erzählen. Die Metalepse in der phantastischen Literatur, Explicatio. Analytische Studien zur Literatur und Literaturwissenschaft (Paderborn: Mentis, 2010). 
zu sehen, sondern in einem formalen Sinn auch ein simultanes Erzählen, das als Jetztzeit das Präsens meint und die Herstellung dieser Erzählung mitdenkt. ${ }^{347}$ Der Abschnitt, in dem dies erzählt wird, ist passenderweise ein Abschnitt, der mit dem Spaziergehen des Erzählers beginnt und mit demjenigen des Räubers fortfährt. Diese metaleptische Struktur erinnert an die Art und Weise, wie der Räuber Edith ihrer Geschichten beraubt hat, mit dem bedeutenden Unterschied, dass der Räuber hier dem Erzähler die Erlaubnis zum Raub erteilt. Ein anderes Beispiel einer solchen Überblendung ist folgendes Gespräch zwischen Wanda und Edith über den Räuber, der, hinter dem Vorhang versteckt, alles mitanhört.

Und hinter einem Vorhang, den er eng zuzog, stand der Gegenstand des Gespräches, unser Räuber, und er hörte dasselbe Wort für Wort, und wir, die wir hier erzählen, standen dicht neben ihm und mahnten ihn an Unparteilichkeit, indem wir ihm in's Ohr flüsterten: „Bleibe kalt und womöglich künstlerisch.“ (AdB 3, 99)

Was sich auf formaler Ebene zeigt, wird auch auf der story-Ebene thematisiert. Die auffälligsten Hinweise auf eine Beziehungsreflexion sind die Verwechselbarkeit des Räubers und des Erzählers, deren Verschwimmen in der Funktionalität, inhaltlich auch die Mitarbeit des Räubers am Roman, der Umstand, dass auch der Räuber schreibt sowie weitere, auch äußerliche Gemeinsamkeiten. Die Gefahr einer Verwechslung von Räuber und Erzähler wird explizit benannt: „Ich muß immer acht geben, daß ich mich nicht mit ihm verwechsle. Ich will doch keine Gemeinschaft mit einem Räuber haben. Der soll noch etwas von mir zu hören bekommen, der." (AdB 3, 71) Die Gefahr, sich selbst mit jemandem zu verwechseln, ist, sofern man sich auf derselben ontologischen Ebene befindet, absurd. Anders ist es, wenn der Produktionsprozess mitbedacht wird. Der diesem vorgehende Satz weist just eine Korrektur der

347 In Walsers Wortschöpfung „Jetztzeitstil“ - eine Zusammenfügung des damaligen Modewortes "Jetztzeit" und „Stil“ - sieht Peter Utz den "Zeitgehalt des Werks“ Walsers und dessen „ästhetische[] Eigenständigkeit“ zusammengeführt. Utz, Tanz auf den Rändern, 14.: „Auch das sperrige Wort vom ,Jetztzeitstil“ verdankt sich [Walsers] kritische[m] Hineinhören in die Zeit und ihrem spielerischen Weiterdrehen; es wird selbst zu einer bewußt holprigen, keineswegs grazilen Mimesis am Zeitstil.“ Utz, 17.

Utz nennt Walsers Sensibilität für die Zeit, verbunden mit dem Aspekt der Oralität, „Ohralität". Dieser Neologismus bezeichnet Walsers „offene[s] Ohr für die Zeit, [in dem] sich sein ,Jetztzeitstil““ begründet: „Deshalb möchte ich die ,Oralität Walsers zur ,Ohralität‘ erweitern und ergänzen, um beides als Einheit verstehen zu können: ohne akustische Sensibilität keine Mündlichkeit in Walsers Schrift, und ohne stimmhaftes Schreiben kein offenes Ohr für die Stimmen der Außenwelt. Ohne Ohr kein Mund, ohne Mund kein Ohr." Utz, 243. 
Personalpronomen auf, in dem das ursprüngliche „ich“ in ein passendes „er“ geändert wird. Dieser Korrekturprozess wird mit der Benennung der Verwechslungsgefahr in den Erzählprozess aufgenommen. ${ }^{348}$

So deutlich diese Vertauschung der Personalpronomina manchmal auf Versehen beruht, so wenig wird dadurch geklärt. Würde der Autor als Kategorie miteinbezogen, so müssten auch andere scheinbare ,Fehler', wie die genannten Überblendungen, ihm zugeschrieben werden, was weitreichende Konsequenzen für die Relation von Erzähler und Figur hätte. Lässt man den Autor außen vor, besteht die Gefahr, dass auf diesen Sätzen eine Interpretation aufgebaut wird, die letztlich kontingent bleiben muss. Fest steht, dass Erzähler und Figur (und Autor) im "Räuber"-Roman in eine komplexe Ambivalenz geraten und die Grenzziehungen undeutlich und fragwürdig werden. Auf diese Weise entziehen sie sich einer klaren Systematisierung und wirken als Momentum der Dynamik und des Zweifels in der narrativen Ordnung des Textes.

In diesem Kontext zeigt sich die problematische Souveränität des Erzählers. Zum einen betont er, dass er die Kontrolle über die Geschichte behalte. Der Umstand, dass er erwähnen muss, dass er die „Direktion“ über die Erzählung hat, zeigt schon, dass sie problematisch geworden ist und die Souveränität so dem Erzählen selbst überschrieben wurde:

Und so behalte ich denn jedenfalls über diese Räubergeschichte hier die Direktion. Ich glaube an mich. Der Räuber traut mir nicht recht, ich lege jedoch keinen großen Wert darauf, daß man an mich glaubt. Ich muß hiezu selber in der Lage sein. (AdB 3, 116)

348 Vgl. den entsprechenden Kommentar von Bernhard Echte und Werner Morlang in AdB 3, 229. Christian Walt nennt diesen Prozess, der sich in Walsers Mikrogrammen an mehreren Stellen beobachten lässt, „Vertextung der Textgenese“. Walt, Improvisation und Interpretation, 88-90. Ein weiteres Beispiel, in dem die Vertextung insofern weniger explizit dargestellt ist, als sie nicht auf den Schreibprozess Bezug nimmt: „Die Schwäne dort im Schloßteich, die Renaissancefassade. Wo sah ich das? Vielmehr, wo hat das der Räuber gesehen?“ (AdB 3, 76) Im „Räuber"-Roman finden sich auch solche Stellen, die nicht vertextet werden, etwa im Gespräch des Räubers mit der „Henri Rousseaufrau“, wo es plötzlich heißt: „Ich habe kein Besitztum', erwiderte ich, ,wovon ich nicht Lust gehabt hätte, Gebrauch zu machen.“ Anschließend geht der Dialog ohne Personalpronomina weiter bis es wieder mit dem Räuber als Subjekt heißt: „Er stellte das aber in Abrede.“ (AdB 3, 18; Hervorhebung L. G.). Benne liest die Stelle um die „Henri Rousseaufrau“ als "eindeutig surrealistisch“. Benne, „,Schrieb je ein Schriftsteller so aufs Geratewohl?’ Der surrealistische Robert Walser“, 54. "Fraglos befinden wir uns in einer Traumsequenz, komponiert aus verschieden [sic] Erinnerungsfetzen, Phantasien, Beobachtungen, Tagträumereien, Déjà-vu-Versatzstücken." Benne, 54. 
Gerade der Räuber, als Figur in der Geschichte des Erzählers, verfügt über ein Eigenleben, das sein Erzähler nicht kontrollieren kann. Diese paradoxe Situation hat ihren Ursprung in dem oben besprochenen ambivalenten Verhältnis von Räuber als Figur (und Gehilfe des Erzählers) und Erzähler als Erzähler und Figur. Auch Edith kommt der Erzähler nicht bei: „Es könnte ihr [Edith] ja einfallen, uns, d.h. mir und meinem Räuber, die Türe vor der Nase zuzuwerfen, indem sie vielleicht uns sagen würde: ,Macht, daß ihr geht.' Mir grollt sie sicher. Ob auch ihm, kann ich unmöglich beurteilen." (AdB 3, 104)

Die eigentümliche Erzählordnung von Robert Walsers prekärem Erzählen, in der die übliche Grenzziehung zwischen narrativen Ebenen ambivalent ist, ermöglicht ein Eigenleben der Figuren. Diese eigentliche Asouveränität des Erzählers wird im „Räuber"-Roman als eine Hingabe an das Erzählen selbst dargestellt: „Ich will mich auf Effektualitäten beschränken, d.h. dem Fluß des Erzählens gehorchen." (AdB 3, 30) Dieser "Fluß des Erzählens“ ist gerade kein Fluss der Erzählung, sondern einer des Handelns, des ,Impulsiven', wie der Erzähler in einer Ansprache an seine Figur Edith darlegt:

Wir sagen das nur, weil uns im Moment nichts Erhebliches einfällt. Eine Feder redet lieber etwas Unstatthaftes, als daß sie auch nur einen Moment lang ausruht. Vielleicht ist dies eines der Geheimnisse besserer Schriftstellerei, d.h. es muß eben ein Impulsives in's Schreiben hineinkommen. ( $\left.\operatorname{AdB}_{3}, 64\right)$

Diese Betonung der Performanz, den Akt des Erzählens, öffnet den Blick auf eine andere Form der Ordnung bei Robert Walser als die eines fixierten Modells. ${ }^{349}$ Seine Vorstellung von Ordnung basiert auf Dynamik und Flexibilität, wie der Erzähler an einer Stelle ausführt: „Unsere Sicherheiten dürfen nichts Starres werden, sonst brechen sie. Es bedarf zur wirklichen Sicherheit des Auftretens und des Weltfühlens eines beständigen kleinlichen Schwankens, Federns." (AdB 3, 79) Das prekäre Erzählen erlangt durch seine Ordnung der Prozessualität, in der der Erzähler eigentlich asouverän, die Erzählung widersprüchlich, die Struktur durch die genannten Überblendungen paradox wird, also wiederum eine neue Souveränität. ${ }^{350}$

349 Christian Walt betont in seiner Analyse der Schreibszene der Improvisation ebenfalls das Impulsive bei Walser, das in seinen Schreib- und Korrekturverfahren verankert ist. Walt, Improvisation und Interpretation, 89.

350 Urs Widmer bezieht diese Souveränität auf den Autor Walser: „Mit einer Souveränität wie kaum je zuvor läßt Walser seine mit höchster Bewußtheit hinimprovisierten Sätze vor uns aufblühen. Sie wirken wie nur so dahergesagt, und sie glühen gleichzeitig vor fiebernder Konzentration. Es ist eine der Qualitäten Walsers, daß er nie ,fertige', ,vollendete‘ Stücke schreiben wollte oder konnte, sondern daß er bewußt den sich von Satz zu Satz bewegenden Akt des Schreibens sichtbar beläßt.“ Widmer, „Der Dichter als Krimineller“, 


\section{Provokationen der Ordnungen}

Der Räuber provoziert Ordnungen. Schon durch die funktionsbestimmende Namensgebung erzeugt er eine Reibung mit der sozialen Ordnung. Normen der Sexualität, Geschlechterrollen, Umgangsformen gegenüber Vertretern der Bürgerlichkeit wie gegenüber Frauen werden vielfach gebrochen und vom Räuber, der mit der psychoanalytischen Schule vertraut ist, ironisch mit einem Arzt diskutiert. ${ }^{351}$ Viele dieser Aspekte wurden in der Forschungsliteratur zu Robert Walser herausgearbeitet. Der Räuber wurde als Repräsentant der IchErfahrung der Moderne charakterisiert. ${ }^{352}$ Auch die Erzählordnung des Textes ist insbesondere durch die Überblendung von Erzähler und Figur perturbiert, so dass nicht nur der Räuber, gleichsam als personifizierte Digression, sondern der „Räuber"-Roman als Erzählung neue Ordnungen provoziert. ${ }^{353}$

Einerseits verfügt der „Räuber"-Roman über einen homodiegetischen Erzähler, der Teil der erzählten Geschichte ist. Andererseits agiert er außerhalb der Geschichte als Erfinder derselben, nimmt eine heterodiegetische Position ein; er bewegt sich gleichsam als handelnde Figur auf der discourseEbene, auf die er auch den Räuber zieht. Die Überblendung der Ebenen von Erzähler und Figur ist inkommensurabel und bringt die herkömmliche Erzählordnung, welche eine unüberschreitbare Grenze zwischen Erzähler und Figur vorsieht, durcheinander. ${ }^{354}$ Verfahren, die normalerweise einen Text

23f. Widmer betont gerade anhand dieses Romans die Notwendigkeit, die damals „immer wieder gehörte These“, es handle sich bei den Texten der Berner Zeit „in erster Linie [um] Zeugnisse [Walsers] zunehmenden psychischen Verstörung“, zu verabschieden. Widmer, 23. Auch Heinz Schafroth betont die Souveränität Walsers, die sich im „Räuber"-Roman darin äußert, dass „komplexeste Erzählkonzeptionen und -strukturen gemeistert sind“. Gerade darin verdeutliche sich das „groteske[] Mißverständnis, in Walsers Berner Prosa [...] zeige sich die beginnende Geisteskrankheit“. Schafroth, „Wie ein richtiger Abgetaner. Über Robert Walsers ,Räuber'-Roman“, 287.

351 Vgl. AdB 3, 112-115; vgl. auch Stephan Kammer, „Walser liest Freud'? oder: Was sich zwischen Texten ereignet“, Vorträge der Robert Walser-Gesellschaft 5 (2002): 35-45.

$35^{2}$ Vgl. Villwock: „Das Sich-Aufführen in vielfältigsten Rollenspielen, das Bestehlen der anderen, das Sich-Produzieren und -Erhalten auf ihre Kosten, das Sich-Entziehen, die transzendentale Heimatlosigkeit, Angst und Lüge sind auch die Existenziale des ,normalen` Bürgers; so gesehen ist der Räuber geradezu repräsentativ für ein ,Ich` unter den Bedingungen des 20. Jahrhunderts." Villwock, Räuber Walser, 11o. Hervorhebung i. O. Vgl. auch Karpenstein-Eßbach, Deutsche Literaturgeschichte des 20. Jahrhunderts, 98-117; Petersen, Der deutsche Roman der Moderne, 286ff.; Thüring, „Der Commis, der Räuber und ihre Geschwister“.

353 Den Fokus auf die Provokation gängiger Normen im Werk Walsers legt Valerie Heffernan, Provocation from the Periphery. Robert Walser Re-Examined (Würzburg: Königshausen \& Neumann, 2007).

354 Es ist erstaunlich, wie wenig diese logischen Unmöglichkeiten, die es schon im Spaziergang gibt, den Lektüreprozess stören. Ohne Weiteres kann man zwischen einer Erzählung, 
strukturieren, wie den Wechsel von Figurenrede und Erzählerrede, Prolepsen und Analepsen zur Orientierung des Lesers sowie Erzählerkommentare, erzeugen im „Räuber“-Roman eine Ordnung des Augenblicks, der Performanz. Der „ordnungsbedürftige[] Leser“355 hat zwangsläufig seine Mühen mit dem, was der Erzähler im Roman „geordnet erzählen“ (AdB 3, 29) nennt. ${ }^{356}$

\subsubsection{Digression in Kurzform}

Bislang wurden in diesem Kapitel Robert Walsers digressive Erzählverfahren anhand zweier umfangreicher Texte analysiert. Grundsätzlich ist das Phänomen der Digression eher in längeren Formen anzutreffen, wie ein Blick auf die Literaturgeschichte zeigt: Cervantes' Don Quijote, Wielands Don Sevilla, allen voran aber Sternes Tristram Shandy sind die Prototypen digressiven Erzählens. Die Kurztexte von Walser demonstrieren jedoch, dass Digression durchaus auf kleinem Raum vorgeführt und ausgeführt werden kann. Im Folgenden stehen zwei Texte von 1931 und 1925/1926 im Zentrum.

Bei Walser muss man im Zusammenhang der Digression achtsam bleiben hinsichtlich der fließenden Abgrenzung von Aufzählungen und den digressiven Verknüpfungen von story-Elementen. ${ }^{357}$ Ein potenzielles Beispiel für eine Aufzählung ist das Prosastück Das Hotel, 1931 in der Zeitschrift Sport im Bild publiziert. Hier werden Beschreibungen einer Hotellobby aneinandergereiht, die zwar jeweils Nuklei von Narrationen werden könnten, jedoch eine stärkere Ordnung als Aufzählung von Elementen, die über den Raum verbunden sind, aufweisen: „Ein Hotel ist eine Angelegenheit der Kleinen und der Großen, die sich mittelstandsvermissend, mithin vorbehältlich durcheinandermischen." (SW 20, 49) Der Text erzeugt seine Kohärenz durch die Abbildung des Disparaten in einer räumlichen Begrenzung: „Was nicht anwesend ist, ist es manchmal gerade dadurch sehr." (SW 20, 49) Dies gilt auch für den Textzusammenhang: Er bietet keine narrative Kette von Ereignissen, sondern Sätze, die über den Raum der Hotellobby zusammengehalten werden. ${ }^{358}$

die tatsächlich stattfindet und einer, die im Prozess erfunden wird, also einer fiktiven und einer metafiktiven, hin und her schalten, obwohl sich die zwei Lektürestrategien systematisch ausschließen.

355 Echte, „Nachwort“, 199.

356 Eine Lesart besteht darin, der Empfehlung des Erzählers zu folgen, dem „[d]as ganze [...] wie eine große, große Glosse, lächerlich und abgründig“ ( $\mathrm{AdB} 3,148)$ vorkommt und den Text entsprechend „als Roman und als Glosse auf den Roman“ zu verstehen. Echte, 213.

357 Vgl. zu einer Diskussion von solchen Techniken der Aufzählung auch Baßler, Die Entdeckung der Textur.

$35^{8}$ Vgl. dazu Claudia Öhlschläger, die den Text als ,Figuration der Krise‘ liest: „Walser setzt der Krisensemantik der zoer Jahre mit ihrer Forderung nach Entscheidung, Trennung und Unterscheidung somit eine Unterschiedslosigkeit und Unentschiedenheit entgegen, 


\section{Disruptive Digression. Einmal erzählte Einer}

Das Prosastück Einmal erzählte Einer erschien am 22. Januar 1931 im Feuilleton des Berliner Tageblatts. Im Gegensatz zum Spaziergang und zum „Räuber“Roman, in denen die Digression über den Raum und mehr oder weniger auschließlich über den Sprechakt als prekäres Kontinuum deutlich war, eignet dem kurzen Text eine disruptive Digression. Der Zusammenhang der Sätze lässt sich auch auf einer Mikroebene bis auf spekulative Assoziationen kaum mehr feststellen. Viermal hebt der Text mit neuen Anfängen an, die jeweils die vorhergehende Erzählung arretieren.

Ich wohnte eine Zeitlang, wie ich mich zu meiner Erheiterung erinnere, bei zwei Frauen, die ich übrigens erst später erwähnen will, indem ich meine Geschichte nicht mit etwas Erlesenem und Ausgezeichnetem beginnen möchte.

Zunächst tritt ein Hund auf, den ich zwar lieber einstweilen noch ein bisschen aufsparen will, ähnlich wie es kleine Kinder mit Schmackhaftigkeiten tun, die sie vor Esslust nicht zu essen fähig sind.

Ein Lakai, doch nein, vorerst von was anderem, nämlich davon, dass ich mir ziemlich lange einbildete, ich sei seriös und ehrsam wie kaum irgendeiner. (KWA III.1, 252)

Zunächst wird eine Erzählsituation etabliert, wie sie schon im Spaziergang vorkommt: Der Erzähler erinnert sich in homodiegetisch extradiegetischer Weise an eine frühere Begebenheit. Es folgt ein Anfangsversuch zunächst mit einem Hund, dann einem Lakaien, Versuche, die schließlich wiederum in die Erzählsituation münden, wie sie schon mit dem ersten Satz erzeugt wurde. Es sind nicht nur Abschweifungen, sondern Zurücknahmen des Gesagten. Die „zwei Frauen“ im ersten Satz will der Erzähler „erst später erwähnen“ und hat sie doch schon im eigentlichen Sinn erwähnt. Gerade diese rhetorische Figur der Paralipse und die Aufschiebung auf später qualifizieren für das Verb „erwähnen“ als Gegensatz etwa zu „beschreiben“. Die Erwähnung hat schon stattgefunden und kann in der Rede nicht mehr zurückgenommen werden. Dies ist also nicht nur ein einfacher Aufschub, wie es etwa der Beginn des „Räuber“Romans („Edith liebt ihn. Hievon nachher mehr.“) ist oder der Konditional im Spaziergang („Es käme jetzt und träte hervor ein Wirtshaus“), sondern eine paradoxe Zurücknahme des Gesagten. Es ist ein Durchstreichen, das das

die mit der kleinen Form in der Weise korreliert, als sie es ermöglicht, den Bewegungsimpuls einer sich wandelnden und als wandelbar diagnostizierten Gesellschaft direkt aufzunehmen.“ Claudia Öhlschläger, „Figurationen der Krise: Robert Walsers Feuilleton im Kontext der Unterhaltungs- und Konsumkultur zwischen 1927 und 1932. Das Beispiel ,Sport im Bild: Kultur, Gesellschaft, Mode'“, in Figurationen der Moderne. Mode, Sport, Pornographie, hg. von Birgit Nübel und Anne Fleig (München: Wilhelm Fink, 2011), 119. 
Durchgestrichene stehen lässt und gleichwohl keine „Vertextung der Textgenese ${ }^{\text {“359 }}$ darstellt.

Die zwei Frauen, mit denen die "Geschichte" nicht beginnen soll, werden später im drittletzten Absatz des Textes noch einmal erwähnt, abermals in Form einer Negation: „Zu den beiden Frauen vom Anfang brauche ich nicht zurückzukehren. Unbewusst nannte ich sie schon." (KWA III.1, 253) Der Rückbezug auf den Anfang ist deutlich. Absurderweise wird nun obige Zurücknahme der Frauen ignoriert. Dass sie ,unbewusst' genannt wurden, stimmt gerade nicht, denn dem Erzähler war ihre Nennung ja bewusst, andernfalls hätte er sie nicht zurücknehmen können.

Eine ähnliche Struktur der Zurücknahme ist auch beim Hund festzustellen, den der Erzähler ,aufsparen' will. Auch hier scheint es sich zunächst um eine einfache Aufschiebung zu handeln, als Prolepse für einen späteren Auftritt. Die dem Hund attribuierten Formulierungen „es tritt auf“ und „zwar lieber einstweilen noch ein bißchen aufsparen“ stehen in einem Widerspruch. Ist der Hund aufgetreten - was durch den Indikativ Präsens garantiert ist - kann er nicht länger aufgespart werden. Der Auftritt könnte herausgezögert werden, hier aber ist er schon vollzogen. Auffällig ist die Formulierung „es tritt auf“, die an die Wendungen im Spaziergang im Konjunktiv erinnert - „[e]s käme jetzt und träte hervor ein Wirtshaus" (KWA I.8, 188) -, und allgemein an Bühnentechnik, an das Theater, in dem Figuren auf- und abtreten. ${ }^{360}$ Im Theater kann eine Figur die Bühne immer wieder verlassen, sie kann auch irrtümlich auftreten, aber sie kann nicht nicht aufgetreten sein, wenn sie aufgetreten ist.

Im übernächsten Abschnitt der Erzählung wird die paradoxe Zurücknahme des Auftritts des Hundes implizit zurückgenommen. Der Erzähler spricht von "obengenanntem Hund, der offenbar ein Wachsamkeitsbeispiel war" und der den Erzähler „energisch und zielbewusst angebellt“ hatte (KWA III.1, 252). Der Hund war bis anhin jedoch gerade nicht wachsam, sondern unsichtbar.

359 Vgl. zu den kommentierten und kommentierenden Korrekturen bei Walser: Walt, Improvisation und Interpretation, $72 \mathrm{f}$. Walt versteht dieses Verfahren der Zurücknahme Walsers als eine im Text „prozessierte ,Konzeptions- oder Skizzenphase‘. [...] Das Setzen von solchen Textbausteinen, auf die vielleicht zurückzukommen sein wird, kann als Methode verstanden werden, Skizzen und ,Ideen' im Verlauf des Schreibens in dieses selbst zu integrieren. Oftmals stellen sie dabei thematische Fremdkörper dar. Ihr Einsatz erscheint eher als zufällig generiertes ,impulsives‘ Schreiben." Walt, 89. Hervorhebung i. O. Walt legt damit den Fokus auf die Textgenese und weniger auf die Funktion dieser Stellen in Poetik und Ordnung.

36o Zur Bedeutung des Theaters und des Theatralischen bei Robert Walser vgl. Borchmeyer, „Robert Walsers Metatheater. Über die Dramolette und szenischen Prosastücke“. Gees, Schauspiel auf Papier; Martina Schaak, „Das Theater, ein Traum“. Robert Walsers Welt als gestaltete Bühne (Berlin: Wissenschaftlicher Verlag Berlin, 1999). 
Die attestierte Zielgerichtetheit des Bellens des Hundes steht in auffälligem Gegensatz zur ziellosen, ,unbewussten' Nennung der zwei Frauen am Anfang des Textes. Ist normalerweise der Hund unverständlich, so scheint es hier der Erzähler zu sein.

An der Reihe der Anfänge ist auffällig, dass die Neuaufnahmen immer kürzer und schneller beiseitegeschoben werden. So heißt es für die zwei letzten: „Ein Lakai, doch nein, vorerst von was anderem, nämlich davon, dass ich mir ziemlich lange einbildete, ich sei seriös und ehrsam wie kaum irgendeiner." (KWA III.1, 252) Dieser Satz nun bringt den Widerspruch auf die kürzeste Form, wird doch der Lakai als bloßes Wort gesetzt und gleich darauf zurückgenommen. Später wird, wie im Falle des Hundes, vom Lakaien in bestimmter Form gesprochen: „Ich traf den blassen Lakaien“ (KWA III.1, 253). Mit dem bestimmten Artikel und dem Attribut blass wird der Anschein erweckt, als sei der Lakai früher schon ordentlich eingeführt worden.

Diese Paradoxien spiegeln sich im eigenartigen Vergleich, den der Erzähler in Bezug auf den Hund verwendet, den er aufsparen will, wie es „kleine Kinder mit Schmackhaftigkeiten tun, die sie vor Esslust nicht zu essen fähig sind.“ (KWA III.1, 252) Scheint damit zunächst das Prinzip von Begehren und Aufschub des Begehrens zur Steigerung desselben benannt zu sein, so wird bei genauerer Betrachtung klar, dass diese Worte ins Paradoxe gewendet sind. Der Grund für das Aufsparen der "Schmackhaftigkeiten“ ist nicht das Erhöhen der Lust, sondern die Unfähigkeit, sie zu essen und zwar „vor Esslust“. ${ }^{361}$ Kommt dazu, dass etwas eigentlich erst als schmackhaft erkannt werden kann, wenn es gegessen ist. Just dieser Schritt fehlt aber in Einmal erzählte Einer. Die Erzählanfänge werden immer nur aufgeschoben und zurückgenommen, um dann vorzugeben, sie seien doch schon erzählt worden. ${ }^{362}$

Für solche Texte wurde in der Narratologie der Begriff der disnarration geprägt. Er bezeichnet "those elements in a narrative which explicitly consider

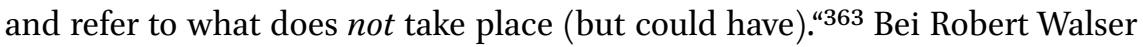

361 Im Kurztext Cézannegedanken (1929) wird „Eßlust“ mit Erfahrung und Verarbeitung der Erfahrung zusammengezogen: „Er aß Früchte so gern wie er sie studierte; er fand Schinken so schmackhaft wie als Form und Farbigkeit, wundervoll' und als Vorkommnis ,phänomenal'““ (KWA III.4.2, 451)

362 Siehe dazu Kap. 3.4 Figurationen des Erzählens, S. 18iff. unten.

363 Gerald Prince, „Disnarrated“, in Routledge Encyclopedia of Narrative Theory, hg. von David Herman, Manfred Jahn und Marie-Laure Ryan (London: Routledge, 2010). Hervorhebung i. O. 
jedoch ist das Eigenartige die Mischung zwischen der ontological denarration ${ }^{364}$ und dem Konditional der disnarration. ${ }^{365}$

Mit diesem mehrfachen Aufschieben und Widerrufen des Anfangs ist die Eigenart des Textes jedoch noch nicht erschöpft. Die Thematisierung des Anfangs wird ohne Kommentar beendet und der Text fortgeführt. Der Erzähler schildert, wie er vor ein „bildhübsches Haus“ „sprang“, um der Besitzerin zu sagen, er ,sei ein Besitzer und Verbraucher von Illusionen“, worauf er von jenem Hund angebellt und vertrieben wird, der oben erwähnt wurde (KWA III.1, 252).

Auf dieses Intermezzo folgt ein neuer Abschnitt mit einer ganz anderen Erzählung über „meine Frau Mama“. Wenig später wird abermals ein neuer Strang aufgenommen, als es heißt: „[Ich] bitte den Leser, mir zu erlauben, ihm zu erzählen, ich sei eines Tages in eine wundersame Stadt gekommen“ (KWA III.1, 252f.), wobei kein Bezug zur „Frau Mama“ hergestellt wird, aber ein solcher auch nicht ausgeschlossen wird. Auf die Erwähnung der Stadt folgt die Wiederaufnahme des Lakaien, wobei möglich ist, dass der Lakai sich in der Stadt befindet, diese Assoziation ist aber nicht zwingend. Eine Verbindung könnte über die Begriffe „Sänfte“, „Kutscherbock“ und „Eleganz“ des Lakaien hergestellt werden.

Ein bemerkenswerter Bruch zu diesem lockeren Assoziationskomplex vollzieht sich im nächsten Abschnitt: „Gemsen, bringe ich nun unerwarteterweise vor, tanzten und hüpften von Fels zu Fels“ (KWA III.1, 253). Der Bruch auf der story-Ebene ist radikal, da hier keine Assoziationen zur Verknüpfung getriggert werden. Paradoxerweise sorgt gerade das "unerwarteterweise“ für eine Normalisierung dieses narrativen Chaos: Die Erzählung nimmt Bezug auf eine ordentliche Erzählung.

Auf die Gemsen folgen zwei Abschnitte im Modus der Iteration: „Täglich putzte ich säuberlich meine Schuhe" und „Bald stand ich still, bald bewegte ich mich.“ (KWA III.1, 253) Diese epilogartigen Sätze erzeugen durch die iterative Erzählweise einen Zustand. Der Text schließt mit einem poetologischen Vergleich zwischen Erzählen und Wirklichkeit:

Beim Erzählen geht es ähnlich zu wie in der Wirklichkeit. Man nimmt sich allerlei vor, denkt an bestimmte Personen und Gegenden, aber beim Wandern verändert sich's, Voreingenommenes verschwindet, das Ungesuchte findet sich ein, Unerwünschtes wird willkommen.

Wie freue ich mich, mit meinem Prosastück bei etwas Bedeutsamem angelangt zu sein. (KWA III.1, 253f.)

364 Vgl. Richardson, „Denarration“.

365 Vgl. für eine Diskussion dieser Begrifflichkeiten mit Bezug auf Robert Walser Frederick, Narratives Unsettled, 39-45. 
Die Frage, die sich nach diesen Zeilen am drängendsten stellt, ist diejenige nach dem ,Bedeutsamen' des Schlusses. Zunächst soll hier jedoch der Analogie zwischen Erzählen und Wirklichkeit nachgegangen werden. Auffällig an diesem Vergleich ist, dass es gemäß dem Erzähler nicht die Fiktion ist, die sich wie die Wirklichkeit verhält, bzw. sich nach dem mimetischen Gebot der aristotelischen Poetik zu verhalten hat. Erzählen ist hier ein Akt, der, wie die Wirklichkeit, unvorhersehbar ist. Die Unvorhersehbarkeit des Erzählens führt, im Gegensatz zum Bellen des Hundes, auf kein anderes Ziel, als den eigenen Erzählprozess hinaus. Das Erzählen als ein zielloses Gehen findet sich auch im Motiv der sauber geputzten Schuhe wieder. Jedoch ist hier, im Gegensatz zum Spaziergang, vom Wandern die Rede. Im Erzählen wird das Erzählte Wirklichkeit:

Gemsen [...] tanzten und hüpften von Fels zu Fels, eine Redeweise, die eklatant beweist, dass mich der Lebensstrom, auf dessen seidenweichfliessendem Rücken mir's gefiel, in die Berge gebracht hatte, wo Hütten standen, die an Zierlichkeit mit Fenstervorhängen oder Schleiern wetteiferten. (KWA III.1, 253)

Es ist die „Redeweise“, die "beweist“, dass das Ich in die Berge gelangt ist; als Begründung dient einzig die Performanz des Satzes. Entsprechend greift hier auch Ross Chambers' Konzept des time-out nicht, da dieses auf der storyEbene angesiedelt ist, die in Einmal erzählte Einer gerade mit derjenigen des discourse verschmilzt. Gleichwohl wird zur Texteröffnung das Angebot eines solchen time-outs gemacht: „Ich wohnte eine Zeitlang, wie ich mich zu meiner Erheiterung erinnere" (KWA III.1, 252, Hervorhebung L. G.). Damit wird eine Schreibszene der Erinnerung und des Nachdenkens evoziert. In Anwendung eines time-outs böte sich an, in digressiver Manier in Erinnerungen zu schwelgen und witzige Anekdoten zu präsentieren. Genau dies verweigert der Text jedoch.

Was jedoch ist das Bedeutsame, bei dem der Text am Ende angelangt sein will und das in scharfem Kontrast zur Ziellosigkeit des Textes steht? Vier naheliegende Lesarten stehen zur Diskussion: Zum einen ist in einer Parallelisierung von Erzählen und Lektüre, wie sie Einmal erzählte Einer konturiert, das Bedeutsame zunächst einmal das Ende des Textes: Bedenkt man das Schreibverfahren, so steht am Ende des Prozesses ein Artefakt, ein beschriebenes Blatt. Des Weiteren beschreibt das Bedeutsame, an dem „angelangt“ wird, den Prozess der Erzählung. Nach den vielfach zurückgenommenen Anfängen hat sich im Verlauf des Textes eine Art Erzählung entwickelt. Eine dritte Option sieht das ,Bedeutsame' in einer verborgenen Bedeutung des Textes liegen. Eine Erkenntnis könnte im Abgleich von Erzählen und Wirklichkeit zu finden 
sein, indem Bedeutung grundsätzlich von Performanz abhängt. Hunde, die bellen, beißen bekanntlich nicht - im Gegensatz zum ,zielgerichteten Bellen des Hundes ist der Text selbst gefährlich. Er ,beißt' Harmlosigkeiten, auf Belangloses gerichtetes Erzählen und Voreingenommenes mit seiner dezidierten Poetik des Ziellosen. Und schließlich kann das Bedeutsame als ironischer Hinweis auf die Bedeutungslosigkeit des Textes überhaupt verstanden werden. Der Text bedeutet nichts. Nach dieser Argumentation würde der Text jeweils das Gegenteil von dem tun, was er zu tun vorgibt und gerade nicht erzählen.

Deutlich wird in Einmal erzählte Einer eine Poetik konturiert, die sich an der Performanz der Sprache orientiert. In extremis stellt das Prosastück eine Art von disruptiver Digression vor, die ihre eigene Ordnung darstellt, beschreibt und in ihrer Vieldeutigkeit verteidigt. Ordnung wird hier als eigenwillige Konstruktion der Erzählung sichtbar. Es geht nicht nur um ein „Modulieren der Signifikanten“366 und nicht um die „Zerstörung der Signifikanz“367, sondern um den Prozess des Erzählens selbst, was auch widersprüchliche, vieldeutige Informationen vermitteln kann, sowohl im Inhalt als auch in den Verfahren selbst. Die Grundlage dieses Erzählens liegt dabei in seiner Performanz.

\section{Das Zentrum als Leerstelle. Der heiße Brei}

Das ,Bedeutsame', das in Einmal erzählte Einer gleichsam als Pointe am Ende aufscheint, wird in Der heiße Brei, einem unveröffentlichten Text, der sowohl als Abschrift wie in der Mikrogrammfassung überliefert ist, von Jochen Greven auf 1925/1926 datiert, noch einmal anders gewendet. Der heiße Brei ist einer jener Texte, die häufig als Beispiele für Robert Walsers Poetik der Digression und des Aufschubs angeführt werden; er benennt das Prinzip des Aufschubs geradezu exemplarisch. ${ }^{368}$ Dabei wird meist folgende Stelle zitiert:

366 Walt, Improvisation und Interpretation, 94.

367 Hans H. Hiebel, „Robert Walsers ,Jakob von Gunten'. Die Zerstörung der Signifikanz im modernen Roman", in Über Robert Walser, hg. von Katharina Kerr, Bd. 2, 3 Bde. (Frankfurt am Main: Suhrkamp, 1978f.), 308-345. Wieder abgedruckt in Hans H. Hiebel, „Robert Walsers ,Jakob von Guntenc. Die Zerstörung der Signifikanz im modernen Roman“, in Robert Walser, hg. von Klaus-Michael Hinz und Thomas Horst (Frankfurt am Main: Suhrkamp, 1991), 240-275.

368 Martin Jürgens liest das Abschweifen ausschließlich negativ als Ausdruck einer Verlusterfahrung, in der das Wichtige „überschattet bleibt von seinem Verlust, und dieser Verlust soll fühlbar gemacht werden“. Jürgens, Robert Walser, 120. Jürgens widmet einige Seiten dem Heißen Brei: Jürgens, 119-124. Vgl. auch Utz, Tanz auf den Rändern, 351; Bleckmann, „Thematisierung und Realisierung der bildenden Kunst im Werk Robert Walsers“, 29-58; Christoph Bungartz, Zurückweichend vorwärtsschreiten. Die Ironie in Robert Walsers Berner Prosa (New York, Bern, Paris, u. a.: Peter Lang, 1988), 162-169; Wolfgang Baur, Sprache und Existenz. Studien zum Spätwerk Robert Walsers (Göppingen: Kümmerle, 1974), 101-111. 
Besteht nicht Schriftstellern vielleicht vorwiegend darin, daß der Schreibende beständig um die Hauptsächlichkeit herumgeht oder -irrt, als sei es etwas Köstliches, um eine Art heißen Brei herumzugehen?

Man schiebt schreibend immer irgend etwas Wichtiges, etwas, was man unbedingt betont haben will, auf, spricht oder schreibt vorläufig in einem fort über etwas anderes, das durchaus nebensächlich ist. (SW 19, 91)

Deutlich unterstrichen wird in dieser expliziten Benennung des Prinzip des Aufschiebens dabei, dass die Digression nicht ein dem Erzählen entgegengesetzter Effekt ist, der die Erzählung behindern würde, sondern ganz im Gegenteil, dass sie ihre eigentliche Form ist. Die „Hauptsächlichkeit“ kann nur erfasst werden, indem um sie herumgeirrt wird; einem gezielten Zugriff muss sie sich entziehen. Wenn auch in Frage gestellt werden kann, ob dieses Herumgehen um den „heißen Brei“ tatsächlich etwas „Köstliches“ ist für den Erzähler oder ob es ironisch als Euphemismus verstanden werden muss, so ist doch unbestreitbar, dass es ein lustvolles Herumgehen und Herumirren ist, welches seinen Antrieb aus sich selbst nimmt.

Was viele Lektüren der Erzählung Der heiße Brei jedoch übersehen, ist, dass durchaus eine Geschichte erzählt wird. ${ }^{369}$ Auf der story-Ebene ist Der heiße Brei die Nacherzählung eines Traumes, während auf der discourse-Ebene die Reflexion über die adäquate Form einer solchen Erzählung dominiert. Die

Für eine Lektüre, die den Fokus auf den Kontext legt, vgl. Karl Wagner, „Österreicheleien“, in Robert Walsers „Ferne Nähe“. Neue Beiträge zur Forschung, hg. von Wolfram Groddeck u. a. (München: Wilhelm Fink, 2007), 100: „Derart praktizierter Aufschub darf Spracherotik genannt werden; die Metapher für derlei Spracherotik aber lautet ,östreicheln', ein zeitgenössisch keineswegs Walser vorbehaltenes Verbum. In diesem Verbum ist das Wort streicheln‘ zur Gänze enthalten." Für seine These untersucht Wagner Walsers Bezug zum österreichischen und Wiener Feuilleton.

Die scheinbare Deutlichkeit dieser Bildlichkeit kann man leicht als selbsterklärend hinstellen. So charakterisiert Hong Walsers Erzählen als „sich erzählend dem Erzählen entziehende[s] Erzählen“ und zitiert kommentarlos aus Der heiße Brei, als sei damit alles gesagt. Kil-Pyo Hong, Selbstreflexion von Modernität in Robert Walsers Romanen „Geschwister Tanner", „Der Gehülfe“ "und „Jakob von Gunten“(Würzburg: Königshausen \& Neumann, 2002), 10.

Den sozusagen umgekehrten Weg nimmt Valerie Heffernan, wenn sie schreibt, dass Der heiße Brei eben mehr als nur eine „Traumerzählung“ sei: „Thus, Der heiße Brei is more than just a Traumerzählung; it is an articulation of Walser's literary vision." Heffernan, Provocation from the Periphery, 180.

369 Jens Hobus ist der Ansicht, dass in Der heiße Brei die Digression - die „labyrinthische Schreibweise“ - weniger "durchgespielt und realisiert“, als "behauptet und thematisiert" wird. Hobus, Poetik der Umschreibung, 92. Der heiße Brei benenne die Funktionsweisen und Bedingungen der Digression: „Es ist die Repräsentation der eigenen Repräsentationsbedingungen, die hier [in Der heiße Brei] unter der Prämisse stattfindet, dass sie eigentlich nicht möglich sei." Hobus, 92. 
Art und Weise des Erzählens orientiert sich dabei in der schon bekannten simultanen Erzählweise am Traumartigen selbst. Mit dem Rahmen des Traumes lassen sich die Widersprüche und die disruptive Erzählweise ansatzweise erklären. Insofern ist es auch ein mimetischer Text, der Erfahrung in die Verfahren des Erzählens übersetzt.

Klein von Gestalt, wie es sich mir in meinem jüngsten Traum zeigte, sei dies Prosastückelchen.

Ich hoffe, mir gelinge nächstens eine umfangreiche dichterische Unternehmung, obwohl ich grundsätzlich immer so wenig wie möglich hoffe. In ein Haus fliegt man meist nicht von oben herab, vielmehr steigt man von unten her, langsam oder schnell, in seine Etagen hinauf. Man scheint es diesbezüglich mit einer natürlichen Bedingung zu tun zu haben. Das Haus, wovon hier gesprochen werden soll, war gleichzeitig proletarischen Charakters und von träumerischzierlicher Art. Als ich gemeinsam mit ihm, den ich im Anfang vorliegenden differenzierten Zeilenreichtums erwähnte, die Stiege oder Treppe hinaufging, kamen wir an einer Gruppe von Sitzenden vorbei, die Arbeiter zu sein schienen. (SW 19, 89)

Irritierend ist hier insbesondere die Grenzziehung zwischen dem, was geträumt wurde und dem aktuellen Erzählprozess, den der erste Satz referiert. Es ist eigenartig, dass der Erzähler nicht vom Inhalt, einzelnen Szenen oder Figuren geträumt hat, die nun wiedergegeben werden sollen, sondern, dass sich ihm "dies Prosastückelchen“ gezeigt hat. Der Text inszeniert gleichsam eine Nacherzählung oder Reproduktion des geträumten Textes. Es ist kein Ereignis und keine Handlung, die sich im Traum gezeigt hat und die jetzt hier erzählt werden wird, sondern das Prosastück selbst.

Im zweiten Satz wird in einem bemerkenswerten Gegensatz zum ersten Abschnitt die Hoffnung auf eine "umfangreiche dichterische Unternehmung“ formuliert. Damit kann nicht das vorliegende und geträumte Prosastück gemeint sein, ist dieses doch "[k]lein von Gestalt". Als Verdeutlichung dessen, wie schwer sich der Akt des Schreibens, die Schaffung einer Erzählung gestaltet, folgt die Beschreibung eines Hauses, das man sich, schnell oder langsam, von unten herauf erschließt. Ähnlich wie eine Erzählung, als deren Metapher das Haus gelesen werden kann, die sich schrittweise aufbaut. ${ }^{370}$

Im Weiteren wird sodann ein Haus geschildert, das aus verschiedenen aufeinander aufbauenden Stockwerken besteht

370 Vgl. auch Valerie Heffernan: „[The] labyrinthine house [is] obviously a metaphor for his textual construction." Provocation from the Periphery, 174. Vgl. dazu Henry Sussmans auf Kafkas Bau bezogene Wendung der „all-embracing metaphor“. Henry Sussman, Franz Kafka. Geometrician of Metaphor (Madison: Coda Press, 1979). Siehe Kap. 4 Unmögliches Erzählen. Franz Kafkas Der Bau, S. 199ff. unten. 
Das Haus selber war ja ebenfalls nur etwas Vorübergehendes, denn ich sah das eigentümliche bauliche Arrangement sich öffnen und schließen, vorhanden sein und doch auch zugleich wieder verschwinden, ich sah, wie es sich entfernte und in die Nähe kam.

Nun waren wir beide in einer Stube, um die sich eine weitere Stube zog. Das eigentliche Zimmer lag oder saß wie ein Kern in der Schale, wie ein Bild im Rahmen, von einem zweiten Zimmer umfaßt, was sehr hübsch und anmutig aussah. (SW 19, 91)

Das metaphorische Haus der Erzählung ${ }^{371}$ wird darauf zu einem tatsächlichen, in welches das Erzähler-Ich mit jemandem, den es „im Anfang vorliegenden differenzierten Zeilenreichtums" erwähnt haben will, hochsteigt. Da bis anhin jedoch keine andere Figur aufgetaucht ist, stellt sich die Frage, worauf sich das „ihm“ bezieht.

Es ist möglich, dass damit der Erzähler selbst gemeint ist, dass also eine Ich-Verdoppelung stattfindet, wie sie schon im Spaziergang und im „Räuber“Roman herausgearbeitet wurde. ${ }^{372}$ Eine andere Möglichkeit besteht darin, dass mit dieser Figur in einer mise en abyme der Traum oder das „Prosastückelchen“ gemeint ist. Auf der Ebene des Traumes könnte man von einem Klartraum oder luziden Traum sprechen, in dem sich der Träumende seines Träumens bewusst ist. Wie schon in Einmal erzählte Einer ist in der Der heiße Brei unklar, wann die story beginnt oder ob sie schon mit jenem einleitenden Wunsch zum Prosastück begonnen hat.

Nach und nach gewinnt die Figur, die den Erzähler im Schlaf besucht, Konturen, bis sie schließlich als ein berühmter Schriftsteller identifiziert wird.

Dies eine wußte ich: ein Schriftsteller von Ruf war's, der da den Weg zu mir gefunden hatte, was für mich weiter gar nichts Erstaunliches besaß, obwohl es wieder als sehr eigentümlich auf mich einwirkte.

War er für mich der heiße Brei, oder war ich er für ihn? (SW 19, 91f.)

So rückt der Text die Frage, wovon er handelt, ins Zentrum. ${ }^{373}$ Die Überblendung zwischen Erzähler und Figur ist einmal mehr bemerkenswert. Und

371 Es sei schon an dieser Stelle auf Kafkas Bau hingewiesen, wo dieser paradoxe Raum um den Raum herum einen „Lieblingsplan“ des Erzählers darstellt. Siehe Kap. 4.1.2 Innen und Außen. Der paradoxe Lieblingsplan, S. 21off. unten.

372 Heffernan weist auf die Ähnlichkeit der Figuren hin, ohne auf die Irritation einzugehen, die der plötzliche Auftritt der anderen Figur auslöst: „They [Erzähler und Figur] share the same function and goal within the text, and in this way, they seem to act as mirror images of one another." Heffernan, Provocation from the Periphery, 178.

373 In einer interessanten Wendung von Walsers „labyrinthischen Schreibweise“ betont Benne, „dass der Leser das Gefühl bekommen muss, dem Erzähler auf einem Weg zu 
doch nimmt diese Erzählweise präzise eine Traumlogik auf, in der die Grenzen des eigenen Ich fließend sind. Es handelt sich hier um den Versuch, gleichzeitig einen bestimmten Traum wie auch die Form des Traumes darzustellen. Dies geht nur über Umwege, über das Herumgehen um den „heißen Brei“. Deshalb ist es auch ein „Prosastück, das ein untersuchendes, prüfendes, tastendes, ganz auf denkbar feinster Aufmerksamkeit beruhendes ist“ (SW 19, 90). Die Sprache muss sich dem Gegenstand anpassen, ihn auch formal abbilden, um die „Porträtierung von etwas im Schlaf Erlebtem“ (SW 19, 90) zu vollziehen.

Der letzte Satz des Prosastücks lautet im schlichten Präteritum: „Jetzt erwachte ich." (SW 19, 92) Der Satz ist aus mehreren Gründen eigenartig. Zum einen ist er für Walsers Berner Zeit eher ungewöhnlich deutlich auf die Handlung bezogen: Häufig enden seine späten Prosastücke mit einem Hinweis auf die Erzählerebene, wie oben in Einmal erzählte Einer - „Wie freue ich mich, mit meinem Prosastück bei etwas Bedeutsamem angelangt zu sein.“ (KWA III.., 254) Dieser Schluss ist, markiert durch das Präteritum, auf der Ebene der story zu verorten und nicht auf der discourse-Ebene. Zum anderen erzeugt der Satz einen phänomenologischen Widerspruch, kann doch das Erwachen selbst, wie das Einschlafen, nicht gleichzeitig erlebt und beschrieben werden. Doch das ,jetzt' suggeriert genau dies. Auf welcher Ebene erwacht das Ich? Als Erzählung und als Traum ist der Satz gewissermaßen doppelt fiktionalisiert, weshalb, so könnte argumentiert werden, um den Bezug zum selbstreferenziellen Ende herzustellen, er als erzählte, geträumte Erzählung eben doch auf der discourseEbene anzusiedeln ist.

Die Mikrogramm-Version des Textes weist eine interessante Variation des Schlusses auf:

War er der heiße Brei (für mich), wenn ich ihm zu sprechen gestattete oder war ich ihn für ihn? Hatte er mir, oder hatte ich ihm etwas von Belang zu sagen[.] Ohne dass ich das eigentlich beabsichtigte, fand ich im heißen Brei die Pointe. Jetzt erwachte ich. ${ }^{374}$

Diese nicht in die Abschrift-Fassung übernommene Stelle unterstreicht deutlich die Bedeutung der Performanz: Es ist der Erzähler, der den Figuren etwas

folgen, der sich im Prozess des Schreibens gerade erst ergibt. [...] Die strukturelle Einfachheit dieses Prozesses ist trügerisch: Was während der einmaligen Lektüre wie ständige, lineare Vorwärtsbewegung wirkt, gibt sich ganz wie beim Labyrinth aus der Vogelperspektive des zyklischen Lesers als hochkomplexes Muster zu erkennen." Benne, ",Schrieb je ein Schriftsteller so aufs Geratewohl?' Der surrealistische Robert Walser“, $5^{8}$.

374 Robert Walser, „[Der heiße Brei] zitiert nach einer provisorischen Entzifferung der KWA - Mkg 85r/II + 75r/I", 2018. Hervorhebung L. G. Ich danke Christian Walt und den Mitarbeitenden der KWA in Zürich für diese provisorische Transkription. 
,gestatten' kann. Dass der „heiße Brei“ die Pointe ist, ist naheliegend, ist er doch als die „Hauptsächlichkeit“ das Zentrum des Textes. Was in Einmal erzählte Einer als das ,Bedeutsame' eine Leerstelle blieb, wird im Mikrogramm zum „heißen Brei“, mithin zum Erzählen als Akt selbst, ist dieses doch gekennzeichnet als digressives Verfahren um den Brei herum.

Das als Pointe bezeichnete ist also keine eigentliche Pointe. Wie das Haus, das der Text als Analogie aufbietet, ist die Erzählung etwas „Vorübergehendes“im Akt des Erzählens wie der Lektüre. Die Pointe ist eine Fixierung. Vielleicht aus diesem Grund hat Walser die Ausführungen dazu nicht in die Manuskriptfassung aufgenommen und ist seiner Tendenz gefolgt, das Deutliche zu verschleiern. In der Ambivalenz und der Performanz des Prozessualen findet das Erzählen zur Freiheit, indem es die Grenzen des Möglichen und Sagbaren selbst setzt. ${ }^{375}$

Robert Walsers Text Der heiße Brei wurde vor allem als eine Inszenierung der Lust am Aufschub und der Verzögerung rezipiert. ${ }^{376}$ Rückt jedoch das ganze Prosastück in den Blick, wird deutlich, dass eine Geschichte erzählt wird, die versucht, das, was sie erzählt, in ihre performative Erzählordnung aufzunehmen. Dadurch entsteht die paradoxe Situation, dass die gewonnene Erkenntnis - die „Pointe“ - dem Verfahren widersprichen kann.

375 Vgl. dazu Urs Widmer, der die Kategorie der Freiheit im Schreiben betont. Den „Räuber“Roman beschrieb er als den "gleichzeitig freieste[n] und bewußteste[n]" Roman Walsers. Widmer, „Der Dichter als Krimineller“, 22.

376 Jedoch ist auch in einer solchen Deutung die Frage, was der heiße Brei sei, nicht einfach aufgehoben. Jens Hobus schreibt: „Wie schon im Text ,Der heiße Brei‘ analysiert wurde, besteht dann das ,Köstliche‘ in der Bewegung um das aufgeschobene Zentrum. Damit richtet sich das Begehren nicht mehr auf das Erreichen eines Signifikats, sondern es richtet sich auf das Erkennen der Bedingungen der Semiose. Der Signifikationsprozess ersetzt somit das Signifikat, weil der Lustgewinn in der Tätigkeit, im Spiel der Signifikanten besteht." Hobus, Poetik der Umschreibung, 96. So auch Heffernan: „For just as ,das eigentliche Zimmer' in the house, created in and through the writing, forever evades the narrator, so too will any pursuit of the central message or meaning in the Walser text prove to be futile." Heffernan, Provocation from the Periphery, 174.

Diese Lektüren, die den Text im Hinweis auf das Untergraben der Bedeutung generell, im dekonstruktivistischen Sinn als Darstellung von Bedeutungsgenerierung verstehen, haben den Nachteil, dass sie den Inhalt des Textes nicht im Blick haben. Diese Lektüre des Textes ist nicht spezifisch auf den Heißen Brei bezogen, sondern lässt sich an zahlreichen Prosastücken von Walser wie von anderen Autoren, besonders auch Franz Kafka, erproben. Es geht in Der heiße Brei tatsächlich auch um einen Traum und die Frage, wie davon zu erzählen sei und nicht nur darum, eine Metaposition zur Beobachtung von Sprache und ihren Mechanismen einzunehmen. 


\subsection{Performatives Erzählen, Metanarration und Metafiktion}

In den Analysen zur Digression wurde schon auf den Begriff der Performanz Bezug genommen. Sie ist die Basis auf der Robert Walsers Erzählen seine Ordnungsfunktion ausstellt - die metanarrativen Einschübe, das simultane Erzählen und die Überblendungen von narrativen Ebenen werden durch die Performanz allererst ermöglicht. Im Folgenden wird Performanz als theoretisches Konzept der Narratologie kurz eingeführt werden. An einschlägigen Stellen im Spaziergang wird Walsers Anwendung performativer Erzählverfahren analysiert. Am Mikrogramm-Text Die grüne Spinne (1924/1925) wird anschließend untersucht, wie Performanz in eine Figuration gefasst wird.

\subsubsection{Zum Begriff der Performanz in der Narratologie}

Der historische Ursprung des Performanz-Konzepts findet sich in den sprachphilosophischen Untersuchungen John Austins, dem Begründer der Sprechakttheorie. Er entwickelte in seinen Vorlesungen How to Do Things with Words das Konzept, wie mittels Sprache Handlungen vollzogen werden. Was bei Austin und auch bei John Searle auf die ordinary language, die Alltagssprache, bezogen ist, gilt in einem spezifischen Sinn auch für die narrative Rede. ${ }^{377}$

Für die Belange der Erzählforschung systematisiert Ute Berns einen engeren und einen weiteren Begriff der Performativität. Performativität im engeren Sinn bezeichnet eine konkrete Aufführungssituation, in der die Rezipienten eine "live presentation of events" beobachten. ${ }^{378}$ Diese kann fiktional oder faktual sein, Theater, Tanz oder Rituale mit festgefügten Abläufen, wie beispielsweise eine Hochzeit oder Beerdigung, umfassen. Im weiteren Sinn bezieht sich Performativität auf die Darstellung, einer „imitation or illusion of performance", wie sie in fiktionalen Texten die Regel ist. ${ }^{379}$ Diese Performativität kann nun zum einen als Handlung auf der Ebene der story, zum anderen in der Darstellung dieser story, also auf der discourse-Ebene wirksam sein: "In this case, the reader's or spectator's attention is directed to the act of narration itself, or to the actions of the narrator, which can be foregrounded

377 Vgl. dazu Uwe Wirth, Performanz. Zwischen Sprachphilosophie und Kulturwissenschaften, 5. Aufl., Suhrkamp Taschenbuch Wissenschaft (Frankfurt am Main: Suhrkamp, 2011); Erika Fischer-Lichte, Ästhetik des Performativen, 9. Aufl. (Frankfurt am Main: Suhrkamp, 2014).

378 Ute Berns, „Performativity“, in The Living Handbook of Narratology, hg. von Peter Hühn u. a. (Hamburg: Hamburg University, 2014), Abschn. 1, http://www.lhn.uni-hamburg.de/ article/performativity.

Berns, Abschn. 2. 
to a greater or lesser degree. “380 Es ist diese Variante der Performativität, die hier von besonderem Interesse ist. ${ }^{381}$ Das Hervorheben des Erzählakts ermöglicht auch selbstreflexive Erzählformen: „The performativity that refers to the act of presenting includes forms of self-reflexifity such as metanarration and metafictionality that effectively dramatize or foreground the act of narration."382

Metanarration und Metafiktion werden zwar häufig als Synonyme verwendet, müssen jedoch deutlich unterschieden werden, wie besonders Birgit Neumann und Ansgar Nünning deutlich gemacht haben: „[M]etanarration refers to the narrator's reflections on the act or process of narration; metafiction concerns comments on the fictionality and/or constructedness of the narrative.“383 Fokussiert Metafiktion auf die Illusion einer erzählten Wirklichkeit, indem sie diese durchbricht, so kann Metanarration gerade eine Erzählerillusion erzeugen, indem der Erzähler deutlich markiert wird. ${ }^{384}$ Metanarrative Kommentare sind durchaus kompatibel mit der erzählten Welt und können

$380 \quad$ Berns, Abschn. 2.

381 Lucia Ruprecht sieht Performanz bei Robert Walser in drei Bereichen am Werk: Als "identitätskonstituierende Funktion“, gerade hinsichtlich der bei Walser diskutierten Autofiktionen, als Beschreibung der "komplex gesteigerte[n] (Selbst)referentialität" sowie als „Einbettung performativen Handelns in Machtstrukturen“. Lucia Ruprecht, „Performanz", in Robert Walser-Handbuch. Leben - Werk - Wirkung, hg. von Lucas Marco Gisi (Stuttgart: Metzler, 2015), 299f. Hervorhebung i. O.

382 Berns, „Performativity“, Abschn. 21.

383 Birgit Neumann und Ansgar Nünning, „Metanarration and Metafiction“, in The Living Handbook of Narratology, hg. von Peter Hühn u. a. (Hamburg: Hamburg University, 2014), Abschn. 1, https://www.lhn.uni-hamburg.de/node/5o.html.

Vgl. auch: „While metafictional comments foreground or disclose the fictionality of a narrative (e.g., ,Of course, Paul, our hero, is just a character in a novel'), metanarrative comments do not undercut the fabric of the fiction. Rather, they are self-reflexive narrative references to the act of storytelling or to those elements by which a narrative is constituted and communicated (e.g., , It is almost impossible to describe what happened in those pregnant moments'), i.e., narrative utterances about narrative rather than fiction about fiction.“ Ansgar Nünning, „Metanarrative Comment“, in Routledge Encyclopedia of Narrative Theory, hg. von David Herman, Manfred Jahn und Marie-Laure Ryan (London: Routledge, 2010). Hervorhebung i. O.

384 Vgl. dazu Monika Fludernik, die argumentiert, dass dies nur für eine beschränkte Zahl von Erzählungen gelte, nämlich eben solche, die einen deutlich markierten Erzähler aufweisen: „What Nünning is saying in effect is that all narrative is mediated by a teller figure, and that narrative texts purvey not merely an illusion of a fictional world but in addition and not merely secondarily - create the illusion of an act of narration. [...] By contrast, however, there are narratives in which the illusion of a teller figure is not forthcoming (interior monologue novels, radical reflector mode texts, dialogue novels) so that one gets at best the remnants of a narrative discourse without any illusionistic features." Monika Fludernik, „Metanarrative and Metafictional Commentary. From Metadiscursivity to 
darin eine Vielzahl von Funktionen wahrnehmen. ${ }^{385}$ Nünning ordnet diese Funktionen in einem Kontinuum zwischen den Polen illusionskompatibler und illusionsdurchbrechender Metanarration an. ${ }^{386}$

In Robert Walsers Texten ist das ganze Spektrum metanarrativer Kommentierung zu finden. Dabei ist besonders das ambivalente, unverträgliche Nebeneinander von gleichzeitig illusionsstützender und illusionsdurchbrechender Metanarration interessant. Stellen, in denen die Illusion eines Erzählers, der seine Geschichte erfindet, stark gemacht wird, stellt er solchen gegenüber, in denen der Erzähler seine Glaubwürdigkeit und seinen ontologischen Status subvertiert.

\subsubsection{Die Ordnung simultanen Erzählens. Der Spaziergang ${ }^{387}$}

Wie schon bei den Ausführungen zur Digression erwähnt, beginnt Der Spaziergang mit einer Erzählsituation, die einem konventionellen Modell entspricht: Es handelt sich um ein scheinbar nachträgliches Berichten eines Ereignisses. Zwar gibt es Verzögerungen, die jedoch noch keine prinzipiellen Störungen verursachen. Im Folgenden sei der Beginn des Spaziergangs noch einmal

Metanarration and Metafiction", Aufsätze | Poetica. Zeitschrift für Sprach- und Literaturwissenschaft 35 (2003): 36 . Hervorhebung i. O.

385 Vgl. dazu Michael Scheffel, der bezogen auf Thomas Bernhards Korrektur anführt: „Innerhalb eines einzigen Satzes erzählt ein Ich-Erzähler von dem, was seinem Erzählen vorangegangen ist, bis er schließlich den Akt des Erzählens bzw. Schreibens und dessen Bedingungen kommentiert. Die Form der Selbst-Betrachtung ist hier ebenfalls konsistent, die Reflexion bezieht sich unmittelbar auf das Erzählen, ohne die Fiktion einer faktualen Erzählung zu verletzen." Michael Scheffel, Formen selbstreflexiven Erzählens. Eine Typologie und sechs exemplarische Analysen (Tübingen: Max Niemeyer, 1997), 58.

386 Vom Pol der Illusionskompatibilität zu demjenigen der Illusionsbruchbrechung führen der Reihe nach die authentizitätsbezogene, kohärenzstiftende, mnemotechnische, phatische, kommunikative, spannungserzeugende, didaktische, komische, parodistische, poetologische, metafiktionale und illusionsstörende Funktion. Nünning, „Metanarration“, 152.

387 Was hier aus einer theoretischen Perspektive untersucht wird, ist häufig als Schreibszene des ,drauflos Schriftstellerns' (vgl. Meine Bemühungen in SW 20, 429) in den Berner Jahren mit Blick auf die Textgenese beschrieben worden, wie sie Walser in zahlreichen Texten variiert. Benne sieht in Walser einen frühen Vertreter der écriture automatique. Benne, ",Schrieb je ein Schriftsteller so aufs Geratewohl?' Der surrealistische Robert Walser“. Die Reflexion auf den Schreibprozess betont Kammer, Figurationen und Gesten des Schreibens. Zur Ästhetik der Produktion in Robert Walsers Prosa der Berner Zeit. Walt arbeitet den Improvisationscharakter von Walsers Schreibszene heraus. Walt, Improvisation und Interpretation. Wenn performatives Erzählen auch durchaus aus der Improvisation entstehen kann und bei Walser vielfach entstanden sein mag, so ist diese doch nicht Voraussetzung dafür. Die Untersuchung der konkreten Genese eines Textes im Schreibprozess und des Erzählens im Text sind zwei unterschiedliche Perspektiven, die sich weder bedingen noch ausschließen. 
wiedergegeben, dieses Mal in der Fassung aus Seeland, dem Erzählband, der gemäß einem Brief Robert Walsers an den Rascher Verlag die „sechs bedeutendsten Prosaarbeiten aus meinem bisherigen künstlerischen Schaffen hier in Biel“" (BA 1, 444, Nr. 376 vom 1.4.1918) enthält. ${ }^{388}$

Eines Vormittags, da mich die Lust, einen Spaziergang zu machen, ankam, setzte ich den Hut auf den Kopf, lief aus dem Schreib- oder Geisterzimmer weg und die Treppe hinunter, um auf die Strasse zu eilen. Im Treppenhaus begegnete mir eine Frau, die wie eine Spanierin, Peruanerin oder Kreolin aussah und etwelche bleiche, welke Majestät zur Schau trug.

Soviel ich mich erinnere, befand ich mich, als ich auf die offene, helle Strasse trat, in romantisch-abenteuerlicher Gemütsverfassung, die mich beglückte. (KWA I.11, 79)

An diesem Abschnitt wird sogleich deutlich, dass sich die Problematik direkter als in der Fassung von 1917 stellt. Der metanarrative Einschub ${ }_{\text {„ }}[\mathrm{s}]$ oviel ich mich erinnere") hat die Funktion einer Authentizitätsbezeugung. Es soll deutlich gemacht werden, dass das zu erzählende Ereignis, der Spaziergang,

388 Jochen Greven ist gleicher Meinung wie Walser und sieht in Seeland „vielleicht den Höhepunkt seiner gegen die Zeit, gegen einen ihm verdächtigen Modernismus stilisierten Bieler Dichtung“. Greven, „Nachwort des Herausgebers“, 215.

Diese Ankündigung Walsers hat durchaus etwas Trotziges an sich. Teilweise lässt sie sich wohl aus der diffizilen Publikationsgeschichte dieses Buchs erklären sowie aus der für 1919 festzustellenden Intensivierung der Korrespondenz mit zahlreichen Verlagen. Seeland, das wie Poetenleben aus der großangelegten Sammlung Studien und Novellen hervorging, in der über hundert Prosastücke hätten versammelt werden sollen, wurde zunächst vom Huber Verlag, der schon Der Spaziergang und Poetenleben herausgab, abgelehnt. In einem Brief vom 28.3.1918 drängt Walser den Huber Verlag auf eine Entscheidung: „Immerhin finde ich Ihr langes Stillschweigen etwas merkwürdig. Ich bin, vom Standpunkt des Schriftstellers aus verpflichtet, die Sache im Auge zu behalten, Sie werden das begreifen. ,Seeland' muß irgendwie und wo feste Unterkunft finden, und deßhalb bitte ich Sie, nicht mehr gar so lange zu zögern, mich Ihren Entschluß wissen zu lassen [...]. Die Sache geht mich sehr nah an [...]." (BA 1, 441f., Nr. 374) Zwei Tage später schickt der Huber Verlag das Manuskript „zu unserm lebhaften Bedauern“ (BA 1, 443, Nr. 375 vom 30.3.1918) zurück. Am 1.4.1918 bietet Walser das Manuskript dem Rascher Verlag an. Nach längerer Korrespondenz über Illustration und Satz und einiger Verzögerung durch Walsers Bruder Karl, der schließlich die Illustrationen erstellt, erscheint es im Herbst 1920 mit Impressum 1919. Vgl. auch den ausführlichen editorischen Bericht zu Seeland von Sprünglin, „Editorisches Nachwort“.

1919 geht Walser zahlreiche weitere Buchprojekte an: den verschollenen ToboldRoman, die Sammlungen Kammermusik, Komödien und Mäuschen (vgl. BA 1, 597, Nr. 501 vom 23.11.1919) sowie das „Miniatur-Buch“ Liebe kleine Schwalbe (BA 1, 6o1, Nr. 505 vom 13.12.1919) und den ebenfalls nicht realisierten Band Der Blumenstrauß (vgl. BA 1, 573, Nr. 480 vom 4.8.1919). In einem Brief an den Rascher Verlag spricht er von "geradezu bitterer Geldnot“" (BA 1, 557, Nr. 465 vom 8.5.1919). 
ein dem Erzählen vorgängiges Ereignis darstellt. Der Eindruck der Fiktion bzw. Autofiktion wird durch eine deutliche Erzählerillusion gestärkt. ${ }^{389} \mathrm{Im}$ weiteren Verlauf des Spaziergangs werden solche Stellen näher zum illusionsdurchbrechenden Pol rücken. Die metanarrative Gestaltung lässt sich nicht mehr einfach in die Ordnung retrospektiven Erzählens einfügen wie folgendes Zitat, in dem die Funktion der Illusionsunterstützung deutlich durchbrochen wird, zeigt:

Ich wittere einen Buchladen samt Buchhändler, ebenso will bald, wie ich ahne und merke, eine Bäckerei mit Goldbuchstaben zur Geltung kommen. Vorher hätte ich aber einen Pfarrer zu erwähnen. Mit freundlichem Gesicht fährt ein radfahrender, fahrradelnder Stadtchemiker dicht am Spaziergänger vorüber, ebenso ein Stabs- oder Regimentsarzt. Nicht unaufgezeichnet darf bleiben ein bescheidener Fussgänger, nämlich ein reich gewordener Althändler und Lumpensammler. Zu beachten ist, wie Buben und Mädchen frei und ungezügelt im Sonnenlicht umherjagen.

„Man lasse sie ruhig ungezügelt, denn das Alter wird sie leider Gottes einst noch früh genug schrecken und zügeln“, denke ich.

Am Brunnenwasser erlabt sich ein Hund, in blauer Luft zwitschern die Schwalben. (KWA I.11, 8o)

Diese Stelle ist, wie das Präsens anzeigt, auf der Ebene des discourse zu verorten. ${ }^{390}$ Was erzählt wird, scheint jedoch vielmehr die story-Ebene zu betreffen, als dass es sich um metanarrative Aussagen handelt.

In einer Studie zum simultanen Erzählen in der ersten Person Singular beschreibt Dorrit Cohn zwei übliche Strategien, mit denen Passagen im Präsens entschärft werden. ${ }^{391}$ Die eine nennt sie die ,Lösung historisches Präsens‘, die andere ,Lösung innerer Monolog،. Im ersten Fall wird das Präsens so

389 Vgl. zur Autofiktion bei Walser Lucas Marco Gisi, „Der autofiktionale Pakt. Zur (Re-) Konstruktion von Robert Walsers ,Felix'-Szenen“, in „... all diese fingierten, notierten, in meinem Kopf ungefähr wieder zusammengesetzten Ichs". Autobiographie und Autofiktion, hg. von Elio Pellin und Ulrich Weber (Göttingen, Zürich: Wallstein, Chronos, 2012), 55-70.

390 Vgl. dazu Michael Scheffel: „In einer reineren Form aber liegen sie [Formen der Selbstreflexion auf der Ebene des Erzählens; L. G.] vor, sobald ein Erzähler den Erzählvorgang auf Kosten des erzählten Vorgangs vergegenwärtigt, indem er unmittelbar sein Erzählen, seine Erzählung oder das Erzählte reflektiert. In der Regel sind diese Reflexionen mit einem Tempuswechsel vom Präteritum in das Präsens verbunden." Scheffel, Formen selbstreflexiven Erzählens. Eine Typologie und sechs exemplarische Analysen, 566 .

391 Vgl. Dorrit Cohn, „Ich döse und wache‘. Die Normabweichung gleichzeitigen Erzählens“, in Der Präsensroman, hg. von Armen Avanessian und Anke Hennig (Berlin, Boston: De Gruyter, 2013), 125-138. Cohn zeigt plausibel auf, wie das klassische Verständnis im Kern eine Definition der Erzählung als Wiedergabe eines vergangenen Ereignisses (etwa bei Robert Scholes, Paul Ricoeur, Friedrich Stanzel, Käte Hamburger) hat und wie diese Definition Präsenserzählungen nicht erfassen kann. 
naturalisiert, dass es stillschweigend als Vergangenheit gelesen wird. ${ }^{392} \mathrm{Im}$ zweiten wird das Präsens als Ausdruck des fiktiven Bewusstseins der Figur verstanden, das sich unvermittelt artikuliert. Bei Walsers Beispiel funktionieren die Lektürestrategien nicht. Das historische Präsens fällt weg, weil es im Spaziergang schon besetzt ist vom Spaziergänger selbst. Auch um einen inneren Monolog kann es sich nicht handeln, da Gedanken, wie im Zitat ersichtlich, mit den entsprechenden Satzzeichen und der Incipit-Formel wiedergegeben sind.

Es bleibt, auf den discourse statt die story zu fokussieren. Die Stelle kann als metaphorischer metanarrativer Kommentar gelesen werden, in dem das erzählende Ich sich überlegt, was es als Nächstes berichten will. Das ,Wittern` des Buchladens weist darauf hin, dass ebendieser Gegenstand der Erzählung werden wird, was sich anschließend bestätigt. Auch die Verwendung des Konditionals weist in diese Richtung. Anders verhält es sich jedoch mit den Elementen, die eine Handlung darstellen, wie der Radfahrer, die spielenden Kinder und der Hund. Diese befinden sich eindeutig auf der story-Ebene im Präsens.

In der Erstfassung von 1917 wird dieses Verwirrspiel noch verkompliziert, wenn es heißt: „Ein [...] Stadtchemiker fährt [...] dicht am Spaziergänger, nämlich an mir, vorüber" (KWA I.8, 168). Diese Überblendung von Erzählzeit und erzählter Zeit, von Erzählerebene und Figurenebene, also von eigentlich disparaten Ordnungen, wird weiter intensiviert, indem der Gedanke des Erzählers ins Präteritum gesetzt ist - "Man lasse sie [die Kinder] ruhig ungezügelt', dachte ich; ,das Alter wird sie einst schon schrecken und zügeln.“ (KWA I.8, 169) - und so die eigentliche, hier durcheinandergebrachte Nachträglichkeit des Erzählens erinnert, nur um im Anschluss wieder zum Hund im Präsens zurückzukehren.

Armen Avanessian und Anke Hennig versuchen die „Gleichzeitigkeitsaporie“ („Ich kann eine Geschichte nicht gleichzeitig erleben und erzählen“) mit einer Anbindung an die Schreibgenese zu erklären:393

392 „Die Lösung historisches Präsens versteht das Tempus der zitierten Passage nicht als ein reales Präsens, das sich auf die Zeit bezieht, in der die Rede scheinbar stattfindet, sondern als ein metaphorisches ,Als-ob'-Präsens, das für die Vergangenheitsform steht und sich auf die Vergangenheit bezieht." Cohn, 132. Hervorhebung i. O.

393 Avanessian und Hennig zitieren denselben Ausschnitt, geben jedoch fälschlicherweise als Quelle die Erstfassung des Spaziergangs von 1917, statt von 1919 an. Vgl. Armen Avanessian und Anke Hennig, „Die Evolution des Präsens als Romantempus“, in Der Präsensroman, hg. von Armen Avanessian und Anke Hennig (Berlin, Boston: De Gruyter, 2013), 155. Vgl. auch Armen Avanessian und Anke Hennig, Präsens. Poetik eines Tempus (Zürich: Diaphanes, 2012). 
Scheinbar naiv lässt sich gegen die vorgebliche Unmöglichkeit synchronen Erzählens nämlich einwenden: Gibt es eigentlich Einfacheres, als eine Geschichte aufzuschreiben, während man sie sich ausdenkt? Jede Geschichte lässt sich zugleich mit ihrem Erfinden notieren. [...] Es handelt sich hier um eine perfekte Überblendung von Fabel und Sujetgegenwart. [...] Wenn uns der Autor eines Textes erzählt, wie er sich gerade etwas ausdenkt, und selbst darauf gespannt ist, welcher Einfall ihm als nächstes kommen wird, erhält Fiktion eine zeitliche Anbindung an die Gegenwart des Denk- oder Schreibprozesses. Dabei kommt es zu einer Fiktionalisierung des Sujets. ${ }^{394}$

Was Avanessian und Hennig formulieren ist zum einen, dass der discourse zu einer Erzählung wird. Dies lässt an Wolf Schmids Konzept der Erzählgeschichte denken, die er definiert als „die Geschichte des Erzählakts, in deren Verlauf die Präsentation der Erzählung hervorgebracht wird.“395 Die Erzählung ist enthalten in der „Gesamtheit der expliziten Wertungen, Kommentare, Generalisierungen, Reflexionen und Autothematisierungen des Erzählers“. ${ }^{396}$ Diese „Texteinheiten konstituieren nicht die Diegesis (die erzählte Welt), sondern die Exegesis (die Ebene des Erzählens)“. ${ }^{397}$ Sowohl auf der story- als auch auf der discourse-Ebene werden „zwei ganz unterschiedliche Geschichten“ erzählt, nämlich die „präsentierte Erzählung mit der in ihr enthaltenen erzählten Geschichte“ und „die Präsentation selbst, d. h. die sie fundierende Erzählgeschichte“.398 Gemäß seinem Vier-EbenenModell ${ }^{399}$ unterscheidet Schmid auch auf der Exegesis zwischen Erzählgeschehen und Erzählgeschichte: „Fehlen explizite Erzählerkommentare und Autothematisierungen des Erzählers, so haben wir keine Erzählgeschichte, müssen aber grundsätzlich ein (natürlich auch fiktives) Erzählgeschehen ansetzen, ohne das es keine Erzählgeschichte gäbe." ${ }^{400}$ Als Beispiele für eine sehr dominante Erzählgeschichte führt er Laurence Sternes Life and Opinion of Tristram Shandy Gentleman an, in dem die Exegesis die Diegesis überwuchere.

394 Avanessian und Hennig, „Die Evolution des Präsens als Romantempus“, $157 \mathrm{f}$.

395 Schmid, Elemente der Narratologie, 246.

396 Schmid, 246.

397 Schmid, 246.

398 Schmid, 246. Hervorhebung i. O.

399 Wolf Schmid unterscheidet die Ebenen "Geschehen“ als unorganisierte Ereignisse, „Geschichte“, in der die Ereignisse in der natürlichen Ordnung stehen, analog zum ordo naturalis, schließlich die „Erzählung“, in der die Ereignisse in die Reihe ihrer tatsächlichen Vermittlung gebracht werden, analog zum ordo artificialis und schließlich die „Präsentation der Erzählung“, die der medialen Vermittlung entspricht, als das Produkt, das vom Rezipienten erfasst werden kann und wiederum Gérard Genettes „narration“ entspricht. Schmid, 223f. Vgl. auch Martinez und Scheffel, Einführung in die Erzähltheorie, 26.

400 Schmid, Elemente der Narratologie, 246. Hervorhebung i. O. 
Das Gegenbeispiel sieht Schmid in La Jalousie von Alain Robbe-Grillet, in dem die Erzählgeschichte ausgespart ist und das Erzählgeschehen vom Leser rekonstruiert werden müsse.

Erzählgeschichte und erzählte Geschichte widersprechen sich im Fall von Walser und, wie zu sehen sein wird, auch bei Kafka. Vor diesem Hintergrund erscheint die Beschreibung, die Avanessian und Hennig geben, eingeschränkt. Der Spaziergang und weitere, ihre Performanz ausstellende Texte Walsers, bewegen sich nämlich zwischen den Polen eines rekonstruktiven und eines prospektiven discourse hin und her und sind entsprechend instabil. ${ }^{401}$ Walser betreibt tatsächlich eine „Fiktionalisierung des Sujets“, wie Avanessian und Hennig argumentieren, erzählt jedoch auch rekonstruktive Erzählsituationen. Es sind entsprechend beide, eigentlich unvereinbaren Erzählordnungen, die in Walsers Texten aktiviert sind. Für den Spaziergang folgt daraus, ähnlich wie für Kafkas Bau, dass hier eine paradoxe Zeitstruktur am Werk ist. ${ }^{402}$

Diese Aporie wird im Spaziergang mit dem Erwähnen des ,Herrn Verfasser zugespitzt. ${ }^{403}$ Mit dem Hinweis auf diesen wird wieder in die Normalität eines retrospektiven discourse übergeleitet, ohne dass die vorangegangenen ordnungstechnischen Kapriolen Konsequenzen zeitigen. Begleitet wird diese Umstellung der Erzählordnung von einem Exkurs über Hüte, der als poetologische Spiegelung der gerade angewandten narrativen Verfahren gelesen werden darf:

Ferner fallen zwei Sommer- oder Strohhüte auf. Die Geschichte mit den Herrenstrohhüten ist die: in der hellen Luft sehe ich nämlich plötzlich zwei entzückende Hüte; unter den Hüten stehen zwei bessere Herren, die einander mittels kühnen, schönen, artigen Hutschwenkens guten Morgen bieten zu wollen scheinen, was eine Veranstaltung ist, wobei die Hüte sichtlich wichtiger sind als ihre Träger und Besitzer. Man möchte jedoch den Herrn Verfasser sehr ergeben gebeten haben, sich vor Witzen wie sonstigen Überflüssigkeiten ein wenig in acht zu nehmen. Hoffentlich hat er dies ein für allemal verstanden.

$\mathrm{Da}$ mir eine stattliche Buchhandlung überaus angenehm auffiel [...]. (KWA I.11, 81)

401 Den Hinweis auf das Schreiben des Autors erklärt das formale Phänomen genauso wenig, wie es dies bei inhaltlichen Interpretationsschwierigkeiten tut. Es ist ein Wechsel der Perspektive, wie ihn auch Christian Walt mit seinem Improvisations-Konzept vornimmt. Vgl. Walt, Improvisation und Interpretation.

402 Siehe Kap. 4.2 Iteration, Singulation und die prekäre Ordnung der Zeit, S. 224ff. unten.

403 Diese Ansprachen an den Verfasser ziehen sich durch Walsers ganzes Werk, man denke nur an Simon. Eine Liebesgeschichte von 1904. Siehe Kap. 1.1 „Wir, die Erzählung“ - Robert Walsers Simon. Eine Liebesgeschichte, S. 3 ff. oben. 
Die Hüte werden hier zu einem Vermittlungselement, indem sie wörtlich einen Kommunikationsakt vollziehen, nämlich einen guten Morgen wünschen, was eine ähnliche Funktion wie das Erzählen selbst hat. Der Erzähler bemerkt sie vor den Personen, die sie tragen, womit auch in der Figuration des Erzählens der Fokus auf den Akt gelegt wird. Dass das Ganze als „Veranstaltung“ bezeichnet wird, betont den Performanzcharakter zusätzlich. Die Umkehrung der Hierarchie zwischen Herr und Hut im Begrüßungsritual - ähnlich wie bei Professor Meilis Hut auf der vorhergehenden Seite: „Sein Hut glich einem unabsetzbaren Herrscher" (KWA I.11, 80) - zieht eine Maßregelung des „Herrn Verfasser" (KWA I.11, 81) nach sich. Mitzulesen ist die Kritik des Ordnungsliebenden an der Inversion von story und discourse, die durch den Einbezug einer weiteren Ebene (der Verfasser statt der Erzähler) noch einmal verschärft wird. Die Maßregelung scheint Früchte zu tragen: Die anschließende Erwähnung der Buchhandlung ist im Präteritum gehalten und orientiert sich strikt an der story-Ebene.

Ein weiteres Beispiel performativen Erzählens findet sich in der Episode um Frau Aebi, bei der der Spaziergänger zum Mittagessen eingeladen ist. Da das Ereignis in der Mitte des Spaziergangs platziert ist, scheint sie dazu prädestiniert, eine Schlüsselfunktion für die Interpretation des Textes einzunehmen: „Ist je ein Provinz- und Hauptstadtautor gegenüber seinem Leserzirkel schüchterner und höflicher gewesen? Ich glaube kaum, und daher fahre ich mit äusserst ruhigem Gewissen im Erzählen und Plaudern fort und melde folgendes: [...]“ (KWA I.11, 104). Diese Stelle ist ein metanarrativer Kommentar mit parodistischer Authentizitätsfunktion. Durch die Leseransprache wird die Illusion eines Erzählers aufgerufen. Dann heißt es weiter:

Um der tausend Gotteswillen, es ist ja höchste Zeit zu Frau Aebi zu springen, um zu dinieren oder mittag zu essen. Soeben schlägt es halb ein Uhr. Glücklicherweise wohnt mir die Dame in allernächster Nähe. Ich brauche nur glatt wie ein Aal ins Haus hineinzuschlüpfen wie in ein Schlupfloch und wie in eine Unterkunft für arme Hungrige und bedauerliche Heruntergekommene. (KWA I.11, 104f.)

Dies könnten, wären sie im Präteritum formuliert, durchaus angebrachte Gedanken des spazierenden, erzählten Ich sein. Ihm würde einfallen, dass er ja zu Frau Aebi gehen muss. Auf der Ebene des Erzählens birgt das Zitat jedoch dieselben unüberwindlichen Schwierigkeiten für die Integrierung in den Rahmen einer herkömmlichen Weltkonstruktion wie die Episode um die Buchhandlung oben. Wieder folgt der Schwenk zurück auf die erzählte Ebene: „Ohne die mindesten lächerlichen Umstände zu machen, fing ich harmlos an 
$\mathrm{zu}$ essen und zwanglos zuzugreifen, indem ich nicht von weitem ahnte, was mir zu erleben bevorstehe." (KWA I.11, 105)

Die Episode um Frau Aebi modelliert den Selbstbezug des Erzählens. Indem der Erzähler plötzlich auf der story-Ebene in der Weise auftritt, wie es die handelnde Figur, also der Spaziergänger tut, der Erzähler sich also sozusagen im Gewand der Figur präsentiert, wird die Erzählung selbst zum Protagonisten. In einer Art mise en abyme tritt der Erzähler in die Erzählung ein. Erzählen wird so als Akt, der die Erzählung erst erzeugt, dargestellt, von der er dennoch Teil ist. ${ }^{404}$

In der Folge der kognitivistischen Arbeiten von Monika Fludernik ${ }^{405}$, Ansgar Nünning ${ }^{406}$ und Werner Wolf ${ }^{407}$ ist von Seiten der unnatural narratology bei der Analyse solcher Texte, die der herkömmlichen Erzählordnung nicht folgen, der Fokus auf die Durchbrechung der ,natürlichen' Ordnung gelegt worden. ${ }^{408}$ Aus der Perspektive der unnatural narratology ergeben sich aus dem simultanen Erzählen logische Komplikationen: „In contrast to the historical present, FPPT [= First Person Present Tense; L. G.] does not just simulate, but actually is a narration from within the incidents. ${ }^{409}$ Die daraus generierten Irritationen und Aporien gehören zum simultanen Erzählen dazu:

$[\mathrm{O}]$ ne should not overlook the fact that the constant attempt to find reasons and systems is a part of the general game one enters when reading a FPPT-narrated text. In most cases the reader's attempt to interpret is left unresolved, if not downrightly rejected, by the text itself. We could go as far as claiming that this

404 Dass Erzähler und Figur hier im Rahmen der autodiegetischen Anlage der Erzählung dieselbe Person bezeichnen, ändert nichts an der fundamentalen Trennung der Funktionen Erzähler und Figur. Vgl. dazu Wolf Schmid: „Mit der Figur ist der Erzähler nicht als Erzähler, d. h. als erzählendes Ich, sondern nur als erzähltes Ich identisch. [...] Der Erzähler als Träger der Erzählfunktion (als Narrator) wird zur Figur (oder: zu einem Aktor) nur dann, wenn von ihm ein Erzähler höheren Grades erzählt, und eine Figur (ein Aktor) kann nur dann zum Erzähler (Narrator) werden, wenn sie als sekundärer [d. h. in genettscher Nomenklatur: intradiegetischer; L. G.] Erzähler fungiert." Schmid, Elemente der Narratologie, 82f.

405 Monika Fludernik, Towards a „Natural“ Narratology (London: Routledge, 1996).

406 Nünning, „Metanarration“; Nünning, „Mimesis des Erzählens“.

407 Wolf, Ästhetische Illusion und Illusionsdurchbrechung in der Erzählkunst.

408 Siehe Kap. 5.2 ,Natural' Narratology (Fludernik), S. 253ff.; Kap. 5.3 Unnatural Narratology, S. 257 ff. unten.

409 Per Krogh Hansen, „First Person, Present Tense. Authorial Presence and Unreliable Narration in Simultaneous Narration", in Narrative Unreliability in the Twentieth-Century First-Person Novel, hg. von Elke D'hoker und Gunther Martens (Berlin, New York: De Gruyter, 2008), 319, https://doi.org/10.1515/9783110209389.317. Hervorhebung i. O. 
feature is a logical consequence of the FPPT insofar as the basic configuration of the mode manifests an encapsulated resistance towards narrative in general. ${ }^{410}$

Wenn auch Der Spaziergang nur stellenweise in der ersten Person Präsens erzählt ist, ist er doch der produktiven Problematik dieser Form ausgesetzt. Gerade die Frage, was Erzählung und was Erzähltes ist, wird in der Ambivalenz dieser Unterscheidung nachdrücklich gestellt. Das simultane Erzählen ist denn auch eine Form, die vielfach für prekäres Erzählen qualifiziert: Der Ursprung der Erzählung, die Position der Sprechposition, mithin die Unmöglichkeit, eine nachvollziehbare, widerspruchsfreie Erzählgeschichte aus diesen Voraussetzungen zu konstruieren, stellt eine prekäre Rahmung dar. Dieser unsichere Status des Erzählens wird zum produktiven Antrieb der paradoxen Ordnung, die nicht fixiert werden kann, weil sie stets im Prozess ist. ${ }^{411}$

\subsubsection{Performanz und Wahnsinn. Die grüne Spinne}

Eine Erzählung, die ihre eigene Performanz exemplarisch beleuchtet, ist Die grüne Spinne. Der Text ist nur in einer Mikrogrammfassung überliefert, die Walser vermutlich zwischen Herbst 1924 und Frühling 1925 notiert hat. ${ }^{412}$ Veröffentlichungen und Abschriften sind keine bekannt. Der Text beginnt mit der Konstituierung seiner Erzählszene:

410 Krogh Hansen, 335 .

411 Henrik Skov Nielsen hat das Konzept der „Unpersönlichen Stimme“ entwickelt, mit dem er Erzählerstimmen jenseits des konventionellen Konzepts eines anthropomorphen Erzählers fassen will. Vgl. Henrik Skov Nielsen, „The Impersonal Voice in First-Person Narrative Fiction“, Narrative 12, Nr. 2 (2004): 133-150.

412 Die grüne Spinne ist auf dem Mikrogrammblatt 26o recto niedergeschrieben; auf dem Kunstdruckblatt sind zwei weitere Texte etwa gleichen Umfangs notiert, die in keinem deutlichen Bezug zueinanderstehen und für meine Belange entsprechend vernachlässigt werden können. Was bei anderen Mirkogrammen häufig der Fall ist - dass die benachbarten Texte ineinander übergehen, Motive sich durch parallele Lektüren erschließen oder der Text Begebenheiten des Papiers aufnimmt -, ist hier also nicht der Fall. Diese Mikrogramme gehören zu den frühsten überlieferten Mikrogrammen. Vgl. Angela Thut, Christian Walt und Wolfram Groddeck, „Editorisches Nachwort“, in Robert Walser. Kritische Ausgabe sämtlicher Drucke und Manuskripte, hg. von Barbara von Reibnitz und Wolfram Groddeck, Bd. VI.1: Mikrogramme 1924/25, hg. von Angela Thut, Christian Walt und Wolfram Groddeck (Frankfurt am Main, Basel: Stroemfeld, Schwabe, 2016), 389; Bernhard Echte und Werner Morlang, „Editorische Vorbemerkung“, in Aus dem Bleistiftgebiet, hg. von Bernhard Echte und Werner Morlang, Bd. 1: Mikrogramme 1924/25, 6 Bde. (Frankfurt am Main: Suhrkamp, 1985), 5-8. Überschreibungen und Streichungen, die in der KWA detailliert aufgeführt sind, werden der einfacheren Lesbarkeit nicht wiedergegeben. 
Es wird gewesen sein, daß es zwei Uhr nachmittags war und zwar in einer denkbar kostbar möblierten Wohnung, deren Ausstattung rein aus Damast bestanden haben mag Es ist ausgeschlossen, daß ich weiß, was eigentlich Damast ist, es genügt, daß ich davon irgendeinmal in irgendeinem Buche las und schnoberte. Es ist herrlich, wie ich das zugebe, so frei und offenmütig und wie ich nun unumwunden eine grüne Spinne in's Logis setze, denn sie fällt mir gerade in die sieben Sinne, derer ich durchaus nach wie vor mächtig bin, obwohl ich mich hie und da zum reinen Vergnügen wahnsinnig geberde, gleichsam in den Samt des vornehmsten Unverstandes hülle, indem mich mitunter der gesunde Verstand langweilt. Es ergibt sich, daß die grüne Spinne, deren Haar von der Farbe der Löwen war und deren Augen tückisch, hinterlistig schillerten, gleich grünen und unergründlichen Steinen, und die Arme besaß, die mit rötlichen Punkten übersät schienen, und auch in der Tat gewesen sind oder geschienen haben zu sein, einen bezaubernd jungen schönen edlen angesehenen und nochmals jungen und vielversprechenden Menschen dicht unter sich hatte, will sagen sanft leitete und bannte. (KWA VI.1, 12f.)

Die Anfangszeilen verdeutlichen den Prozess des Erzählens: Auch hier ist eine „Fiktionalisierung des Sujets“ festzustellen, wie Avanessian und Hennig dies in Bezug auf den Spaziergang formuliert haben. ${ }^{413}$ Die Art und Weise, wie dies geschieht, ist jedoch noch einmal zugespitzter, wird hier das Sujet (der discourse) gleichzeitig zur story, indem es die Genese derselben aus der spontanen Einbildungskraft verfolgt. Die Formulierung des Erzählers, dass ihm die Spinne in die „sieben Sinne“ fällt, lässt sich als Metapher für einen Einfall verstehen, den der Erzähler sogleich ins „Logis“ der Fiktion, einbaut. Die Fiktion wird um den Einfall der Spinne herum aufgebaut. Es ist ein Erzählen am Werk, das simultan erzählt, wie eine simultane Erzählung entsteht. Deshalb rückt der Text diese Form des Erzählens in den Zusammenhang mit Wahnsinn, weil darin die Grenzen zwischen den narrativen und innerfiktionalen Ebenen unbekümmert übertreten werden. Bildbereiche der Spinne und ihrer Netze, dem Ekel und der Angst davor sind mit Wahnsinn konnotiert. ${ }^{414}$ Aus den "sieben Sinne[n]" heraus erzeugt der Erzähler eine Wirklichkeit, die keine konsistente Differenzierung zwischen den narrativen Ebenen, textinterner Fiktion und Fakt zulässt. Der Einfall der Spinne, zuerst deutlich der Ebene des Erzählers zugeteilt, verschiebt sich unkommentiert auf die Ebene des Erzählten. Nach der Schilderung einer Dreiecksgeschichte, wie sie Walser auch im „Räuber“Roman und in anderen Prosastücken und Briefen wiedergibt, wird wiederum der Erzählakt mittels eines metanarrativen Einschubs betont.

413 Avanessian und Hennig, „Die Evolution des Präsens als Romantempus“, 158.

414 Vgl. etwa die Bedeutung von Spinnen, Spinnennetzen und das Spinnen von Fäden in Friedrich Glausers Matto regiert (1937). 
Es ist doch hoffentlich wahr, was ich da schreibe, sonst hole mich die grüne Spinne [...]. Die riesig hohen Fenster schimmerten nachts in einer Pracht, wie mein Mund und sein bescheidenes Werkzeug, meine angestammte Sprache, es nicht zu beschreiben und hervorzustammeln vermögen. (KWA VI.1, 13)

Die grüne Spinne, die hier noch „mythische“ Figur ist, wird später zu einer Figur, die tatsächliche Wirkung haben mag, wenn es heißt: „Grüne Spinne, du bist die Erotik, über die ich mich auftragsgemäß lustig mache, obwohl nicht gern. Sie umgarnt auch mich." (KWA VI.1, 13) Die Elemente und Motive des Textes werden, als wären sie materiell, bearbeitet, umhergeschoben und behalten für den Moment doch ihre Stabilität. Wie beim Handwerk hinterlässt die Schrift immer eine Spur der Bearbeitung. Bei Walser weist diese Spur auf den Akt des Erzählens als Hersteller der Erzählung hin. ${ }^{415} \mathrm{Zu}$ diesem Fokus auf die Herstellung passt die Frage, woher das Material dazu stammt, rufen doch die auffälligen Textilmetaphern geradezu zur Intertextualität auf. ${ }^{416}$ Die grüne

415 Vgl. zur Bedeutung der Spur bei Robert Walser Lucas Marco Gisi, „Vom Verschwinden des Autors. Robert Walsers Spuren“, Études Germaniques 285, Nr. 1 (2017): 91-109, https://doi. org/10.3917/eger.285.0o91. Zu Walsers Arbeitsweise: Jochen Greven, „Indem ich schreibe, tapeziere ich.' Zur Arbeitsweise Robert Walsers in seiner Berner Zeit", in Bildersprache, Klangfiguren. Spielformen der Intermedialität bei Robert Walser, hg. von Anna Fattori und Margit Gigerl (Paderborn: Wilhelm Fink, 2008), 13-31.

416 Curt Johannes Brauns Kriminalroman Die grüne Spinne, in dem Detektiv Frank Gordon einen rätselhaften Fall lösen muss, ist 1921 erschienen und bildet mit großer Wahrscheinlichkeit den intertextuellen Hintergrund: Curt Johannes Braun, Die grüne Spinne, Kleine Kriminal-Bücher 119 (Dresden: Mignon-Verlag, 1921). Der Titel wird auch in Die Stadt, einem unveröffentlichten Manuskript, von Greven auf die Jahre 1932/1933 datiert, erwähnt. Darin hat dem Protagonisten die „Büffetdame des Gasthofes, worin er vorübergehendermaßen logierte“ das „vermutlich spannend geschriebene Buch“ geschenkt (SW 20, 118). Die geschilderte Stadt weist sowohl Reminiszenzen an Biel wie an Bern auf: Beide Städte verfügen mit Magglingen und dem Gurten über hochgelegene Orte bzw. Hügel, zu denen Standseilbahnen führen, und wo auch großzügige Hotelanlagen stehen, wobei Biel mit dem „sogenannten Jägerschlößchen [...], einem gotisierenden Haus" (SW 20, 118) deutlicher hervortritt. Wenn es sich, wie es wahrscheinlich ist, um Brauns Kriminalroman handelt, kann allerdings mit der „Herberge“, in der ihm das Buch überreicht wurde, nicht das Hotel Blaues Kreuz gemeint sein, in dem Walser von 1913 bis 1920 in Biel logierte, da der Roman erst 1921 erschien, es sei denn, das Impressum ist nachdatiert. Wertet man das Alter der Unterkunft, laut dem Erzähler „aus dem sechzehnten Jahrhundert" (SW 20, 119), höher, so rücken die Adressen und die Zimmervermieterinnen in der Berner Altstadt wieder in den Fokus. Schließlich mag man auch einen Bezug zur fantastischen Horrorgeschichte Die Spinne des erfolgreichen Schriftstellers Hanns Heinz Ewers sehen, in der eine rätselhafte Frau, die sich als Spinnenwesen herausstellt, Besitz von den Pensionären am Fenster gegenüber ergreift und sie mit ihrem Blick dazu bringt, sich am Fensterrahmen zu erhängen. Die Spinne erschien 1908 in einer Beilage des Berliner Tageblatts und in Ewers in zahlreichen Auflagen gedruckter Sammlung Die Besessenen, jedoch nie als Titel auf einem „Büchlein“ (SW 20, 118). Vgl. Hanns Heinz 
Spinne ist eine Geschichte darüber, wie aus dem Erzählen, aus einem sprachlichen Akt, Wirklichkeit werden kann, die eben doch Sprache bleibt. Dieses performative Verfahren wird vorgeführt, in Figurationen abgebildet und als Geschichte erzählt.

\subsection{Figurationen des Erzählens}

Nach den narratologischen Analysen soll im Folgenden in einer rhetorischen Analyse herausgearbeitet werden, wie das Erzählen in Figurationen gefasst wird, die ihrerseits prekär sind. ${ }^{417}$ Wie beim „heißen Brei“ steht bei Robert Walser eine solche Figuration des Erzählens häufig im Zentrum eines Textes oder einer Episode. Wenn die folgenden Ausführungen über die Figurationen auf das Essen fokussiert sind, so ist doch festzuhalten, dass Walser eine Vielzahl solcher Metaphern auf das Erzählen bezieht. Die größte Aufmerksamkeit wurde bisher dem Spazieren als poetologischer Metapher geschenkt. ${ }^{418}$ Weitere Motive und Bilder, auf die hier nicht eingegangen wird, betreffen das Wasser (die plaudernden und plätschernden Bäche als Bilder für den prekären Erzählfluss), das Handwerk (Schustern und Hobeln der Texte), ${ }^{419}$ den Komplex Erotik, Anziehung und Liebe, ${ }^{420}$ das Schreiben und die Schrift, ${ }^{421}$ das Horchen und Hören, ${ }^{422}$ das Textile und Metaphern des Wahnsinns, wie es bereits in der

Ewers, „Die Spinne“, in Die Besessenen. Seltsame Geschichten, 8. Aufl. (München, Leipzig: Georg Müller, 1913), 99-146. Auch Jeremias Gotthelfs Schwarze Spinne wurde zwischen 1915 und 1925 in verschiedenen Verlagen neu aufgelegt. Naheliegend scheint, dass Walser verschiedene Quellen und Erinnerungen zusammengeführt hat, so dass der Ursprung unkenntlich gemacht wird. Zu Walsers Materialbasis der Berner Zeit vgl. Walt, Improvisation und Interpretation, 81-86.

417 Stephan Kammer fokussiert auf das Schreiben als Textproduktion und orientiert sich weniger am Erzählen. Vgl. Kammer, Figurationen und Gesten des Schreibens. Zur Ästhetik der Produktion in Robert Walsers Prosa der Berner Zeit.

418 Vgl. Albes, Der Spaziergang als Erzählmodell; Niccolini, Der Spaziergang des Schriftstellers; Pestalozzi, „Spazieren und Schreiben. Franz Kafka ,Der plötzliche Spaziergang“ und Robert Walser ,Der Spaziergang'“; Rothemann, Spazierengehen - Verschollengehen. Zum Problem der Wahrnehmung und der Auslegung bei Robert Walser und Franz Kafka; Stefani, Der Spaziergänger.

419 Vgl. etwa in Eine Art Erzählung: „Bin ich gut aufgelegt, d.h. bei guter Laune, so schneidere, schustere, schmiede, hoble, klopfe, hämmere oder nagle ich Zeilen zusammen, deren Inhalt man sogleich versteht. Man kann mich, falls man Lust hiezu hat, einen schriftstellereden Drechsler nennen. Indem ich schreibe, tapeziere ich." (SW 2O, 322)

420 Hierfür grundlegend: Hobus, Poetik der Umschreibung.

421 Grundlegend dafür: Baßler, Die Entdeckung der Textur; Kammer, Figurationen und Gesten des Schreibens. Zur Ästhetik der Produktion in Robert Walsers Prosa der Berner Zeit.

422 Dies hat insbesondere Peter Utz erarbeitet: Utz, Tanz auf den Rändern. 
obigen Lektüre von Die grüne Spinne zur Sprache kam. Diese Motive sind vielfach miteinander verknüpft, wie etwa in der Grünen Spinne, wo das Textile mit Schrift und Erotik zusammenhängt, und erzeugen redundante Metaphorisierungen. ${ }^{423}$ Es wird zu sehen sein, wie die formalen Eigenschaften der Performanz und Digression, mithin das prekäre Erzählen auch in den Figurationen des Essens deutlich werden.

Grundlage für die Analyse der Erzählfiguration des Essens sind Briefe und Texte aus allen Werkphasen. So lässt sich auch erahnen, wie sich diese Figurationen entwickelt haben. Anders als im vorangehenden Teil wird die Auseinandersetzung nicht mehr primär narratologisch geführt, sondern auf die inhaltlichen Bedeutungsbeziehungen fokussiert. Die Erkenntnisse zu den narrativen Eigenheiten Walsers gilt es dabei mitzudenken, sind seine Erzählfigurationen ja Figurationen zum oben untersuchten Erzählen und nehmen bloß eine andere Perspektive auf die Erzählverfahren ein. Es wird zu sehen sein, wie die formalen Eigenschaften der Performanz und Digression, mithin das prekäre Erzählen auch in den Figurationen des Essens deutlich werden.

Zunächst wird anhand eines frühen Briefes an Walsers Schwester Lisa die Inszenierung des Gegensatzes von Essen und Schreiben herausgearbeitet. Mit der Episode um Frau Aebi aus dem Spaziergang und Walsers Briefen an Frieda Mermet wird ein zweiter Antagonismus von Überessen und Hunger thematisiert. Schließlich kommt mit dem Prosastück Auflauf (1929) ein Beispiel einer kompletten Vermengung von Essen und Schreiben in den Blick.

\subsubsection{Hunger und Erzählen. Vom Briefeschreiben}

Ich habe Hunger! Und immer, wenn ich Hunger habe, gelüstet es mich, einen Brief zu schreiben! An irgend jemand! Das ist doch begreiflich! Mit gefülttem Magen denke ich nur an mich, nie an jemand anders! Mit gefülltem Magen bin ich also glücklicher! Denn das ist doch kein Glück, sich nach etwas Fernem zu sehnen! Nun bin ich an dem Punkt, worüber ich in diesem grünen Brief mit dir reden möchte, sehr gern, wenn ich nur könnte. (BA 1, 16, Nr. 5 vom 30.7.1897)

423 Eine Ausnahme stellen Roser und Schuller dar: Dieter Roser, Fingierte Mündlichkeit und reine Schrift. Zur Sprachproblematik in Robert Walsers späten Texten (Würzburg: Königshausen \& Neumann, 1994), 80-97; Marianne Schuller, „Robert Walsers Poetik des Winzigen. Ein Versuch“, in Robert Walsers „Ferne Nähe“. Neue Beiträge zur Forschung, hg. von Wolfram Groddeck u. a., 2007, 74-81; Marianne Schuller, „Zwischen Brief und Literatur. Zu Robert Walsers Korrespondenz mit Frieda Mermet“, Vorträge der Robert Walser-Gesellschaft 11 (2009): 16-27. Sowie Iris Denneler, „Erzähle ich eine Geschichte, so denke ich ans Essen. Zur kulinarischen Poetologie Robert Walsers", Wirkendes Wort. Deutsche Sprache und Literatur in Forschung und Lehre 49, Nr. 1 (1999): 46-62; Peter von Matt, „Wer hat Robert Walsers Briefe geschrieben?“, in „Immer dicht vor dem Sturze ... “Zum Werk Robert Walsers, hg. von Paolo Chiarini und Hans Dieter Zimmermann (Frankfurt am Main: Athenäum, 1987), 98-105. 
In diesem Brief an seine Schwester Lisa, den Robert Walser aus Zürich schreibt, wo er sich nach einem rund einjährigen Aufenthalt in Stuttgart aufhält, wird eine Aporie zwischen Schreiben und Glück geschildert. Nur mit dem Mangelgefühl des Hungers, so schreibt Walser, empfindet er Sehnsucht „nach etwas Fernem“, dessen Ausdruck schließlich das Schreiben ist. An wen dieses Schreiben adressiert ist, scheint in der Argumentation keine Rolle zu spielen, wichtig ist ausschließlich, dass geschrieben wird. Essen als Befriedigung des Hungers kommt so gewissermaßen einer Alternative zum Schreiben gleich: entweder essen oder schreiben. Die Sehnsucht ist zwar kein Glück, jedoch durchaus wünschenswert, wie im Verlauf des Briefes argumentiert wird.

Hunger als körperliche Metapher für Sehnsucht löst sozusagen den geistigen Hunger aus, der, wie angedeutet wird, mit Schreiben gestillt wird. Schreiben ist der Sehnsucht insofern verwandt, als es beim Schreiben auch um ein Imaginieren von Dingen geht, die ihrerseits ,fern' sind. Schreiben ist nicht Mittel zum Zweck, der Adressat des Briefes ist irrelevant, sondern auf die Tätigkeit des Briefeschreibens als Form der Kommunikation ausgerichtet. Der körperliche Hunger als Ursprung des Schreibens stellt eine kecke Ironisierung des hehren Dichtens „sehnsüchtige[r] Lieder“ (BA 1, 17) dar.

In seiner dreifachen Charakterisierung der Sehnsucht hebt Walser die Künstlichkeit derselben hervor: Die Sehnsucht sei „erstens etwas Ueberflüssiges, zweitens etwas Begreifliches und drittens etwas Unbegreifliches" (BA 1, 16). ${ }^{424}$ Überflüssig ist die Sehnsucht, weil sie eine Belästigung darstellt und keine Möglichkeit zur Überwindung dieses Zustandes trägt. ${ }^{425}$ Unbegreiflich ist die Sehnsucht, „weil so viele Menschen ohne sie, die Ueberflüssige, nicht leben können, weil so viele Menschen Sehnsucht betreiben, in Sehnsucht vergehen und nicht aus der Sehnsucht herauskommen, ja sogar darin eine Art Süssigkeit fühlen." (BA 1, 16)

424 In dieser dreiteiligen Figur kommt man nicht umhin, an Kafkas vielzitierte Wendung der drei Unmöglichkeiten des deutschjüdischen Schreibens zu denken. Vgl. Kafkas Brief an Max Brod vom Juni 1921: Max Brod und Franz Kafka, Eine Freundschaft, hg. von Malcolm Pasley, Bd. 2: Briefwechsel, 2 Bde. (Frankfurt am Main: Fischer, 1989), 36o. Vgl. dazu Gilles Deleuze und Félix Guattari, Kafka. Für eine kleine Literatur [franz. 1975], übers. von Burkhart Kroeber, 8. Aufl. (Frankfurt am Main: Suhrkamp, 2012), 24.

425 Marianne Schuller weist darauf hin, dass im Überflüssigen auch Überfluss mitzuhören sei: „Wenn Sehnsucht etwas Überflüssiges genannt wird, so ist darin zugleich auch der Überfluss, also das Gegenteil von Mangel, mitzuhören. Sind also in der Sehnsucht Mangel und Überfluss verschränkt, so setzt sich die Schleife von Hunger und Brief wieder und wieder in Gang: Weil die Sehnsucht das ist, was nicht gestillt werden kann." Schuller, „Zwischen Brief und Literatur. Zu Robert Walsers Korrespondenz mit Frieda Mermet“, 2o. Allerdings ist es ja gerade der Hunger, der erst die Sehnsucht auslöst. Weiter beachtet Schuller auch die anderen Bestimmungen des Begreiflichen und Unbegreiflichen nicht explizit. 
Walser betont, dass Sehnsucht etwas Konstruiertes ist: Sehnsucht wird ,betrieben', ihr liegt ein aktives Herstellen eines Mangels zugrunde, worin wiederum der Genuss liegt. Das Paradoxe an der Sehnsucht liegt gemäß seinem Brief darin, dass die Sehnsucht ein Mangel ist, dessen Abwesenheit ebenfalls ein Mangel wäre. Hier wird keine Theorie der Sublimierung formuliert, die einen Mangel im künstlerischen Akt in ein Kunstprodukt überführt. Auch am Ende des Briefes ist der Hunger noch da, wie Walser - nach dem Bescheid, es sei „für heute [...] genug!“ - deutlich schreibt:

Ach, was soll ich zu Nacht essen? Schwierige Frage in solch traurigen Fressverhältnissen! Siehe, da nützt einem die Sehnsucht auch nichts. Oder verhilft mir die Sehnsucht nach einem saftigen Braten und einem Glas Veltliner zu beiden? Macht die Sehnsucht etwa, daß ich nicht so langweiliges Zeug zu fressen kriege, wie es der Fall ist? Die That allein kann hier helfen! (BA 1, 17, Hervorhebung i. O.)

Das Schreiben hat den Hunger nicht getilgt, sondern höchstens aufgeschoben. Während des Aufschubs des Essens ist eine Verschiebung eingetreten: Es ist nicht mehr so, dass der unbedingte Hunger („Ich habe Hunger!“) als solcher bestehen bleibt. Nicht mehr nur die Form ist wichtig, sondern auch der Inhalt. Das vorhandene Essen wird als langweilig empfunden. Was in den Worten der „traurigen Fressverhältnisse[]“ und dem Ruf nach der „That“ anklingt, ist Walsers damalige Sympathie für den Sozialismus. ${ }^{426}$ Jedoch ist die frühe Lyrik,

426 Im Brief vom 3.3.1897 erkundigt sich Walser nach einer Stelle bei der sozialistischen Zeitschrift Arbeiterstimme: „Nun meine ich, wenn ich bei Ihnen arbeitete, sei's noch so geringe Sache, wüßte ich doch, es hätte einen Wert und ein Verdienst. Kurz gesagt, ich möchte zu gerne, einer Partei dienen, der mein ganzes Herz angehört; und ich würde mir ganz gewiß durch Treue und Fleiß und Eifer Ihre Zufriedenheit erringen können." (BA 1, 11, Nr. 1 vom 3.3.1897) Später schickt er Robert Seidel das Gedicht mit dem vielsagenden Titel Zukunft! zum Abdruck (BA 1, 14f., Nr. 4 vom 10.6.1897) Vgl. auch: Markus Bürgi und Katharina Kerr, „Die drei frühesten bisher bekannten Briefe Robert Walsers und ein Gedicht aus der Zeit seines ersten Zürcher Aufenthaltes", in Robert Walser zum Gedenken. Aus Anlaß seines 20. Todestages am 25. Dezember 1976. Im Auftrag des Robert Walser-Archivs der Carl Seelig-Stiftung Zürich, hg. von Elio Fröhlich und Robert Mächler (Zürich und Frankfurt: Suhrkamp, 1976), 14-43.

Eine ähnliche Gegenüberstellung von Handlung und Reflexion findet sich später auch in Simon. Eine Liebesgeschichte, wo Aggapaia, der Ehemann der Herrin, am Ende handlungsunfähig wird: „Er klebt an seiner Überlegung fest.“ (SW 2, 22) Siehe Kap. 1.1.1 Performanz als Ordnungsverfahren, S. 6ff. oben.

Auch bei Franz Kafka wird der gegenseitige Ausschluss von Handeln und Reflexion in Der Bau wichtig werden. Siehe Kap. 4.1.3 Der panische Plan und die geplante Panik, S. $216 \mathrm{ff}$. unten. 
abgesehen vom kämpferischen Zukunft!, eher melancholisch. ${ }^{427}$ Die "traurigen Fressverhältnisse[]" führen bei Walser selbst bekanntlich nicht zur "That", sondern zum Schreiben, zur Proliferation der Sehnsucht nach dem Fernen. Die „That" entfaltet sich im Erzählen, gerade auch insofern als dieses in seiner performativen Anlage selbst tätig wird.

\subsubsection{Stücklein essen mit Frau Aebi und Frieda Mermet}

Die Episode um Frau Aebi findet sich ziemlich genau in der Mitte des Spaziergangs und verdient durch diese zentrale Position besondere Beachtung. ${ }^{428}$ Durch die Überblendungen von erzählter Zeit und Erzählzeit kann die Szene als mise en abyme der ganzen Erzählung gelesen werden, in die der Erzähler bloß "glatt wie ein Aal [...] hinein zu schlüpfen“ braucht (KWA I.8, 192). Die Episode schildert das mehrfach angekündigte Mittagessen, in dem der Spaziergänger angehalten wird, immer weiter zu essen, obwohl er längst satt ist. Am Schluss will er fliehen, worauf ihm Frau Aebi erklärt, dass sie „sich einen Scherz mit mir erlaubt habe, den ich so gut sein solle, ihr nicht übel zu nehmen“" (KWA I.8, 194). Schließlich reißt sich der Spaziergänger los, hin zu seinem nächsten Abenteuer, das ihn zum Schneidermeister Dünn führen wird. 429

Die Episode lässt sich, vergleichbar mit der Szene um den Riesen Tomzack, als ein Ausweichen vor der schematischen Vorlage der Abenteuergeschichte lesen. Statt eines Kampfes stellt Frau Aebi, die im Schema der Abenteuergeschichte die Rolle des Antagonisten einnehmen würde, das Ganze als Scherz dar. ${ }^{40}$ Die Erzählung weicht sozusagen in die Parodie aus. Der Fokus soll im

427 Vgl. dazu Marc Caduff, der sich mit dem Frühwerk Robert Walsers unter dem Schlagwort der Revision auseinandersetzt: „Das lyrische Frühwerk Walsers [...] ist von einer durch vielerlei Widerstände ausgelöste melancholische Grundstimmung charakterisiert, die sich mit den intertextuellen Verweisungszusammenhängen als revisionäre Poetik beschreiben lässt. Dabei entwickelt sich mit der Reflexion des Mangels als Bedingung eine kreative Spannung, die wiederum einen produktiven Prozess in Gang setzt." Caduff, Revision und Revolte, 55. Bemerkenswert ist, dass sich diese Figur des Mangels, die die Produktion in Gang setzt, auch im hier besprochenen Brief zeigt.

428 Siehe Kap. 3.2.4 Digression als Aufschub, Ausweichen und Abweichen, S. 125ff.; Kap. 3.3.2 Die Ordnung simultanen Erzählens. Der Spaziergang, S. 17off. oben.

429 Auch dieses Abenteuer ist poetologisch überformt: Im Streitgespräch darüber, ob der Anzug passt, der Schnitt den Spaziergänger gut kleide oder nicht, reflektiert der Text auf das eigene Verhältnis von Form und Inhalt.

430 Claudia Albes liest die Szene psychologisch als Doublebind-Situation, in der die Worte Frau Aebis als „Wahrheit oder als Lüge aufzufassen sind“. Albes, Der Spaziergang als Erzählmodell, 263. Auch versucht sie, die Begegnung realistisch zu lesen. Sie nimmt den Moment, als „Frau Aebi am Wahrheitsgehalt der Beteuerung ihres Gastes zweifelt“, dass dieser satt sei, zum Ausgangspunkt ihrer Lektüre, die die Begegnung realistisch zu lesen 
Folgenden jedoch auf die Überblendung der Motive Essen, Erzählung und Lesen gelegt werden. Um den Zusammenhang dieser Elemente deutlich zu machen, ist es nötig, etwas ausführlicher aus der Episode zu zitieren.

Ohne die mindesten lächerlichen Umstände zu machen, fing ich harmlos und zwanglos an zu essen und wacker zuzugreifen und ahnte nicht von weitem, was mir zu erleben bevorstand. Ich fing also an, wacker zuzugreifen und tapfer zu essen. [...] Als ich plaudern und Unterhaltung machen wollte, wehrte mir Frau Aebi ab, indem sie sagte, daß sie auf jederlei Unterhaltung mit der größten Freude verzichte. Das seltsame Wort machte mich stutzig, und es begann mir angst und bang zu werden. Ganz im geheimen fing ich an, vor Frau Aebi zu erschrecken. Als ich aufhören wollte, abzuschneiden und einzustecken, weil ich deutlich fühlte, daß ich satt sei, sagte sie mir mit fast zärtlicher Miene und Stimme, die ein mütterlicher Vorwurf leise durchzitterte: „Sie essen ja gar nicht. Warten Sie, ich will Ihnen hier noch ein recht saftiges, großes Stück abschneiden." Ein Grauen durchrieselte mich, und ich erkühnte mich, höflich und artig einzuwenden, daß ich hauptsächlich hergekommen sei, um einigen Geist zu entfalten, worauf Frau Aebi unter einem liebreizenden Lächeln sagte, daß sie das keineswegs für nötig halte. „Ich vermag unmöglich, weiter zu essen“, sagte ich dumpf und gepreßt. Ich war schon nahe am Ersticken und schwitzte bereits vor Angst. Frau Aebi sagte: „Ich darf unmöglich zugeben, daß Sie schon aufhören wollen, abzuschneiden und einzustecken, und nimmermehr glaube ich, daß Sie wirklich satt sind. Sie sagen ganz bestimmt nicht die Wahrheit, wenn Sie sagen, daß Sie bereits am Ersticken seien." (KWA I.8, 193f., Hervorhebung L. G.) ${ }^{431}$

Auf diese Art und Weise wird die Geschichte noch zwei Seiten weitergesponnen. Repetitiv werden dieselben Wörter gebraucht und immer wieder die Wendung ,Stück' vorgebracht. Das Stück oder Stückli ist jedoch bei Walser, wie unter anderem an den Briefen an Frieda Mermet gezeigt werden kann, immer auch das ,Prosastücklí. Vor diesem Hintergrund stellt sich die Frage nach der Bedeutung dieser Episode noch drängender. Ist das Essen der Stücke mit dem Verfassen derselben verknüpft? Ist damit, wie in der traditionellen Metapher vom Lesen als Essen, die Walser auch vielfach verwendet, die Lektüre eigener Texte gemeint?432 Und wie hängen diese Optionen mit der

versucht und sich entsprechend fragen muss, wie Frau Aebi die Sattheit ihres Gastes übersehen könne. Albes, 26o. Die Auflösung, dass alles ein Scherz gewesen sei, liest sie hingegen als Hinweis auf den „,ironische[n] Erzähler, dessen Aussagen darum nie wörtlich genommen werden können, weil er ständig und blitzschnell zwischen einem Zustand scheinbarer Authentizität und einem Zustand reflexiver Distanz zu sich selbst hin und her wechselt." Albes, 266.

431 An dieser Stelle wird wieder aus der Erstfassung von 1917 zitiert, da die Überblendung deutlicher hervortritt.

432 Bei Walter Benjamin, der Walser bekanntlich sehr schätzte, heißt es in den Denkbildern: „Romane zum Beispiel sind dazu da, verschlungen zu werden. Sie lesen ist eine Wollust 
Sattheit des Ich zusammen? Zu guter Letzt erschwert auch das weitere Verhalten der Figuren die Interpretation - was hat es mit der Verweigerung des Plauderns von Frau Aebi auf sich? Und wie hängt diese Verweigerung mit der ,plaudernden`Erzählweise des Spaziergangs zusammen?433

Eine adäquate Lektüre muss darauf aufbauen, die enge Verknüpfung der verschiedenen Figurationen zu betonen, so dass Essen, Lesen und Schreiben zusammenfallen und nicht mehr systematisch auseinandergehalten werden können. Diese stehen in einem poetologischen Zyklus, in dem das Schreiben der Stücke die Lektüre derselben voraussetzt. Vor dem Hintergrund dieser asystematischen Ordnung ist auch Frau Aebis Ablehnung des Plauderns zu sehen. Das Plaudern auf der Ebene der handelnden Figur soll zugunsten des Plauderns des Prosastücks aufgegeben werden: Nicht die Figur soll sprechen, sondern das Prosastück selbst soll Unterhaltung machen. Dieses artikuliert sich in den vielfachen Nennungen des Stücks - eine prekäre Figuration, die einmal mehr die Performanz des Erzählens betont.

Der Spaziergänger erstickt jedoch beinahe an den vielen Prosastücken, die ihm vorgesetzt werden, die er produzieren und lesen muss. Die „Hausfrauen [...], die vor Liebenswürdigkeit gegenüber ihren Gästen fast überfließen“ (KWA I.8, 194) haben einen hohen Verbrauch an Prosastücken, der mitunter einen Druck auf die Autoren ausübt, so dass diese mit der Produktion kaum nachkommen. ${ }^{434}$

Die Essenspoetik, die hier an der Szene bei Frau Aebi im Spaziergang herausgearbeitet wurde, findet ihre Entsprechung in den Briefen an Frieda Mermet, Walsers Freundin aus Bellelay, mit der er die intensivste Korrespondenz

der Einverleibung. Das ist nicht Einfühlung. Der Leser versetzt sich nicht an die Stelle des Helden, sondern er verleibt sich ein, was dem zustößt. Der anschauliche Bericht davon aber ist die appetitliche Ausstaffierung, in der ein nahrhaftes Gericht auf den Tisch kommt." Walter Benjamin, „Denkbilder“, in Walter Benjamin. Gesammelte Schriften. Unter Mitwirkung von Theodor W. Adorno und Gershom Scholem, hg. von Rolf Tiedemann und Hermann Schweppenhäuser, Bd. IV.1: Kleine Prosa. Baudelaire-Übertragungen, 7 Bde. (Frankfurt am Main: Suhrkamp, 1972), 436 („Romane lesen“).

433 Der Erzähler spricht von seinem „Erzählen und Plaudern“ (KWA I.8, 192).

434 Dass der Braten als Metapher für Erzählungen durchaus als Auszeichnung zu sehen ist, zeigt sich daran, dass dieser dem von Walser durchaus geschätzten Jeremias Gotthelf vorbehalten war. Walser schreibt an Frieda Mermet im Januar 1924: „Gegenwärtig liest man im Emmenthalerblatt eine Geschichte von Jeremias Gotthelf: Betrachtungen vom Wandergesellen Jakob, und die sind so schön zu lesen, als äße man knusperigen Braten. Gotthelf's Sätze schmecken wie nach Fleisch: hat man sie gelesen, so hat man sich förmlich dran ersättigt, von einem spielend-reichen gesunden Geist sind sie schauspielhaft hingeworfen." (BA 2, 82, Nr. 606 vom 4.1.1924) 
überhaupt geführt hat und eine Zeit lang eine Hochzeit denkbar gewesen wäre. ${ }^{435}$ Vom Briefwechsel sind 183 Briefe aus dem Zeitraum von 1913 bis 1942 erhalten. Der erste Brief, datiert auf den 13.12.1913, ist nach einem Treffen bei Walsers Schwester Lisa geschrieben, der letzte vom 20.4.1942 aus der Heil- und Pflegeanstalt Herisau; die Briefe aus Herisau bestehen jedoch nur noch aus kurzen und pflichtbewussten Sätzen. ${ }^{436}$ Die Hauptphase der Korrespondenz ist vom Beginn 1913 bis etwa 1928, mit einem kleineren Unterbruch, anzusetzen. Die Briefe entwickeln eine eigene Ritualität: Frieda Mermet schickt Walser Nahrungsmittel, flickt seine Socken und anderes, worauf Walser sich ausführlich bedankt und neue Wünsche anmeldet. ${ }^{437}$ Seine Briefe spielen verschiedene Rollen für Frieda Mermet durch, er inszeniert sich in unterschiedlichem Gewand, gibt sich charmant, abweisend, humorvoll, stellenweise herablassend und verweist so auch auf Motive aus der Trivial- und Märchenliteratur. ${ }^{438}$ Mitte April 1919 schreibt Walser aus dem Hotel Blaues Kreuz in Biel, wo er seit April 1913, nur von Militärdiensten unterbrochen, wohnte:

435 Laut Robert Mächler hat Walser Mermet einen Antrag gemacht, den diese „herzenskluge Frau" ablehnte. In einem späten Brief an Carl Seelig, Walsers Vormund, Förderer und Nachlassverwalter sagt sie, sie hätte ihn wohl geheiratet, wenn sie „wirtschaftlich besser gestellt gewesen wäre." Robert Mächler, Das Leben Robert Walsers. Eine dokumentarische Biographie, vom Verfasser neu durchgesehene und ergänzte Ausgabe der 1966 im Kossodo Verlag Genf und Hamburg erschienenen Biographie (Frankfurt am Main: Suhrkamp, 1992), 13of.

436 Vgl. dazu das Diagramm „Umfang und zeitliche Verteilung wichtiger Briefwechsel“ in Peter Stocker, „Korrespondenz“, in Robert Walser-Handbuch. Leben - Werk - Wirkung, hg. von Lucas Marco Gisi (Stuttgart: Metzler, 2015), 223f. Zu den Briefen an Frieda Mermet vgl. den entsprechenden Eintrag im Robert Walser-Handbuch von Marianne Schuller: Marianne Schuller, „Briefe an Frieda Mermet“, in Robert Walser-Handbuch, hg. von Lucas Marco Gisi (Stuttgart: Metzler, 2015), 224-23o.

437 Peter von Matt nennt den Briefwechsel ein „jahrzehntelanges Fütterungsritual“: „Er [Walser] verlangt Atzung aus ihren Händen wie ein Vogel aus dem Schnabel der Alten, will Atzung in Brocken, in Bitzen, in Mocken, in Stücken“. Matt, „Wer hat Robert Walsers Briefe geschrieben?“, 101. Peter von Matt vertritt die These, dass der Briefwechsel von Robert Walser „allein gesteuert und geregelt" wird. Matt, 101. Da Frieda Mermets Briefe nicht erhalten sind, kann grundsätzlich nur darüber spekuliert werden, wie sie sich verhalten hat. Die Ansicht, sie habe aktiv zu diesem Dialog beigetragen und mit Walser in einem ihnen eigenen Code einen persönlichen Dialog geführt, steht derjenigen gegenüber, dass Walser weniger wichtig war, wer der Adressat war, als dass er einen für solche Schreiben hatte, wie es im zitierten frühen Brief an seine Schwester heißt. Dass Walsers Briefe Kunststücke voller rhetorischer Kniffe sind und sich entsprechend auf der Grenze von Fiktion und Faktualität bewegen, ist deutlich.

438 Andrea Hübner weist darauf hin, dass auch trivialliterarische und märchenhafte Schemata in den Briefen eine wichtige Rolle spielen und diese deshalb präzise in Walsers Werk passen: „Es soll [...] hervorgehoben werden, daß sich auch in den Briefen an Frau Mermet, die als biographische Dokumente gelesen werden, in denen Walser aber mit 
Liebe Frau Mermet.

Ich habe Ihr Päckli ohne Brief aber mit Züpfen und Anken erhalten. Für den Brief, den ich nicht erhielt, danke ich nicht, weil das nicht im Bereich der Möglichkeit liegt. Wohl aber danke ich für das Empfangene und Genossene. Es schmeckte sehr gut, und ich bin für gute Sachen empfänglich, wie wenn ich ein Banquiers wäre. Schriftsteller stecken gern Stücke von weißmehligen Wecken in den Mund. Im Uebrigen bin ich fleißig gewesen und habe ein weiteres Stück Arbeit hinter mir, nämlich die Zusammenstellung von dreißig Prosastücken, die ein sehr nettes Buch darstellen. [...] Viel Neuigkeiten kann ich nicht auftischen, da ich meist zu Hause sitzen geblieben bin [...]. (BA 1, 549f., Nr. 457 vom 12.4.1919)

Es lässt sich hier beobachten, wie die „Stücke“ zunächst Esswaren darstellen, Süßigkeiten, wie das ,Stückli für Patisserie. ${ }^{439}$ Dieses Stück wird zur Arbeit, zur Schriftstellerei. Sodann wird die Nachricht selbst zum Gericht, das zum Verzehr im Brief aufgetischt wird. Es ist also das Prosastück bzw. der Brief selbst, der aufgetischt, zur Lektüre angeboten und verspeist wird. ${ }^{440}$ Viele Neuigkeiten enthält die Nachricht jedoch nicht - es geht weniger um das Berichten von Information als um die gegenseitige Lektüre und Verköstigung, mithin mehr um den Akt der Kommunikation als um dessen Informationsgehalt.441

Das „Stück“ hat offenkundig sowohl bei Frau Aebi wie auch bei Frieda Mermet eine erotische Komponente. Bei Frau Aebi liegt die vieldeutige erotische Aufladung auf der Hand, die zwischen Geschlechtsverkehr und Subordination changiert. Auch das ostentative Hervorheben einer wie auch immer gearteten Kastrationsangst ist auffällig. Die Korrespondenz zwischen

dem Aufgreifen standardisierter Versatzstücke trivial-klischierte Situationen entwirft, andeutungsweise das vollzieht, was sein literarisches Werk kennzeichnet - nämlich die irreduzible Pluralisierung des Subjekts als Ausdruck für die Unmöglichkeit, ein verbindliches und eindeutiges Ich zu bestimmen." Hübner, Ei', welcher Unsinn liegt im Sinn?, 173.

439 In einem Brief an Max Rychner von der Redaktion Wissen und Leben vollzieht Walser im September 1925 eine Überblendung von Prosastück und Patisserie: „Ich hielt für angebracht, nach Wien, im K. K.-Stil, kund und zu wissen zu tun, Sie hätten gesagt, ich sei etwas wie ein Shackespeare des Prosastückli's. In Biel, zu meiner Jugendzeit, ging ich hie und da in die Confiserie Stücker, um Zäner oder Zwänz'gerstückli zu kaufen.“ (BA 2, 142, Nr. 655, undatiert, vermutlich Sept. 1925)

440 Vgl. Silvia Henke, „Eigensinnige Briefe. Zwischen Literatur- und Medienwissenschaft“, in Weiterlesen. Literatur und Wissen, hg. von Ulrike Bergermann und Elisabeth Strowick (Bielefeld: transcript, 2007), 174-198.

441 Vgl. dazu den Ausbruch des erzählenden Ich im Spaziergang gegen die „verdorbene[n], sensationslüsterne[n] Neuigkeitenschnapper [...], die unglücklich sind, wenn sie nicht fast jede Minute nach niedagewesenen Genüssen lüsten können“ (KWA I.11, 138). 
Mermet und Walser ist untergründig erotisch aufgeladen, wird an manchen Stellen explizit, insbesondere was Subordinationsfantasien Walsers angeht. ${ }^{442}$

Im Zentrum des Spaziergangs steht also mit der Szene um Frau Aebi ein als (erotische) Lektüre und Erzählen doppelt besetzter Vorgang. Diese Deutung unterstreicht die Wichtigkeit von Inter- und Intratextualität bei Walser. ${ }^{443}$ Wie beim Essen, bei dem die ursprünglichen Rohstoffe in der Zubereitung des Gerichts nicht mehr erkennbar sind, so ist hier die Lektüre im Zentrum des Spaziergangs verschleiert - im Vorgang des Erzählens werden, wie bei der Nahrungsaufnahme, die Beweismittel vernichtet. Das Essen ist der materielle und mediale Indikator des Erzählens. In dieser Auslegung wird eine zirkuläre, erotische und selbstreferenzielle Bewegung betont: Was durch das Erzählen hergestellt wird, steht wiederum im Zentrum der Geschichte und wird von dieser verwendet. ${ }^{444}$

In Walsers Essensmetaphern sind Lesen, Schreiben und Erzählen also verschränkt. Das Erzählen meint immer auch eine Lektüre, eine Lektüre immer auch das Schreiben. Das zeigen die vielen intertextuellen Verweise, Walsers Technik des Umschreibens und Neuschreibens eigener wie fremder Texte. Als Schreibender produziert er Lesbares und Essbares. Setzt man den Spaziergang und die Briefe an Frieda Mermet in Bezug zum frühen Brief von 1897 an Lisa Walser, fällt auf, dass die Relation von Essen und Erzählen, die dort noch als Gegensatz konturiert war, komplexer geworden ist. Wie besonders an der Episode um Frau Aebi deutlich wurde, wird das Essen in das Erzählen integriert. Essen ist hier Bestandteil des Schreibens. Im Folgenden wird zu sehen sein, wie im Prosastück Auflauf(1929) Essen und Schreiben noch einmal stärker miteinander verwoben werden.

\subsubsection{Sättigender Hunger. Auflauf}

Im Prosastück Die grüne Spinne von 1924/1925, das im Zusammenhang des performativen Erzählens schon besprochen wurde, spielt das Essen ebenfalls eine wichtige Rolle. Am Ende heißt es:

\footnotetext{
442 Vgl. zu den erotischen Konnotationen Matt, „Wer hat Robert Walsers Briefe geschrieben?“; Schuller, „Briefe an Frieda Mermet“. Schuller schlägt eine interessante Lektüre von „lieb“ und „Leib“ vor, die auf die Ambivalenz zwischen Zärtlichkeit und Dinghaftigkeit aufmerksam macht.

443 Die Bedeutung der Revision im Sinn einer Re-Lektüre und eines Wiederschreibens im Frühwerk zeigt: Marc Caduff, Revision und Revolte. Zu Robert Walsers Frühwerk(Paderborn: Wilhelm Fink, 2016). Für die Mikrogramme, vgl. Walt, Improvisation und Interpretation.

444 Vgl. Lukas Gloor, „Robert Walsers Grenzwertigkeit. Erzählen-als-Schreiben in ,Der Spaziergang'“, Colloquium Helveticum 46 (2017): 179-186.
} 
Es beliebt mir, mit nach Käse duftenden Fingern an diesen hervorragend feinen Zeilen herumzuarbeiten, ich aß nämlich eben ein mit besagtem Materia Nahrungsmittel ziemlich reichlich belegtes Brötchen und sog alsdann noch den Saft einer Birne kunstvoll ein und lecke mir nunmehr friedvoll die Lippen [...]. [...] Es muß, es muß diese mit Schlangen umwundene Geschichte nun plötzlich geendet sein, denn es muß gestanden sein, daß ich Sehnsucht nach einem Glas Bier habe, die ich mit unnachsichtlicher Rücksichtslosigkeit ausgleichen will. Dem Leser statte ich für die Geduld, daß er mir sein Ohr während dieser Abwicklung lieh, heißgekochten Dank ab. (KWA VI.1, 13f.)

Hier schließen sich Essen und Erzählen nicht mehr aus, sondern finden simultan statt. Die Sachlage ist ganz konkret - der Erzähler muss während des Erzählens gegessen haben, wie im Nachhinein deutlich wird. Explizit schreibt sich der Text in eine doppelt konnotierte Erzählsituation der Mündlichkeit und Schriftlichkeit ein, indem das Ohr des Lesers angesprochen wird. Eine zusätzliche Komplizierung der mündlichen Erzählsituation findet durch das simultane Essen und Erzählen statt: Mit vollem Mund ist es bekanntlich schwierig deutlich zu reden. Es ist hier also eine inszenierte und gleichzeitig unmögliche Mündlichkeit am Werk. ${ }^{445}$ Das Essen dient zwar auf der discourseEbene als Abschluss, nicht aber auf der story-Ebene. Das Ende des Erzählens wird aus der Erzählgeschichte, die hier eine Schreibszene darstellt, hergeleitet.

Im Prosatext Auflauf, am 26.7.1929 im Feuilleton des Berliner Tageblatts erschienen, wird das Verhältnis von Essen und Erzählen vor dem Hintergrund einer Poetik des Paradoxen direkt aufgegriffen. Dort heißt es in einer paradoxen Zuspitzung: „Sollte ich nicht den Beweis erbracht haben, dass der Hunger in gewisser Hinsicht vollständiger sättigt, als es das kompletteste Essen imstande ist?" (KWA III.1, 236) In dieser Darstellung vom sättigenden Hunger findet sich eine weitere Figuration des Erzählens. Es wird sich im Folgenden zeigen, wie Walser im Paradox eine adäquate Aussageform zur Beschreibung seines Erzählens findet. Die poetologische Lektüre und die doppelte Codierung mit Essen und Erzählen werden gleich zu Beginn mit der Benennung eines Gerichts im Titel des Textes etabliert. Im Auflauf schwingt zum einen die von Walser häufig verwendete Gattungsbezeichnung des Aufsatzes mit, so dass Gericht und Lektüre überblendet werden. Mit dem ersten Satz des Textes - „Vielleicht wäre ein Strudel besser gewesen." (KWA III.1, 236) - wird diese Doppelung des Titels weitergeführt, insofern als der „Strudel“ den Sudel, die Skizze mitdenken lässt. Auch die anschließenden Zeilen handeln von Gerichten - Käseschnitten,

445 Zur Inszenierung des Mündlichen vgl. Roser, Fingierte Mündlichkeit und reine Schrift. Zur Sprachproblematik in Robert Walsers späten Texten. Vgl. auch Peter Utz' „Ohralität“, die die Bedeutung des Horchens für die Mündlichkeit betont: Utz, Tanz auf den Rändern, 243 f. Siehe FN 349, S. 152 oben. 
Bratkartoffeln, Würsten -, bis ein Bruch mit der bisherigen Thematik in Aussicht gestellt wird: „Derartiges für Erfordernis haltend, spreche ich von in wundervoll geschriebener Prosa verfasstem Buch, um zugleich alles übrige darüber sorgenvoll für mich zu behalten.“ (KWA III.1, 236) Zunächst scheint der erste Teilsatz („[d]erartiges für Erfordernis haltend“) eine typische Floskel Walsers zu sein, mit der er disparate Elemente verknüpft. Deutet man jedoch die figurative Wendung auf poetologischer Ebene, ergibt sich ein Bezug zur vorhergehenden Beschreibung einer Wurst: „Eine Wurst soll von Umglänztheit blitzen; die Haut muss das Fleisch stramm umsitzen." (KWA III.1, 236) Diese Darstellung lässt sich als poetologisch-normative Aussage über das wünschenswerte Verhältnis von Form und Inhalt einer Erzählung verstehen. Das ,sorgenvolle' Schweigen bezieht sich nun als Kritik auf ein Buch, das zwar schön geschrieben ist, aber dem die Form fehlt, dessen „Haut“ das „Fleisch“ eben nicht „stramm umsitz[t]“. Das Essen wird zur Materialisation des Erzählens.

Mit dem Wort „zugleich“ wird die Gleichzeitigkeit verschiedener, auch gegensätzlicher, Bedeutungsebenen betont: Dinge werden gesagt und zugleich verschwiegen. Das Verschwiegene und das Gesagte stehen nebeneinander. Folgende Stelle lässt sich als Manifest des Intuitiven lesen, als Poetik des NichtBewussten, des Verborgenen, welcher die Performanz des Erzählens zugrunde liegt.

Ich nahm mir fest vor, keinem Fräulein, keiner Freundin, keiner Frau, keinem Freund, keinem Kameraden, keinem Kind und keiner Magd mehr ein Wort zu schreiben, da mir dies meiner Ueberzeugtheit nach schaden würde. Vergangene Woche schadete ich mir durch zu starke Unbewusstheitsabwesenheiten. Mitunter verwirren mich meine Klugheiten. Ich nahm mir vor, zurückweichend vorwärtszuschreiten, faulenzend arbeitsam zu sein, mich auf dem Wege der Lieblosigkeit im Gebiet des Liebens auszuzeichnen. (KWA III.1, 236)

Wenn der Erzähler sagt, dass er sich „fest vor[nahm]“, niemandem „mehr ein Wort zu schreiben“, um dann im nächsten Satz zu sagen, dass er sich mit "starke[n] Unbewusstheitsabwesenheiten“ - also durch Bewusstsein schadete, dann heißt dies, er schadete sich, indem er sich an den Vorsatz hielt und nicht schrieb. Diese Verbindung von Rationalität und Sich-Schaden ist eine ,verwirrende Klugheit', weil in der Regel vom Bewusstsein, von der Vernunft Positives und Produktives erwartet wird, im Falle des Erzählers die vernünftigen „zu starke[n] Unbewusstheitsabwesenheiten“ jedoch schaden. ${ }^{446}$

446 In dieser Formulierung ist ein Bezug zu Sigmund Freuds Psychoanalyse unübersehbar. Walser kannte Freuds Theorie wahrscheinlich aus einzelnen Artikeln. Freuds Sprachtherapie und dessen Sexualitätskonzeption hat in Walsers Werk zahlreiche Spuren hinterlassen, sehr deutlich wird dies etwa im 27. Abschnitt des „Räuber“-Romans, wo der Räuber 
Die ,verwirrende Klugheit' ist auch ein retrospektiver Kommentar auf das bisher Geschriebene und in diesem Sinn ein Hinweis auf die Re-Lektüre des Textes. ,Klug' ist die Feststellung, weil der Erzähler Einsicht zeigt und einen Bezug auf den komplexen Zusammenhang von Güte und Unbewusstsein sowie Sich-Schaden und Rationalität herstellt. Die positive Beurteilung des Textes fügt sich in die Poetik des Auflaufs ein: Aussagen und Klugheiten kommen erst im freien Spiel des Textes und der Worte zustande. Es ist ein ,Sich-selberLesen', das hier vorgeführt wird.

Im Text folgen weitere Beispiele solcher „Klugheiten“, die in ihren Variationen nicht mehr als bloße Paradoxien gelesen werden können, sondern eine Poetik des paradoxen Schreibens formulieren. Gegensätze werden nebeneinander gestellt - zurückweichen/vorwärtsschreiten, faulenzen/arbeiten, Lieblosigkeit/Liebe - und nicht in einer dialektischen Bewegung auf einen logisch sicheren Boden gebracht, sondern sozusagen auf der Ebene ihrer Begegnung mit Bedeutung beladen, die sie in ihrer Gleichwertigkeit bestätigt. ${ }^{447}$ Der eine Teil impliziert den anderen im Akt des Erzählens: Das Ich weicht im Schreiben zurück, der Text wird dennoch länger; es faulenzt beim Arbeiten, da es sich seinem Unbewussten ergibt; Lieblosigkeit ist ein Weg in die Liebe als

dem „Herr[n] Doktor“ davon erzählt, „daß ich mich dann und wann als Mädchen fühle.“ $(\mathrm{AdB} 3,112)$ Eine andere Stelle betrifft die „Sexualautorität“, die dem Räuber einen Brief schreibt, als dieser sich in einem Sanatorium im "Zimmer Nr. 27“ - diese Nummer wird mit Nachdruck genannt und so der Bezug zum Doktor-Kapitel hervorgehoben - befindet (AdB 3, 145). Vgl. zur Psychiatrie: Gisi, „Das Schweigen des Schriftstellers. Robert Walser und das Macht-Wissen der Psychiatrie“. Vgl. auch Kammer, „,Walser liest Freud'? oder: Was sich zwischen Texten ereignet“. Stephan Kammer hat die Bedeutung des Schlafs in Walsers Poetik hervorgehoben: Kammer, Figurationen und Gesten des Schreibens. Zur Ästhetik der Produktion in Robert Walsers Prosa der Berner Zeit, 141-183.

447 Für dieses Nebeneinander von Gegensätzen findet sich beim Erfinder des Begriffs der Ambivalenz Eugen Bleuler eine pathologisierende Entsprechung - nicht nur unpassend als Diagnose, sondern auch durch den Umstand, dass im Auflauf aus der Ambivalenz in der Performanz derselben eine Erzählung entsteht, die ihr eigenes Entstehen, ihr Bedeuten und Nichtbedeuten lustvoll kommentiert und eben nicht statisch in der Ambivalenz verharrt. Laut Bleuler ermögliche es die "schizophrene[] Ambivalenz" - die zu den „akzessorischen Symptomen“ der „Dementia praecox“ gehöre - „daß Gegensätze, die sich sonst ausschließen, nebeneinander in der Psyche exisiteren. Liebe und Haß gegenüber der nämlichen Person können gleich feurig sein, ohne einander zu beinflussen (affektive Ambivalenz [...]). Der Kranke will zugleich essen und nicht essen; er tut das, was er nicht will, ebensogut wie das, was er will (Ambivalenz des Willens; Ambitendenz)“. Schließlich nennt Bleuler auch die „intellektuelle Ambivalenz“, die im „[Z]erfließen zu einem Begriffe" von gegensätzlichen Vorstellungen und Konzepten besteht. Bleuler, Lehrbuch der Psychiatrie, 285. Hervorhebung i. O. Vgl. zum Paradox: Bungartz, Zurückweichend vorwärtsschreiten. 
Zeichen der emotionalen Beteiligung, in welcher auch die Bedeutung der Subordination mitspielen mag. 448

Vor dem Hintergrund dieser Dynamik ist der eingangs zitierte „Beweis“ zu verstehen, „dass der Hunger in gewisser Hinsicht vollständiger sättigt, als es das kompletteste Essen imstande ist" (KWA III.1, 236). ${ }^{449}$ Vollständiger als das „kompletteste Essen“ sättigt der Hunger in seiner Verbindung zum Erzählen: In der Lektüre, dem Verspeisen eines Textes, findet das Subjekt Nahrung. Gehen Erzählen und Lektüre Hand in Hand, so auch Hunger und Essen. Das eigentliche Ereignis dieser Texte ist das Erzählen des Textes selbst. Die subversive Performanz ist mit diesem Einschreiben des Erzählverfahrens auf die Spitze getrieben. Im Verlauf von Auflauf wird diese Poetik weitergeführt:

Für mich enthält der Journalismus zweifellos Poesie, und wenn ich je Notizen usw. in die Blätter, die die Welt bedeuten, schrieb, so tat ich dies infolge unwiderleglicher Befehlsgebung meines Innenlebens, das hin und wieder von der Idee erfüllt zu sein scheint, Sprechen sei nützlich und Mitteilsamkeit schön. (KWA III.1, 237)

Das „Innenleben[]“ veranlasst den Erzähler zu schreiben. Diese Poetik ist keineswegs als zufallsgesteuertes, quasi dadaistisches, bedeutungsloses Schreiben konturiert, sondern versteht sich durchaus als „nützlich“ und „schön“. „Nützlich“ ist der Text insofern, als er eine Aussage macht, wenn sie auch nicht klar ist und vielleicht, wie im "Räuber"-Roman, bedeutet, dass aus ihr „absolut nichts gelernt werden kann“ (AdB 3, 15). Passend zu dieser Wendung kritisiert der Erzähler in Auflauf Autoren, die eine „zu üppige Bildungsfülle“ (KWA III.1, 237) tragen. Ein Text muss über einen „Mangel an

448 Vgl. dazu Peter Utz, der in diesem Zusammenhang eine Differenz zu Franz Kafka ausmacht: Er sieht bei Walser die Bewegung und Performanz im Vordergrund und betont bei Kafka das Paradox: „In ihrer Häufung entlassen Walsers Paradoxe den Leser allerdings leichter aus der Zange des Widerspruchs als die Paradoxe Kafkas. Doch dadurch werden sie auf ihre Weise als Figuren einer labyrinthischen Bewegung lesbar. Denn in der fortwährenden Verschiebung jener Bilder, in denen sich die Paradoxie konstituiert, bleibt der Diskurs für weitere Assoziationen des Lesers offen; ein paradoxes Bild löst das andere zwar nicht auf, aber ab. [...] Statt den Leser in die Enge des Begriffs zu treiben, treiben die Widersprüche in Walsers Texten ihren Leser in die Weite einer fortwährenden Bilderflucht und induzieren so eine endlose Bewegung." Utz, Tanz auf den Rändern, 411.

449 Die Ironie darf nicht übersehen werden, nennt der Erzähler sein Prosastück doch selbst eine „immens korrekte Posse“ (KWA III.1, 237), die denjenigen, die „Appetit auf ein Lächeln" haben, mitgeteilt wird. In „Posse“ mag auch die „Sauce“ mitschwingen. Der Aussagegehalt bleibt, wie bei Einmal erzählte Einer und dem Heißen Brei, ambivalent. 
Wissen“ (KWA III.1, 237) verfügen, um einen Sinn zu haben. ${ }^{450}$ Vor diesem Hintergrund ist auch der Schluss der Mikrogramm-Fassung des Auflaufs zu verstehen, der für die Publikation im Berliner Tageblatt gestrichen wurde. Nach Erwähnung der Transformation des verspeisten Apfelauflaufs durch die Verdauung - „auf dem Weg nach Hause wollte sich der eßbare Auflauf in einen Auflauf ungenießbarer, weil unerfreulicher Natur verwandeln“ (AdB 6, 561) heißt es in der Mirkogramm-Fassung resümierend:

Ach, wie viel schöner ist es, etwas zu spielen als bloß etwas zu sein. Im Sein $\operatorname{lag}[\mathrm{en}]$ mir die Worte wie erkrankt im Bett, im Spielen lebten sie wieder auf, wurden neu. Ist dies die Ursache, weshalb ich nicht zu sagen vermag, wie ich bin? Hier offenbart sich's, dort nicht. Um vor mir zu fliehen, um dem Michfindenmüssen auszuweichen, lief ich weit herum, zwecklos. Im Spiele(n) fand ich die Erweiterung meiner Eigenart, die sich öffnete, wenn sie sich nicht durch mich beobachtet sah. $\left(\mathrm{AdB} 6,5^{61}\right)^{451}$

Mit Nachdruck wird die Bedeutung des Spiels hervorgehoben. Im dynamischen, assoziativen Spiel, in dem die Dinge nicht denotiert werden, sondern den Worten, Materialien und Erzählelementen eine nicht kontrollierende, sondern freie, auch paradoxe Bedeutungskonstruktion zugestanden wird, fühlt sich der Erzähler bei sich. Die Worte liegen „wie erkrankt im Bett", wenn sie in ihren herkömmlichen Bedeutungskontexten verwendet und in die üblichen Erzählformen gepresst werden, die Walser, wie gezeigt, vielfach zitiert, um neue Formen zu finden. Erst wenn sie aus der Last der „Bildungsfülle“, die auch diesem Kontext zuzurechnen ist, befreit werden, werden sie lebendig, interessant und in diesem Sinn auch sättigend. Die Art und Weise, wie die Sätze im Auflauf und auch in vielen anderen Texten verknüpft sind, die exzessiv betriebene Mehrdeutigkeit der Worte und das ständige Unterlaufen des eigenen Erzählverfahrens ermöglichen dem Text, Lebendigkeit im Prozess des Erzählens zu entfalten. ${ }^{452}$

450 „Ueberproduktion in bezug auf Erziehung kommt vielleicht irgendwelcher Belastetheit gleich. Beispielsweise könnte vorkommen, dass das Theaterstück eines Dramatikers, auf dessen Achseln eine zu üppige Bildungsfülle ruht, nicht über einen artigen, willkommenen Mangel an Wissen verfügte, weshalb es entweder überhaupt nicht aufgeführt würde oder, zur Aufführung gebracht, gewissermassen immerhin äusserst respektabel durchfiele." (KWA III.1, 237)

$45^{1}$ Die runden Klammern verweisen hier auf Varianten der Entzifferung, die serifenlose Type auf unsichere Entzifferung gemäß AdB. Vgl. „Editorische Eingriffe und gestrichene Stellen“ im Anhang in AdB 6, 712.

$45^{2}$ Vielzitiert ist die Wendung aus dem Prosastück Meine Bemühungen: „Wenn ich gelegentlich spontan drauflos schriftstellerte, so sah das vielleicht für Erzernsthafte ein wenig komisch aus; doch ich experimentierte auf sprachlichem Gebiet in der Hoffnung, in der 
In dieser Prekarität des Erzählens stellt sich die Frage, ob Auflauf seinem formulierten Ideal der ,strammen' Entsprechungen von Form und Inhalt genügt. Dass es sich beim Auflauf um einen Text handelt, der gerade keiner Systematik nachkommen will, ist offensichtlich. Die lebendige Dynamik des Textes kann jedoch als narrative Form verstanden werden. Die passende Form ist gleichsam ein Erzählverfahren, das die Genese des Textes im Text spiegelt und so auf sein fortlaufendes Entstehen referiert. Diese Form korrespondiert mit dem Inhalt, der im Erzählprozess entsteht und seinerseits auf der storyEbene auf die eigene Prekarität Bezug nimmt.

In der Fassung, die im Berliner Tageblatt publiziert wurde, endet der Text ohne die Ausführungen zum Apfelkuchen, dessen Verdauung und den grundsätzlichen Überlegungen zum Spiel. Es heißt lapidar: „Mein heutiges Abendessen bestand aus Apfelauflauf." (KWA III.1, 238) In der Bezugnahme auf den Titel und den Anfang des Prosastücks wird für das Tageblatt im Gegensatz zum Mikrogramm ein klassisches Ordnungselement zitiert. Der Inhalt wird durch eine äußere, aufgesetzte Klammerung umfasst, die Poetologie zurückgebunden, der Aussagegehalt umso mehr im Spielerischen gehalten, als dieses Spielerische nicht ausgesprochen wird.

\section{$3 \cdot 5$}

\section{Souveränität des befreiten Erzählens. Fazit}

Bei Robert Walser wird das prekäre Erzählen hauptsächlich durch drei Verfahren erzeugt: Ambivalentes Verwenden von Erzählen und Beschreiben, Digression und Performanz. Erzählen orientiert sich in der Erzählen-BildRelation weniger an einer bestimmten Struktur von Kausalität und Ereignis, als vielmehr an der Haltung des Erzählers zum bildnerischen Motiv. Dieser Bezug zum Bild ist wichtiger als die Erzählhaftigkeit des Bilds. Das Bild wirkt dabei auch bei der Auflösung der konventionellen Narrativität mit. Die diachrone Entwicklung von Walsers Erzählen lässt sich auch anhand des Grads der Integration der Texttypen Beschreibung und Erzählung im chatmanschen Sinn darlegen: von der eher aufgesetzten metaleptischen Struktur des Frühwerks bis hin zur strukturellen Verwobenheit in der Berner Zeit.

Sprache sei irgendwelche unbekannte Lebendigkeit vorhanden, die es eine Freude sei zu wecken.“ (SW 20, 429f.) Vgl. dazu Wolfram Groddeck, „Versuch, ein Selbstbildnis herzustellen'. Ein philologisch-poetologischer Kommentar zu Robert Walsers Prosastück ,Meine Bemühungen“', in „... all diese fingierten, notierten, in meinem Kopf ungefähr wieder zusammengesetzten Ichs". Autobiographie und Autofiktion, hg. von Elio Pellin und Ulrich Weber (Göttingen, Zürich: Wallstein, Chronos, 2012), 29-53. 
Das zweite dominante Verfahren des prekären Erzählens bei Walser ist die Digression. Dieses Verfahren wird insofern radikalisiert, als es keine bloß temporäre Abschweifung ist, die wieder zu einem narrativen Hauptstrang zurückfindet. Digression ist ein formales Verknüpfungsprinzip: Die Erzählelemente (Szenen, Episoden, Figurenreden, Themen) werden im Sinn einer Kontiguität des Raums und der Erzählstimme aneinandergereiht. Präsent ist es in den Figurationen des Aufschubs, des Ausweichens und Abweichens präsent. Auf diese Weise weicht Walsers Erzählen in verschiedenen Dimensionen von etablierten Ordnungen ab: Die Figuren halten sich nicht an bürgerliche oder kleinstädtische Normen, die Narration entspricht nicht den Erzählkonventionen und schließlich wird auch vom Prinzip der verbindlichen Ordnung und Form überhaupt abgewichen.

Dies führt zum dritten zentralen Verfahren: der Performanz. Walsers Texte erzeugen ihre Ordnung prozessual im Changieren zwischen Erzählillusion und Illusionsdurchbrechung. Auf vielfältige Weise gestalten metanarrative Kommentierungen die Erzählung als autopoietisch im Akt des Erzählens erzeugt. Innerhalb dieser Struktur können wiederum andere Modelle etabliert und etwa retrospektiv erzählende Erzählsituationen dargestellt werden. Dieses prekäre Erzählen ist beweglich, prozessual, kontingent und kann sich so gleichsam eigene Regeln setzen. Aus dieser Prekarität erwächst eine neue Souveränität, die nicht in der Kontrolle des Erzählers über die story zu verorten ist, sondern in der Befreiung des discourse von Ordnungs- und Kontrollzwängen. ${ }^{453}$ Auch inhaltlich findet das prekäre Erzählen Ausdruck in zahlreichen Figurationen. Essen als Figuration des Erzählens bietet Raum für die komplexen Verschränkungen von Selbstreflexion und Erzählen, Zwang wie Befreiung der Erzählung. In diesem Sinn wird das prekäre Erzählen zu einem befreiten Erzählen.

453 Walsers Erzählweise muss also keineswegs über Negationen und Mangelerscheinungen beschrieben werden. Ausschließlich negativ charakterisiert es Andres: „Informationsgehalt, Bedeutung und Sinn reduziert Walser auf ein Minimum: kaum Handlung, keine Figurenkonstellationen, keine Entwicklung. An deren Stelle setzt er eine Fülle von Motiven und Stoffen, die auftauchen und wieder verschwinden, weil kein Rahmen sie hält und kein Thema sie begrenzt.“ Andres, Robert Walsers arabeskes Schreiben, 51. Und: „Disparate Einzelmomente werden aneinandergereiht, ohne den Eingriff eines selektierenden und interpretierenden Subjekts. [...] Alles erscheint ohne Zusammenhang als eine Anhäufung indifferenter Stoffe.“ Andres, 53. Bezogen auf den „Räuber“-Roman: „Der Räuber-Roman [sic] erzählt keine Geschichte“. Andres, 145.

Vgl. auch Andrea Hübner: „[I]ndem die Elemente der Histoire ihren Discours widerspiegeln, verlieren sie ihren Eigenwert und stellen sich somit ebenfalls in den Dienst der Verweigerung eines konsisteten [sic] und in sich abgeschlossenen Plots, wie ihn der Leser der traditionellen Trivialliteratur erwartet." Hübner, Ei', welcher Unsinn liegt im Sinn?, 129. 